\title{
Rursus
}

Poiétique, réception et réécriture des textes antiques

$11 \mid 2017$

Nature et morale : sources, et postérité homilétique, des encyclopédies du XIIle siècle

\section{Questio satis iocunda est: Analisi delle fonti di questiones et responsiones del Liber de natura rerum di Tommaso di Cantimpré*}

Questio satis iocunda est: Analysis of the sources of the questiones and responsiones of the Thomas of Cantimprés Liber de natura rerum

\section{Mattia Cipriani}

\section{OpenEdition}

\section{Journals}

Edizione digitale

URL: http://journals.openedition.org/rursus/1330

DOI: $10.4000 /$ rursus. 1330

ISSN: 1951-669X

\section{Editore}

Université Nice-Sophia Antipolis

Notizia bibliografica digitale

Mattia Cipriani, «Questio satis iocunda est : Analisi delle fonti di questiones et responsiones del Liber de natura rerum di Tommaso di Cantimpré* », Rursus [En ligne], 11 | 2017, mis en ligne le 27 octobre 2017, consulté le 06 mai 2019. URL : http://journals.openedition.org/rursus/1330 ; DOI : 10.4000/ rursus. 1330

Questo documento è stato generato automaticamente il 6 maggio 2019.

Rursus 


\title{
Questio satis iocunda est : Analisi delle fonti di questiones et responsiones del Liber de natura rerum di Tommaso di Cantimpré*
}

\author{
Questio satis iocunda est: Analysis of the sources of the questiones and \\ responsiones of the Thomas of Cantimpré's Liber de natura rerum
}

Mattia Cipriani

\section{Introduzione : " stile enciclopedico » e uso delle fonti del Liber de natura rerum}

Per redigere le loro opere, gli enciclopedisti del XIII sec. (Arnoldo Sassone, Tommaso di Cantimpré, Bartolomeo Anglico, Pseudo-John Folsham, Vincenzo di Beauvais...) non inventarono nulla, ma si limitarono a selezionare, ricopiare ed ordinare i dati ripresi da auctoritates antiche o contemporanee. Eseguendo tali operazioni, ognuno di questi compilatori divenne quindi un vero e proprio autore, e mostrò un attento e personale « stile enciclopedico » che ne evidenziò concezioni personali e scopi : tali autori, infatti, ripresero e utilizzarono solo le idee che considerarono utili per le loro opere, lasciando da parte $\mathrm{i}$ dati accessori o che non ritennero coerenti con la visione che volevano trasmettere. ${ }^{1}$

2 Tutto ciò è perfettamente dimostrato nelle due stesure autoriali del Liber de natura rerum ${ }^{2}$ (d'ora in poi, Thomas I e Thomas II) ${ }^{3}$, composte fra il 1241 e il $1255^{4}$ dal domenicano Tommaso di Cantimpré (1201-1270 / 71). Thomas I è divisa in 19 libri ed è caratterizzata da : A. Descensus Uomo-Terra dei libri I-XVI / ascesa al mondo celeste dei libri XVII-XIX ; в. Organizzazione dei lemmi dal generale al particolare (in ordine alfabetico o a capite ad calcem) ; c. Inserimento di capitoli monografici di ostetricia (libro I), veterinaria aviaria (libro V) e incisione litologica (libro XIV) che danno una sfumatura anche pratica 
all'opera; D. Scelta precisa di dati e auctoritates; ed E. Stile di composizone attento e coerente $^{5}$. Benchè articola in più transizioni ${ }^{6}$, la seconda redazione del Liber sottolinea nuovamente la mens e i fini tommasiani : essa mantine infatti tutti gli elementi appena elencati di Thomas I, e vi aggiunge 301 passaggi complementari (concentrati principalmente nel libri I e IV-V), 29 capitoli interi (inseriti soprattutto nei libri I, IV e $\mathrm{XIV}^{7}$ ) e il libro XX, De ornatu celi ${ }^{8}$ (suddiviso a sua volta in 23 capitoli) $^{9}$.

3 Analizzando quindi a questo punto gli interessi e il modus scribendi del domenicano, è doveroso innanzitutto sottolineare che Tommaso si concentra principalmente su una descrizione del Creato concreta e pragmatica. Nonostante le spiegazioni morali e le interpretazioni allegoriche del Liber siano presenti nel Liber - sono infatti più di 250 -, Tommaso, già nel Prologus all'opera, sottolinea la sua visione, ovvero che la Natura esemplifica già di per sé potenza e bontà divine :

Proinde moralitates et significantias rerum breviter in quibusdam per intervalla distinximus et ideo non continue, quia vitavimus prolixitatem. Nunc igitur quantum hoc opus prosit et quantam utilitatem prestare possit hiis qui verbo predicationis volunt insistere, ad plenum scire hominum estimo neminem nisi cui in profundioribus divina sapientia dederit intellectum. Dicit enim Aristotiles, 'De animalibus', libro XI: "Sive sit nobilissimum sicut illud quod celeste est, sive ignobile sicut est creatura animalium, ex causa magne dilectionis illis qui id possunt cognoscere. Propter hoc igitur debemus considerare formas creaturarum et delectari in artifice qui fecit illas, quoniam artificium operantis manifestatur in operatione. Et propter hoc ", ait, " intendamus in naturis animalium vilium et non grave sit nobis, quoniam <in> omnibus rebus naturalibus est mirabile et res naturalis nobilis, quoniam non fuit ullum naturatum otiose creatum neque casualiter, sed propter aliquod complementum; et ideo habet aliquod etiam reputatu vilissimum locum et ordinem nobilem ». [...] Hiis ergo scriptis si quis studium adhibuerit ad argumenta fidei et correctiones morum integumentis mediis sufficientiam reperiet, ut interdum predicatore quasi e vestigio scripturarum apte digresso cessantibus eloquiis prophetarum ad evigilationem brutarum mentium oculata fide creaturarum testes adducat, ut si quem sepius audita de scripturis et inculcata non movent, saltem nova in ore suo pigritantium aures demulceant ${ }^{10}$.

Nonostante ciò, il frate di Cantimprè non deriva però i suoi dati materiali solo da trattati di filosofia naturale come il De animalibus di Aristotele o il Circa instans, ma li estrapola anche da testi eterogenei come la Constitutiones del IV Concilio lateranense, l'Ars maior di Elio Donato, il Commentarium in Isaiam di Aimone di Auxerre e l'Historia romana di Landolfo Sagace ${ }^{11}$. Per evitare al suo pubblico sbagli più o meno gravi nella comprensione della Natura, il frate di Cantimpré decide inoltre di usare quasi esclusivamente opere vicine alla sua realtà: salvo qualche raro e brevissimo riferimento anonimo, per le sue spiegazioni naturalistiche il compilatore non utilizza infatti né testi arabi, né trattati troppo specialistici, ma si rifà quasi unicamente ad opere di facile comprensione per i suoi lettori, come è esemplificato nel libro I dall'uso dell'introduttiva Anathomia di Riccardo Anglico $^{12}$.

Continuando l'esame dello stile del domenicano, è necessario far notare come egli distingua - più o meno apertamente ${ }^{13}$ - fra fonti di primo piano e auctoritates accessorie. I lemmi del Liber sono infatti costruiti partendo da blocchi di dati-chiave a cui sono «agganciate" informazioni integrative che rendono il discorso più sfaccettato $\mathrm{e}$ approfondito. Le fonti basilari - inserite in ogni momento delle voci, spesso ricopiate letteralmente, ma con un ordine diverso da quelli dei testi-fonte - sono la principale «miniera» di informazioni dei capitoli e il supporto ideologico dei libri tommasiani : rientrano ad esempio in questa categoria la Naturalis historia di Plinio e il Polyhistor di 
Solino ${ }^{14}$ e l'anonimo Experimentator ${ }^{15}$; tali auctoritates non sono tuttavia costanti e variano a seconda dell'argomento trattato : in questo modo, ad esempio, Aristotele è la « colonna portante » del libro IV, De quadrupedibus, ma è accessorio per la sezione XVI, De septem regionibus et humoribus aeris, dove è invece centrale il Liber quatuor distinctionum di Michele Scoto $^{16}$. Le fonti complementari - spesso accorpate in sezioni a sé stanti e riprese in maniera meno strutturata di quelle primarie - forniscono poi notizie integrative al discorso delle auctoritates principali o creano un ponte fra argomenti diversi ${ }^{17}$ : sono esempi di tale categoria le sequentiae di Adamo di San Vittore, l'anonima Ecloga Theoduli e le Antiquitates Iudaicae di Giuseppe Flavio ${ }^{18}$. Nonostante tale marginalità, il frate deriva la maggior parte delle aggiunte di Thomas II da auctoritates di questo tipo : per le espansioni al Liber - 192 delle quali sono mediche, pratiche e descrittive, e sono introdotte in libri (De anathomia, De quadrupedibus, De avibus, De lapidibus pretiosis) dai contenuti concreti e quotidiani ${ }^{19}$ - Tommaso si serve infatti soprattutto di testi nuovi e che non sembrano essere stati presenti nei manoscritti ricopiati per Thomas $I^{20}$; ciò è ben dimostrato dall'introduzione, nella nuova versione del Liber, di excerpta del De re medica di «Plinio junior', degli Otia imperialia di Gervasio di Tilbury e dell'Opus agricolturae di Palladio ${ }^{21}$. Va poi sottolineato che, in molte occasioni, il frate di Cantimpré costruisce le sue voci legando assieme nozioni derivate solo da un'unica auctoritas, sia di primo che di secondo piano : nella sua enciclopedia si possono così trovare capitoli copiati interamente dalle basilari Etymologie di Isidoro di Siviglia ed altri costruiti invece solo unicamente dati dall'accessoria Epistola Alexandri ad Aristotelem de miraculis Indie ${ }^{22}$.

Nell'elaborazione del Liber, un ruolo particolare è in terzo luogo svolto da passi biblici e idee tommasiane ; questi excerpta - inseriti come interpolazioni al discorso principale servono al domenicano per spiegare da punti di vista personali e diversi (morali tropologici, pratici,...) notizie ritenute ambigue o di difficile comprensione per il suo pubblico; tale atteggiamento è ben esemplificato con i passi del pragmatico e nonidentificato Liber rerum : tali estratti, spiccatamente descrittivi e legati ad una spiegazione quotidiana della Natura, sono infatti spesso accompagnati da brani biblici che utili a collocarli in un contesto cristiano ${ }^{23}$.

7 Assemblando il suo discorso in questi modi, il frate di Cantimpré compone lemmi solidi e sfacettati, in cui i concetti principali sono supportati da punti di vista diversi e concreti, ma dove è a volte complicato distinguere l'auctoritas ricopiata: non sempre, infatti, il domenicano dichiara l'identità delle fonti che sta impiegando nel suo articolato stile « ad incrocio "; l'Historia orientalis di Giacomo di Vitry è così ad esempio usata praticamente solo dopo locuzioni precise (ut dicit Iacobus, ut dicit Hystoria orientalis), mentre il De lapidibus di Marbodo - in una copia di famiglia $\delta$ - $A$ o $\delta$ - $B$ - è invece l'anonimo cardine del libro XIV, De lapidibus pretiosis ${ }^{24}$.

8 Per concludere, in questo complesso sincretismo contenutistico, Tommaso impiega quindi un enorme numero di opere eterogenee (naturalistiche, mediche, esegetiche, poetiche, musicali, lessicografiche, storiografiche,...) che vengono accuratamente scelte e interconnesse per trasmettere idee personali e giungere così a specifiche finalità concrete ${ }^{25}$. Fra tali auctoritates si trovano anche trattati naturalistici sotto forma di questiones et responsiones : alcune di queste opere, benché secondarie per l'economia del Liber, vengono impiegate dal compilatore di Cantimpré in entrambe le redazioni dell'enciclopedia per rivolgersi direttamente al lettore e approfondire meglio argomenti precisi. 


\section{Le fonti dialogiche del Liber de natura rerum}

\section{Stile tommasiano e fonti di questiones et responsiones}

Prima di procedere nell'analisi del modo in cui il domenicano utilizza questi testi, è necessario però individuarli con precisione. Tale operazione è resa tuttavia difficoltosa dall'intricato rapporto fra modus scribendi tommasiano e stile dialogico: come già evidenziato da Isabelle Draelants ${ }^{26}$, il vocabolario del Liber è infatti spesso influenzato da quello della disputa scolastica e dei trattati di questiones naturales ${ }^{27}$, e ciò è visibile soprattutto 1) in un'organizzazione dei discorsi che richiama spesso a quella del dibattito scolastico (questio-obiectio-responsio-determinatio) e 2) in un diffuso impiego di espressioni dialogiche che rimandano al confronto actor / respondens. ${ }^{28}$ Per isolare precisamente le fonti che il frate di Cantimpré usa per «discutere» direttamente con il suo lettore è quindi necessario distinguere gli excerpta e le locuzioni che Tommaso introduce personalmente o deriva da fonti di vario genere, da quelli che invece ricopia fedelmente da specifici trattati di questiones et responsiones.

10 Una prima selezione deriva dall'analisi delle espressioni dialogiche generali e personali ${ }^{29}$ presenti nel Liber (alii vero contra, certum est quod, disserimus, notandum quod, notandum ut, probavi, probavimus, prudenter discutienti relinquimus, quidam dicunt, relinquimus, ut ostendemus). Benché il compilatore di Cantimpré inserisca il 90\% (99 su 111) di tali locuzioni soprattutto di propria mano o riprendendole da opere eterogenee (De animalibus di Aristotele, De imagine mundi di Onorio Augustodunensis, Historia orientalis di Giacomo da Vitry, Circa instans dello Pseudo-Plateario, Liber quatuor distinctionum di Michele Scoto, e - nella seconda redazione del Liber - da una fonte medica non riconosciuta e Liber Kyrannidarum), nelle poche sezioni - soprattutto in Thomas II - che non derivano da questi trattati si possono infatti individuare alcune delle fonti dialogiche tommasiane, ovvero la Philosophia di Guglielmo di Conches $^{30}$ e le anonime questiones salernitane ${ }^{31}$.

11 Tale distinzione è ampliata poi dall'esame delle espressioni legate al dibattito actor / respondens (constat ergo, habet... questionem, patet autem quod, quare, quare ergo, queritur, questio... est, questio quomodo, questioni responderi potest, respondemus, respondendum est, respondeo, respondere possumus, responderi, respondet, si itaque, si item, si questio, solutio, solvi... sic, solvitur...32) presenti nell'enciclopedia domenicana : il brabantino ricava infatti la maggior parte di queste locuzioni - presenti già in Thomas I, ma aumentate in Thomas II - direttamente dalle Questiones naturales di Adelardo di Bath ${ }^{33}$, dalla Philosophia di Guglielmo di Conches ${ }^{34}$, dalle anonime questiones salernitane e, infine, da qualche altro testo dialogico non riconosciuto ${ }^{35}$. In questi casi si presenta quindi una situazione invertita rispetto a dove il frate di Cantimpré introduce formule generali e personali: le sezioni di mano tommasiana o che il domenicano deriva da opere eterogenee (Liber monstrorum attribuito ad Aldelmo di Malmesbury, Naturalis historia di Plinio, Glosa super Exodum, Liber quatuor distinctionum di Michele Scoto, De imagine mundi di Onorio di Autun) in questi casi sono infatti in netta minoranza ${ }^{36}$ rispetto a quelle che egli ricopia invece dai trattati di questiones et responsiones.

12 Anche se, nel ricopiarla, Tommaso non riprende nessuna delle formule appena elencate, è infine doveroso aggiungere un'altra auctoritas dialogica a quelle appena elencate. Per redigere i capitoli De arte obstetricandi e Quot modis nascuntur pueri ${ }^{37}$, il frate di Cantimpré 
copia infatti l'abbreviazione Non omnes quidem della Gynecia di Muscio - a sua volta un

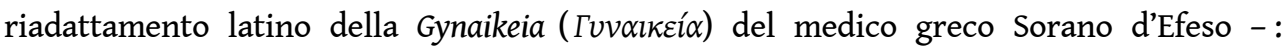
assieme ad un'epistola introduttiva a tali sezioni, egli attribuisce quest'opera alla regina Cleopatra e la usa per discutere problemi di ostetricia pratica, creando così la prima sezione monografica del Liber ${ }^{38}$.

Sulla base di quanto discusso è quindi evidente che il compilatore ha avuto sul suo tavolo di lavoro diverse auctoritates (Questiones naturales, Philosophia, questiones salernitane ${ }^{39}$, Non omnes quidem, uno o più testi da cui copia le questiones non riconosciute) che presentano $\mathrm{i}$ loro dati naturalistici e medici sotto forma di dibattito e quesito. Al fine di comprendere il ruolo che tali opere hanno avuto nel Liber è però a questo punto necessario effettuare un'ulteriore diversificazione: è infatti doveroso far risaltare che egli non usa le sue auctoritates di questiones et responsiones in maniera sempre costante o unitaria, ma le ricopia in due maniere distinte.

\section{Auctoritates dialogiche come fonti specialistiche : la Philosophia e il Non omnes quidem}

Osservando infatti gli excerpta che Tommaso ricava dalle fonti di questiones et responsiones, è evidente che il domenicano ha un atteggiamento diverso quando riprende la Philosophia e il Non omnes quidem da quando invece trascrive le Questiones naturales e le questiones salernitane.

15 Considerando quindi innanzitutto come il frate di Cantimpré ricopia l'opera del normanno, è possibile evidenziare che il domenicano usa 16 sezioni della Philosophia ${ }^{40}$ in 11 capitoli di Thomas $I^{41}$; nel riprendere questi excerpta - attribuiti in tre occasioni a " Iohannes philosophus» e al libro "Flores philosophie $»^{42}-$, egli conserva tuttavia solo pochissime locuzioni dialogiche originarie ${ }^{43}$; così facendo, il compilatore non crea però, tramite questi passaggi, quella discussione con il pubblico che caratterizza invece altri momenti della sua opera. Atteggiamento analogo è tenuto con le espansioni derivate dalla Philosophia e introdotte nei libri XVIII, De passionibus aeris, e XIX, De quatuor elementis ${ }^{44}$, di Thomas II : anche in questi momenti Guglielmo di Conches è infatti usato senza riprendere le sue espressioni di dibattito, ma solo come approfondimento dei capitoli meteorologici o come fonte di passi platonici. Discorso a sé stante deve infine essere fatto per il libro XX del Liber: in questo caso il domenicano mantiene infatti tutte le locuzioni dialogiche primitive ; considerando questa sezione, va però sottolineato che Tommaso ha qui un atteggiamento singolare : per sua stessa ammissione ( Post finem laboris nostri vicesimam quoque editionem apponimus, sed hanc non tanquam ex nostra compilatione, sed tanquam necessariam ipsi operi precedenti: addidimus tamen aliqua et quedam subtraximus, atque nonnulla correximus $»^{45}$ ), egli infatti riprende qui la Philosophia senza attuare quel preciso stile enciclopedico di selezione, « frammentazione » $\mathrm{e}$ « legatura » che caratterizza invece tutte le altre sezioni del Liber ${ }^{46}$.

Prima di procedere con la nostra analisi, è a questo punto doveroso fare qualche breve considerazione sulla copia - o meglio, sulle copie - della Philosophia che Tommaso deve aver avuto sul suo tavolo di lavoro durante la stesura del Liber. Il fatto che le sezioni guglielmine di Thomas I siano accompagnate, nella prima redazione dell'enciclopedia tommasiana, da rimandi «scorretti » porta infatti a credere che in questo caso il frate di Cantimpré abbia utilizzato una versione della fonte attribuita a Iohannes philosophus e intitolata Flores philosophie. Sebbene non sia ad oggi possibile chiarire con certezza il 
perché di tale malinteso, possono comunque essere avanzate tre ipotesi ugualmente valide per provare a spiegarlo, ovvero che il domenicano: 1) abbia ripreso una copia completa della Philosophia con titolo e attribuzione diversi ; 2) abbia ripreso una copia completa della Philosophia intitolata Flores philosophie e priva di autore, e l'abbia poi attribuita erroneamente ; e, infine, 3) abbia usato un florilegio guglielmino composto da un certo «Iohannes $»^{47}$. La prima teoria deriva dalla trasmissione stessa dell'opera del normanno : come ben discusso da Paul Edward Dutton, la Philosophia circolò infatti spesso senza titolo, sotto nomi diversi (Philosophia, Summa philosophie, Summa et nucleus tocius philosophie, Compendium philosophie,...), anonima o con indicazioni autoriali insolite (Ugo di San Vittore,.... $)^{48}$; se questo fosse il caso giusto, il frate di Cantimpré avrebbe quindi usato una delle copie « differenti » del trattato guglielmino. La seconda ipotesi è basata sia sulle problematiche di anonimato esposte dallo studioso canadese, sia su un tipico atteggiamento tommasiano : come è ben visibile nel Liber con il Aldelmo di Malmesbury / Liber monstrorum ed "Esculapius» / Sesto Placito Papiriense, il frate tende infatti ad attribuire un'opera adespota all'ultimo autore menzionato in quel codice-fonte ${ }^{49}$; se questa congettura fosse corretta, l'enciclopedista avrebbe qundi attribuito il Flores a « Iohannes » perché, nel manoscritto sulla sua scrivania, tale testo era privo di indicazioni autoriali ed era direttamente preceduta da un trattato di un certo « Giovanni »; in questo senso non si può nemmeno escludere che questo «Iohannes " non sia altro che Giovanni di Salisbury, celebre allievo del magister normanno: se così fosse, la Philosophia sarebbe quindi stata qui accorpata a trattati dell'inglese ${ }^{50}$. L'ultima tesi deriva dall'analisi delle sezioni guglielmine in Thomas I, dal titolo dato alla fonte da Tommaso («Flores philosophie ») e dall'esistenza - ben dimostrata da Martin Grabmann ${ }^{51}$ - di florilegi contenenti excerpta del normanno ; tale idea è inoltre supportata anche dall'attribuzione di due passi naturalistici in De gallina ancora a Iohannes / Iohannes philosophus ("Iohannes: Cum vero in abscondito ova posuerit, surgens clamando, ea raptoribus prodit...», "...et tamen - sicut dicit Iohannes philosophus -, post partum cantat....152): il fatto che non sia stato possibile trovare l'autore di questi rimandi, fa infatti sorgere il dubbio che abbiano fatto parte di una raccolta di citazioni realizzata da un certo «Iohannes»; se fosse questa, infine, l'ipotesi corretta, il compilatore di Cantimpré avrebbe quindi ricopiato gli excerpta della Philosophia da un'antologia dai contenuti medico-naturalistici eterogenei e almeno in parte guglielmini ${ }^{33}$.

Ossevando invece gli excerpta della Philosophia introdotti in Thomas II, sembra possibile sostenere con una certa sicurezza che il frate di Cantimpré abbia in questo caso ripreso una copia completa e anonima dell'opera del normanno : come detto in precedenza, tali passaggi sono infatti molto più ampi di quelli in Thomas I e vengono introdotti senza alcun richiamo autoriale. In altre parole, per concludere, Tommaso sembra quindi aver avuto suo tavolo di lavoro due versioni differenti della Philosophia : una - forse non completa, ma sicuramente con indicazioni di titolo e autore «diverse » - per Thomas I, e un'altra - completa, ma probabilmente adespota - per Thomas II ${ }^{54}$.

18 Tornando a questo punto all'analisi delle auctoritates dialogiche come fonti specialistiche, il brabantino usa il trattato ginecologico Non omnes quidem in modo analogo a quanto fatto con quello del maestro chartriano: anche in questo caso Tommaso ne riprende infatti solo le parti più tecniche e, salvo un'unica eccezione, toglie quasi tutte le locuzioni discorsive presenti (quid faciendum sit, sicut diximus) ${ }^{55}$, rendendo di conseguenza la spiegazione distaccata e priva di un'interazione diretta con i suoi lettori. 

questiones presentate dal philosophus inglese: 11 di questi sono introdotti già in 3 capitoli di Thomas I (libro IV, Primo generaliter, libro XI, Primo generaliter, e libro XII, Primo generaliter), mentre gli altri vengono inseriti in alcune espansioni anatomiche e zoologiche a Thomas II ${ }^{59}$ (libro I, De capite, De manibus, De nervis, ancora nel libro IV, Primo generaliter, e libro V, Primo generaliter) ${ }^{60}$. Tali quesiti - usati sempre senza alcuna indicazione di provenienza - sono poi spezzettati e ricombinati dal domenicano in 28 ampie porzioni di testo suddivise in 7 capitoli del Liber: come sua consuetudine il compilatore di Cantimpré riprende infatti dalla fonte solo le parti ritenute funzionali al suo discorso, eliminando invece i passaggi considerati accessori. ${ }^{61}$

Per quello che riguarda lo stile con cui Tommaso riprende le Questiones naturales, il frate ricopia questa fonte in due modi. Nel primo - più «specialistico » e analogo a quello tenuto con Philosophia e Non omnes quidem -, il domenicano si limita ad estrapolare da Adelardo le informazioni che gli interessano come se la fonte fosse un testo naturalistico non-discorsivo ; nonostante la loro fedeltà all'originale, ciò avviene però solamente nelle espansioni di Thomas II ai capitoli De capite e De manibus. Nella seconda maniera - puramente dialogica e legata al dibattito tommasiano con il suo pubblico - il frate di Cantimpré, toglie i quesiti originari della fonte e li sostituisce con locuzioni (quare ergo, querendum, proinde queritur, habet enim maximam questionem, queri potest, queri iterum potest, 
queritur ergo non immerito, questio autem non parva est, questio quoque satis iocunda, reor autem hoc modo, solutio, solvitur sic, et solvitur, sic ergo solvitur, solvitur autem potest sic, unde) che trasformano la discussione diretta fra Adelardo e il nipote in un dibattito fra Tommaso e il lettore ; a differenza di quanto accaduto per le riprese puramente "scientifiche", in questi casi gli excerpta adelardiani sono inoltre ricopiati con maggiore libertà : il domenicano tende infatti a spiegare questi passaggi con le proprie parole, o a «smontarne » i contenuti a seconda delle proprie esigenze per poi legarli a piacimento con locuzioni proprie (cum enim, enim, huic rationi etsi, ideo...quia, et ita dispositio, unde accidit $u t$ ). A prescindere da quale dei due modi scribendi Tommaso utilizzi, egli non usa però sempre la struttura originaria dei quesiti : nelle sezioni Primo generaliter dei libri IV e $\mathrm{X}$, il brabantino inverte e fonde infatti materiale di questiones sequenziali per arrivare alle risposte che ritiene complete ${ }^{62}$.

Esaminando invece dove il compilatore di Cantimpré usa il testo del philosophus di Bath, è possibile innanzitutto considerare che il frate impiega gli excerpta adelardiani nei libri dedicati all'uomo, agli animali e alle piante; tali estratti sono ricavati solo dalle prime 47 domande delle Questiones naturales, ovvero da quelle sezioni dedicata specificatamente a tali argomenti, e senza che Tommaso - come è invece suo costume con altre fonti del Liber ${ }^{63}$ - adegui ai suoi scopi dati da sezioni generiche della sua fonte ${ }^{64}$. Sempre considerando la posizione in cui il brabantino usa le sezioni di Adelardo, è poi possibile sottolineare che, a parte per i passaggi inseriti nei lemmi anatomici (libro I, De capite, De manibus, De nervis), il frate impiega tali estratti solo nei vari Primo generaliter : questi excerpta sono introdotti nella parte iniziale o centrale dei lemmi e sono combinati principalmente con passi ricavati da fonti basilari ai libri considerati (Aristotele, Riccardo Anglico, Plinio), anche se vengono a volte accostati a fonti complementari (Guglielmo di Conches, Giovanni di Salisbury, Gregorio Magno, Agostino) e a sezioni allegoriche dello stesso Tommaso ${ }^{65}$; tale atteggiamento evidenzia anche una differenza con l'uso delle Questiones salernitane, che, per la maggior parte dei casi, sono invece utilizzate in lemmi monografici su singoli animali ${ }^{66}$. In altri termini, riprendendo le Questiones naturales, il frate di Cantimpré sembra quindi aver compiuto scelte ben precise al momento di decidere in quale contesto e in che modo utilizzare l'opera di Adelardo.

Quanto ai contenuti che Tommaso riprende dalle sezioni dell'inglese, il frate di Cantimpré le impiega per approfondire da un punto di vista concreto e vicino alla realtà del lettore alcuni aspetti del suo discorso anatomico, zoologico e botanico: in questo modo, ad esempio, il domenicano riprende dal philosophus di Bath la spiegazione su come i medici possano conoscere l'estensione dei nervi umani, quella sul perché il corpo umano galleggi dopo alcuni giorni trascorsi in acqua, o, infine, quella riguardante la capacità di alcuni uccelli di mangiare le pietre ${ }^{67}$. Va inoltre specificato che Tommaso non riprende mai le tesi platoniche care al filosofo inglese, ma solo quelle strettamente legate alle scienze naturali68.

Il fatto che Tommaso si muova in un ampio range - quasi due terzi ${ }^{9}{ }^{9}$ del testo adelardiano e che lo impieghi nei modi appena descritti, indice poi a credere che il predicatore abbia avuto tale auctoritas sul suo tavolo di lavoro e che l'abbia utilizzata di prima mano ; il completo anonimato ${ }^{70}$ in cui Tommaso mantiene questa fonte fa però pensare che il domenicano abbia avuto a disposizione un manoscritto privo di indicazioni autoriali, e, forse, mancante della sezione metereologica e astronomica ${ }^{71}$. La prima di queste idee è basata sull'osservazione dei testimoni delle Questiones : un quarto - 6 su 28 dei manoscritti contenenti quest'opera sono infatti privi di titolo e nome dell'autore, e ciò 
spiegherebbe perché il brabantino non abbia menzionato l'auctoritas inglese ${ }^{72}$. La seconda idea è invece legata ad una sezione dialogica inserita nel libro XVII, Generaliter de septem planetis et motu eorum, quomodo fiant aut et cuius ignis eorum mittatur; benché Adelardo indaghi approfonditamente tale discussione nel quesito $74^{73}$, il domenicano preferisce infatti usare un'altra fonte dialogica per spiegare l'argomento; in tal senso non è comunque possibile escludere completamente che la scelta del compilatore sia detatta da motivazioni ideologiche, più che dalla consultazione un testimone delle Questiones privo della parte astronomica.

\section{Le questiones salernitane anonime}

salernitane si hanno anche nei lemmi Primo generaliter de anathomia, De ove, De ceraste e De ferro ${ }^{78}$ : nel primo caso, Tommaso introduce un modo di dire ("Grece homo 'microcosmus' - quasi 'minor mundus' - dicitur») presente anche nella domanda B 2; nella seconda occasione, al pari del quesito B 98, il brabantino discute invece l'usanza invernale delle pecore di coricarsi a destra ; nel terzo momento, il compilatore parla della proprietà antivenefiche del corno dei cerastes («qui cultelli ad mensas imperatorum ante omnem cibum ponebantur, ut illi sudore manifestarent si quis cibus fuisset appositus veneno infectus ») trattate anche nella questio B 103 ; nel quarto ed ultimo caso Tommaso espone alcune proprietà galleggianti dell'acciaio e del ferro ( $"$ calibs in argento vivo supernatat, et hoc quia porosum est et ideo levigatur; ferrum vero si in vivo argento proieceris statim submergitur ») accennate anche nella domanda N 65. Nonostante la somiglianza di contenuti, in questi casi il predicatore sembra tuttavia rifarsi a informazioni circolanti nel milieu culturale del tempo ${ }^{79}$, più che direttamente ai quesiti naturalistici anonimi ${ }^{80}$.

31 Per quello che concerne lo stile con cui Tommaso riprende le questiones salernitane, l'enciclopedista ne ricopia con precisione passaggi ampi, usando come al solito solo le porzioni di testo che ritiene utili per il Liber. Nonostante questo atteggiamento, nei capitoli De glire, De urso e Primo generaliter de arboribus communibus, il brabantino introduce però brevi integrazioni (scilicet aquas, quedam in aere ut cyniphes, et maxime in Europa, que partes frigidissimas habet, generare non possent, fructus, et in quibusdam aliis fructibus, et caliditate) che lo aiutano a spiegare quanto sta discutendo e che, con grande probabilità, sono di sua stessa mano ${ }^{81}$. Il domenicano, inoltre, anche nel riprendere questa fonte dialogica, attua i due atteggiamenti già evidenziati con le Questiones naturales, ovvero usa l'auctoritas sia come un testo scientifico non-dialogico sia come base per fornire spiegazioni scientifiche dirette al lettore. La modalità non-dialogica - che, come già con Adelardo, è meno diffusa dell'altra - è infatti presente solo nei lemmi sull'orso e, in parte, sul leone : in queste occasioni, introdotte o spezzate dalle locuzioni et hec ratio, et est ratio quomodo hoc fieri potest e certum est autem quod, Tommaso estrapola dai quesiti salernitani i 
dati naturalistici puri, senza riprendere le domande dirette che caratterizzano la fonte. Il modo dialogico è invece rispettato in tutte le altre occasioni, compresa la sezione finale del lemma sul felino : in questi casi il frate di Cantimpré usa precise locuzioni (queritur ergo quomodo hoc fit, queritur ergo, questio est, questio, si vero queritur utrum, solutio, solvitur) che rendono alla lettera, in modo diretto o indiretto, i quesiti originari, anche conservandone perfettamente l'iniziale struttura domanda / risposta. Con l'unica eccezione dell'excerpta in De urso - introdotto dalla locuzione invenitur in libris phisicorum -, tutte queste domande sono inserite senza alcuna indicazione della fonte di provenienza.

32 Osservando invece dove il brabantino utilizza questa auctoritas, è evidente che egli - al contrario di quanto fatto con Adelardo - preferisce ricopiare tale fonte nelle voci specialiter, piuttosto che nelle introduzioni generaliter ai capitoli. Le questiones salernitane sono inoltre impiegate solo nella seconda redazione dell'enciclopedia tommasiana, e dopo fonti primarie (Agostino, Solino, Plinio, il Physiologus, Experimentator) o secondarie (Palladio) per l'economia del Liber ${ }^{82}$.

Per quanto riguarda le informazioni che Tommaso estrapola da questa fonte, il frate di Cantimpré la utilizza per indagare ed approfondire argomenti botanici e zoologici del Creato, completando così le informazioni di altre auctoritates. In questo modo, nei complementi sugli animali il domenicano usa le domande salernitane per parlare del rapporto fra le bestie discusse e l'aria, il fiato e il respiro; negli approfondimenti sulle piante, Tommaso usa invece i quesiti naturalistici per spiegare alcune differenze fisiche (foglie, corteccia, quantità di nocciuoli...) fra le diverse pianti e fra i vari frutti. Sulla base di quanto detto, anche in questo caso si può quindi affermare che il domenicano, riprendendo questa fonte, abbia compiuto una scelta attenta, consapevole e coerente.

Quanto detto porta a pensare che Tommaso abbia avuto sul suo tavolo di lavoro un manoscritto contenente le questiones salernitane e che le abbia ricopiate di prima mano. Non sembra inoltre scorretto sostenere che il frate di Cantimpré abbia avuto a disposizione un codice che 1) conteneva solo due "grappoli » di quesiti in prosa - uno zoologico, nell'ordine N 62, N 64, N 66, ed uno botanico, nell'ordine B 61, B 62, B 64, Ba 10, B 65 , B 66 -, e che 2) doveva essere composito rispetto a quelli editi da Lawn $^{83}$ : l'enciclopedista brabantino riprende infatti domande e risposte che oggi si possono trovare solo in testimoni fra i più antichi ma ben distinti, ovvero i manoscritti Oxford, Bodleian Library, Auct. F.3.10, e Paris, B.n.F. Lat. $18081^{84}$. L'idea che la raccolta di quesiti salernitani posseduta da Tommaso sia stata parziale potrebbe essere suggerita anche dall'osservazione di alcuni contenuti del Liber, come la già menzionata spiegazione del galleggiamento di un corpo morto: benché tale quesito sia presente in entrambi i manoscritti appena citati, per discutere la questione il frate preferisce infatti rifarsi ad Adelardo e alla sua teoria umorale, piuttosto che ai dialoghi salernitani ${ }^{85}$. Infine, sebbene l'idea che il frate di Cantimpré abbia posseduto una raccolta contenente poche questiones salernitana sembri la più corretta, come per il caso di Adelardo non è però da escludere completamente né che il brabantino abbia avuto a disposizione più manoscritti da cui copiare le risposte, né, soprattutto, che la motivazione delle sue scelte sia ideologica e non legata alla disponibilità, e cioè che - in casi simili a quello appena discusso -, egli abbia preferito i contenuti del philosophus inglese perché maggiormente in linea con il suo modus pensandi.

Per concludere, sembra utile qui aggiungere qualche breve considerazione sul rapporto di Tommaso con le fonti di origine salernitana. Sulla base delle ricerche effettuate fino ad 
oggi, è infatti possibile osservare che, oltre alle questiones, il frate di Cantimpré ricopia anche altri testi della stessa origine, vale a dire la Practica di Bartolomeo, la Chirurgia Salernitana anonima e l'Ars medendi di Cofone ${ }^{86}:$ al pari dei vari quesiti, anche gli excerpta di tali trattati sono inseriti solo in Thomas II. Sebbene non sia ancora possibile dire quali siano i manoscritti precisi a cui il domenicano si è rifatto in queste occasioni, o il modo con cui è entrato in contatto con tali opere, è comunque evidente che, per la seconda redazione del Liber, egli ha avuto la possibilità di lavorare con una biblioteca medica decisamente più ampia e « internazionale » di quella usata per Thomas I.

\section{Le questiones non riconosciute} Primo generaliter e De yride lapide, e libro XVII, Generaliter de septem planetis et motu eorum, quomodo fiant aut et cuius ignis eorum mittatur ${ }^{87}$ contengono excerpta dialogici di cui non è stato possibile riconoscere la fonte ${ }^{88}$. Per concludere la nostra analisi di come Tommaso usa le questiones et responsiones per creare un dialogo con il pubblico della sua enciclopedia è doveroso quindi analizzare anche queste porzioni di testo.

in primo luogo la sezione dialogica nel capitolo De caco, è introdotta eccezionalmente già nella prima versione del Liber : tale ripresa anonima è collocata dopo una descrizione derivata dal Liber monstrorum dello Pseudo-Aldelmo ${ }^{89}$, e prima di rimandi mineralogici e biblici di mano tommasiana. Tale porzione di testo serve al frate di Cantimpré per spiegare come la creatura non bruci per il suo stesso alito infuocato, e, di conseguenza, per collocare il mostro nella realtà quotidiana. L'idea che questo passaggio sia derivato da un'opera di questiones et responsiones deriva innanzitutto dall'osservazione del vocabolario utilizzato: al pari degli excerpta adelardiani e "salernitani », questa sezione è infatti caratterizzata da locuzioni dialogiche (queri potest quomodo, respondere possumus) che rimandano chiaramente al dibattito actor / respondens caro a Tommaso. Tale congettura è poi avvalorata dall'osservazione dei contenuti del paragrafo: per il legame con la quotidianità, la discussione su respiro / alito e il tentativo di spiegare "scientificamente » un'azione magica, il passaggio presenta infatti evidenti somiglianze con il « grappolo » di questiones salernitane discusso in precedenza ${ }^{90}$. Sulla base di quanto detto si può quindi sostenere che il compilatore ha avuto a disposizione i suoi quesiti salernitani già per Thomas I, decidendo però di utilizzarli direttamente solo nella seconda redazione della sua enciclopedia ${ }^{91}$.

Per quanto concerne invece il quesito nel lemma De linche, è introdotto solo nella seconda redazione del Liber ed è caratterizzato dal tipico vocabolario dialogico tommasiano ( questio autem non modica est quomodo hoc possit). Al pari delle altre sezioni di questiones et responsiones, tale paragrafo - concluso con un breve passaggio (quicquid viderit, statim cum oculos averterit, obliviscitur) verosimilmente derivato dal Summarium Heinrici ${ }^{92}$ - è inoltre inserito per spiegare « scientificamente » le capacità visive del felino, approfondendo così in modo specialistico una sezione naturalistica copiata da Giacomo da Vitry, Marbodo di Rennes e Plinio. Cercando di individuare l'auctoritas tommasiana, è possibile rilevare che il passaggio riporta contenuti spesso dibattuti nei testi scientifici coevi - si vedano come esempi gli Aphorismi di Urso di Calabria e le opere enciclopediche di Alexander Neckam ${ }^{93}$ - : nonostante l'argomento, il frate di Cantimpré non sembra tuttavia riprendere né queste opere, né i trattati di Roberto Grossatesta ( $† 1253)$, uno dei più importanti autori di ottica del tempo ${ }^{94}$. Sempre cercando la fonte tommasiana, è doveroso poi evidenziare un parallelo fra il passaggio in De linche e un'altra opera del brabantino, la Vita preclare 
virginis Margarete Yprensis ${ }^{95}$ : sebbene i passaggi differiscano leggermente - la perspicacitas lucis del Liber è perspicuitas lucis nella Vita ${ }^{96}$-, la stessa spiegazione ottica si ritrova infatti in entrambe le opere tommasiane ; in tal senso è anche molto importante rimarcare che il passo presente nella Vita non può essere derivato dal Liber: secondo Meersseman editore moderno del testo agiografico -, tale opera venne infatti redatta verso il $1240^{97}$, e cioè prima della stesura di Thomas I e Thomas II ${ }^{98}$; per redigere la sezione enciclopedica sulla lince, Tommaso deve quindi essersi rifatto alla sua opera, ad una fonte comune o ai suoi stessi appunti ${ }^{99}$. Per concludere, nonostante sia sicuro che l'auctoritas usata dal frate di Cantimpré per questo passaggio sia stata un'opera di questiones et responsiones, sorge però qualche dubbio che si tratti effettivamente di un quesito salernitanto ; a differenza del rinvio in De urso - introdotto dalla locuzione plurale in libris phisicorum ${ }^{100}-$, quello in De linche è infatti presentato con l'espressione singolare secundum philosophum, e ciò potrebbe suggerire un'auctoritas differente o addirittura la creazione della questione da parte dello stesso Tommaso: come ben noto, il domenicano insegnava nelle scuole domenicane ${ }^{101}$, e non si può quindi escludere completamente che abbia redatto in prima persona delle questioni anonime rivolte ai suoi studenti ${ }^{102}$.

Esaminando in terzo luogo i quesiti in Primo generaliter de lapidibus, il frate di Cantimpré lo inserisce - assieme ad alcune affermazioni sull'Oriente che sono, con grande probabilità, di sua stessa mano - prima di un rimando ai Metereologica di Aristotele ${ }^{103}$. Al pari delle altre sezioni di dibattito, anche questo passaggio è caratterizzato da espressioni che richiamano il discorso actor / respondens (est autem questio quomodo fiunt, respondemus, sed, et questio magna est, unde et quomodo) e serve al domenicano per approfondire in maniera specialistica il suo discorso : tramite questa sezione Tommaso spiega infatti tecnicamente come si formano le rocce e da che cosa dipende la loro diversità di colore e di virtù. Prendendo in considerazione la misteriosa fonte da cui il brabantino ha ripreso questo paragrafo, vi sono elementi discordanti sulla sua derivazione ; inizialmente si può infatti pensare che tale passaggio non derivi da una raccolta di quesiti salernitani in quanto 1) queste opere contengono pochissime sezioni mineralogiche ${ }^{104}$, e 2) la sezione è introdotta da un richiamo (philosophorum) simile a quello in De linche; nonostante ciò, bisogna però tenere conto che 1) vocabolario e contenuti della sezione tommasiana ricordano da vicino le questiones mineralogiche edite nelle opere di Lawn e di Filthaut ${ }^{105}$, e 2) il frate di Cantimpré afferma qui di rispondere usando parole / sentenze / detti di philosophi (respondemus ex dictis philosophorum) che, con grande probabilità, sono i quesiti salernitani. Per concludere, sembra quindi corretto sostenere che, anche in questo caso, la fonte usata dal domenicano sia qualche questio salernitana non presente nei testi da noi consultati.

Discorso identico può essere fatto per l'altra aggiunta discorsiva del libro XIV : anche la variante $^{106}$ presente nel lemma De yride lapide ha infatti le caratteristiche delle sezioni dialogiche tommasiane, ovvero una lingua che rimanda al dibattito maestro / allievo ( queritur autem quomodo fiat, et solvimus quod) e contenuti tecnico-pratici che spezzano e approfondiscono passaggi naturalistico-descrittivi derivati da fonti primarie (in questo caso Plinio). Sulla base di quanto detto - e, nuovamente, come per la sezione in Primo generaliter -, anche per questa porzione di testo discorsiva si può quindi sostenere con buona sicurezza che sia derivata da qualche raccolta di questiones salernitane non riconosciuta. firmamento, si tratta eccezionalmente di un excerptum discorsivo inserito già nella prima 
redazione del Liber. Analogamente alle altre sezioni dello stesso tipo, questo passaggio anonimo presenta il tipico vocabolario che rimanda alla disputa (querendum est autem, proinde queritur unde, solutio) e contenuti che vanno a spiegare in maniera semplice una sezione descrittiva (ripresa qui da Onorio). Prendendo a questo punto in considerazione la sconosciuta auctoritas di Tommaso, è necessario anticipare che tale discussione è molto diffusa nelle opere del tempo : come ben evidenziato da Theodore Silverstein, il quesito deriva infatti da un frammento del De philosophia di Aristotele, è copiato nel De natura deorum di Cicerone e, tramite qualche intermediario, è poi ripreso nella Metaphysica di Avicenna e in quella di Al-Ghazali, nelle Questiones naturales di Adelardo di Bath, nel De natura rerum di Alexander Neckam e nel Tractatus de anima di John Blund ${ }^{107}$. Per concludere, sebbene anche in questo caso non sia stato possibile individuare la fonte del Liber, si può comunque sostenere che il compilatore domenicano non ricopi Adelardo di Bath, ma riprenda piuttosto qualche intermediario di derivazione araba: la sezione tommasiana condivide infatti il lessico (triplex est enim motus rerum: naturalis, violentus et voluntarius) delle opere di Avicenna e Al-Ghazali ${ }^{108}$, ma non del philosophus inglese ${ }^{109}$.

\section{Conclusione}

Avendo quindi dimostrato che, per creare sezioni di approfondimento nelle sue redazioni del Liber, Tommaso usa in modo consapevole e preciso fonti di questiones et responsiones, per concludere la nostra analisi è doverso a questo punto sottolineare perché il domenicano decide di ricopiare queste auctoritates.

Sulla base di quanto osservato si può infatti sostenere che il frate di Cantimpré abbia ripreso tali opere per due ragioni. La prima è legata agli stessi contenuti dei trattati dialogici, ed è anche una delle cause per cui, fra XII e XIII sec., queste opere scientifiche ebbero grande successo su entrambe le sponde della Manica ${ }^{110}:$ sia le Questiones naturales di Adelardo di Bath che le questiones salernitane fornivano infatti soluzioni semplici, precise e razionali ai problemi di tutti i giorni ${ }^{111}$.

La seconda motivazione è invece connessa alla stessa tipologia testuale di queste opere : usando tali trattati e le tecniche di scrittura che li contraddistinguono, il frate di Cantimpré sembra infatti voler " parlare » ai suoi lettori e ricollegare il suo insegnamento - con tocchi leggeri ma decisi - alle discussioni che animavano le università e gli studia in cui si muoveva. In questo modo, tramite la ripresa di opere di questiones et responsiones, non solo Tommaso fornisce ai lettori / predicatori che stava educando informazioni più complete e pertinenti, ma li spinge anche a riflettere in maniera ancora più attiva sul mondo che li circonda : in queste maniere tali predicatori erano di conseguenza ancora più perparati per istruire il loro stesso, vasto, auditorio ad una visione del Creato precisa e corretta ${ }^{112}$.

\section{Appendice}

La seguente Appendice riporta i passaggi del Liber de natura rerum nominati in precedenza, ovvero : nella sezione A, i passi che il frate di Cantimpré deriva da Guglielmo di Conches ${ }^{113}$ ; nella sezione B quelli che egli ricava dal Non omnes quidem; nella sezione C gli excerpta copiati dalle Questiones naturales di Adelardo di Bath; nella sezione D quelli derivati dalle questiones salernitane; e, infine, nella sezione E, i passaggi dialogici di cui non è stata 
individuata la fonte precisa. Tutte queste citazioni sono introdotte dal titolo del capitolo in cui si trovano e - dove non sono collocate all'inzio o alla fine del lemma - sono accompagnate dagli excerpta che le precedono / seguono: in questo modo è possibile vedere il contesto in cui sono collocate e capire meglio il pensiero tommasiano.

Come anticipato in precedenza, il testo qui presentato è quello ricostruito per la nostra tesi di dottorato ${ }^{114}$. L'esigenza di usare un'edizione diversa da quelle precedenti è derivata soprattutto dal fatto che nessuno di questi lavori mostra le fonti usate dal frate di Cantimpré per comporre il Liber. Sebbene, agli occhi di una persona lontana dalla materia, tale carattere possa sembrare secondario, ciò rende estremamente difficile la collocazione di un'enciclopedia medievale nel contesto culturale del suo tempo : senza uno studio delle auctoritates che stanno alla base di un'opera di questo tipo è infatti difficilissimo cogliere in modo preciso il pensiero e la forma mentis che hanno spinto alla sua stesura, e, di conseguenza, i fini stessi per cui essa è stata realizzata.

La nostra edizione - che si si distingue quindi dalle precedenti per un'analisi attenta e precisa delle fonti, ma anche perché, tamite il confronto con le auctoritates, colma molte delle cruces in esse presenti - si basa sul confronto di alcuni manoscritti ritenuti ottimali. Il punto di partenza di Thomas I è stato il manoscritto Latin 523A della Bibliothèque nationale de France (d'ora in poi : Par) : a parte brevi sauts du même au même, questo codice è infatti completo, preciso e raccoglie tutti i 19 libri della prima fase dell'opera tommasiana; per Thomas II sono stati invece consultati i manoscritti Harley MS 3717 della British Library di Londra (d'ora in poi: Lon, visto anche da Boese) e XIV.A.15 della Národní knihovna Ceské republiky di Praga (d'ora in poi : Pr) ${ }^{115}$.

Le trascrizioni di questi manoscritti rispettano le grafie originarie, con l'eccezione di una regolarizzazione di maiuscole e minuscole, una separazione delle parole unite, l'introduzione di interpunzione moderna e l'inserimento del simbolo <...> quando un passo è saltato dall'autore. Le aggiunte a Thomas II sono inserite nel testo precedute $\mathrm{e}$ seguite da due asterischi ${ }^{* *} . .{ }^{* *}$; quando presenti, le lezioni alternative sono invece mostrate in colonne affiancate ; se una lezione è presente solo in una delle fasi di Thomas II, è specificato in nota; tutti gli interventi e le lezioni diverse sono segnalate in nota secondo lo schema : lezione modificata (in corsivo)], lezione originale (in corsivo) Par, lezione originale (in corsivo) Lon, lezione originale (in corsivo) Pr ; nella fonte : lezione della fonte (in corsivo).

Oltre a ciò, in nota sono inseriti i riferimenti alle fonti riscontrate. Dove possibile, tali rimandi seguono lo schema : Autore (abbreviato), Opera (abbreviata, in corsivo) Libro (in numeri romani), Capitolo. Paragrafo (entrambi in cifre arabe). Per queste opere sono state usate le abbreviazioni :

Adelard. Adelardus Bathoniensis

Quest. : Questiones naturales

51 Al-Ghaz. Al-Ghazali (Abū Ḥāmid Muhammad Ibn Muhammad Aț-ṭūsī al-Ghazālī)

Met. : Metaphysica

52 Aldel. Aldhelmus Malmesberiensis

Lib. monstr. : Liber monstrorum ${ }^{116}$

Alex. Neck. Alexander Neckam

De nat. rer. De natura rerum 


$$
\text { De anim. : De anima }
$$

De animal. : De animalibus

De coel. : De coelo

Meteor. : Meteorologica

Phys. : Physica

Topic. : Topica ${ }^{117}$

Aug. Aurelius Augustinus

Conf. : Confessionum libri

Contra Faust. : Contra Faustum Manicheum ${ }^{118}$

57 Avic. Avicenna (Abū 'Alī al-Ḥusayn ibn 'Abd Allāh ibn Sīnā)

Met. : Metaphysica

58 Bas. Basilius Magnus

Hex. : Homiliae IX in Hexaëmeron ${ }^{119}$

59

Bed. Beda Venerabilis

De nat. : De natura rerum ${ }^{120}$

60

$$
\text { Comm. : Commentarius in Platonis 'Timaeum }{ }^{121}
$$

61 Cic. Marcus Tullius Cicero

De nat. deor. : De natura deorum ${ }^{122}$

62

Marb. Marbodus Redonensis

Lapid. : De lapidibus ${ }^{130}$

74 Pall. Palladius

Op. Agr. : Opus agricolture ${ }^{131}$

75 
« » citazione letterale o con variazioni minime ;

' ' citazione non-letterale o citazione all'interno di una citazione ;

( ) termine o frase che non è fuori luogo rispetto al contesto in cui appare ma assente nella fonte utilizzata dall'autore ;

[] espunzione o possibili espressioni dell'autore del Liber;

[...] parte del testo non utilizzata ma presente nell'originale ;

$<>$ integrazione meccanica ;

$<. . .>$ mancanza di una porzione di testo ;

ivi nello stesso luogo del testo già riportato

" " discorso diretto

Non inveni fonte non trovata

om. omittit / omittunt

\section{A. Sezioni derivate da Guglielmo di Conches}

\section{Liber I : De anathomia humani corporis}

\section{De capite}

Capita infantium antequam loquantur nondum impleta sunt, sicut postea dicemus quando de embrione loquemur. ${ }^{138}$

Testa capitis continet tres cellulas : unam anterius, secundam in medio, tertiam posterius. In prima, anterius, formatur virtus fantastica vel ymaginaria; in secunda, que est in medio capitis, virtus intellectualis ; in tertia, que est posterius, virtus memorialis ; prima concipit, secunda discernit, tertia discussa et diiudicata custodit ${ }^{139}$; unde visum est, aliquando ut homo vulneratus in anteriori parte capitis, ymaginari non potuit; in posteriori vero parte capitis ${ }^{140}$ vulneratus memorie virtutem perdidit. ${ }^{141} *$ "Ingenium quidem per humiditatem viget, memoria per siccitatem $»^{142}$. 


\section{(1)} ditur matrix, ita ut nec acus, sicut dicit Ypocras, possit ingeri, postquam facta est conceptio. Est autem sperma conveniens geniture quod non nimis sit calidum, vel frigidum, vel siccum, vel humidum ". 'Si autem modum excedat in una istarum qualitatum, conveniens sperma non est, nec aptum ullatenus geniture ${ }^{143}$. Proinde dicunt quidam 'solum semen virile sufficere ad conceptum nec necessarium semen femineum' : mentiuntur plane qui hoc dicunt. ${ }^{144}$ Proinde notandum quod 'nulla femina animalium recipit coitum post impregnationem nisi mulier; equa enim et alia animalia postquam impregnate fuerint, coitum fugiunt ${ }^{\prime 145}$.

$[. .$.

'Mulieres post impregnationem gravantur et videtur super earum oculos quedam obscuritas, et apparet in quibusdam cito post decem dies et in quibusdam tardius' ${ }^{146}$. Iohannes philosophus, in libro Florum Philosophie, conceptionem et nativitatem hominis ita distinguit : 'At quia', inquit, 'conceptione menstruum solet cessare, <merito queritur> ${ }^{147}$, quia hoc contingat ${ }^{\prime}{ }^{148}$. Et disseramus : certum <est, quod $>{ }^{149}$ omnis mulier frigida est. «Calidissima quippe mulier, frigidissimo viro frigidior est. Cibum bene non potest digerere remanentque superfluitates, que per singulos menses purgantur ipseque purgationes vocantur menstrua. Conceptione vero facta geminatur calor ex fetu unde melius cibus digeritur, nec tante superfluitates oriuntur. Iterum quia ex sanguine matris nutritur fetus, non indiget purgatione. Inde est quod cum cetera animalia, ex quo nata sunt gradiuntur, homo vero non graditur, quia ex sanguine menstru <at> $0<$ in utero> nutritur ». .50 " Spermate igitur in matrice locato oreque eiusdem clauso, si in dextra parte (matricis) remaneat, masculus efficitur, quia epar est in dextra parte matrici vicinum et ideo meliori et calidiori sanguine fetus nutritur, qui est proprius masculorum. Si autem in parte matricis sinistra sperma resederit, femina efficitur, quia a fonte caloris, id est ab epate, ille locus separatur. Si vero non bene in dextra parte sed aliquantulum versus sinistram partem plus tamen versus dextram (locatum fuerit semen), vir effeminatus generatur. Si vero in sinistra parte ita quod aliquantulum versus dextram (semen disponitur), mulier virilis efficitur $»^{151}$ que viragines dicuntur. Igitur concepto fetu 'incipit virtus digestiva operari, que calore matri<ci>s semen inspissat circumduciturque semen folliculo quodam qui provenit ex siccitate; iste folliculus custodit semen, ne alique superfluitates illi se commiscentes ipsum corrumpant. Hic folliculus (vocatur secundina) et crescit cum puero et cum puero de matrice exit. Septimo igitur die a die conceptionis, sicut dicit Macrobius, gutte sanguinis in superficie folliculi incipiunt apparere ${ }^{152}$. Vicesimo primo die ille gutte sanguinee miscentur semini. Septimo autem die post vicesimum primum diem ipsum quasi media specie inter carnem et sanguinem coagulatur. Exinde incipit virtus formativa et formatur embrio. Cuius partes ille que sunt frigide et sicce in osseam substantiam : que vero frigide et humide in flegmaticam, ut est pulmo; que vero calide et sicce in colericam, ut est cor; que vero calide et humide in sanguineam, ut est epar, modo mirabili dividuntur. Deinde sequitur virtus concavativa, que manus digitosque distinguit, que nares auresque perforat, deducit et ad instar fistularum flexibilium venas cavat, quibus sanguis deferatur per membra et partes singulas corporis ${ }^{153}$.

\section{De infusione anime rationalis et unde anima}

93 humidus per arterias et venas discurrere, motumque et vitam conferre; hic motus 
septuagesimo die a die conceptionis incipit $»^{154}$; quod autem anima datur solo Dei munere videtur evidentissime Aristotiles dicere in libro De animalibus, ubi ait: 'Intellectus rationis (id est anima rationalis) intrat corpus embryonis extrinsecus, et ipse est solus divinus, quoniam operatio eius non habet communicationem cum operatione aliquo modo corporali' ${ }^{155}$.

[...]

Merito autem queritur, ut dicit Iohannes in libro Florum Philosophie, 'quomodo puer pascitur in matris utero' ${ }^{156}$. Dicimus quod quedam vena (quam nervum vocat Iohannes ${ }^{157}$ ) de matrice mulieris extenditur usque ad umbilicum $<$ pueri $>158$, per quem puer sanguinem a matris epate descendentem attrahit. Et virtute eiusdem sanguinis quasi alimento nutritur puer et crescit in robur debitum, at quia puer medio epate sanguinem « digestum recipit, non indiget egestione superfluitatum $»^{159}$. 
Ut dicit Experimentator 'onager ex naturali industria, quando eum persequuntur canes, emittit stercus suum odoriferum canibus, circa quod detentis canibus eos illudit et evadit et fugit ad tutiora' ${ }^{\prime 172}$.

\section{Liber XVIII : De passionibus aeris} generaturque impetus, qui, si ascenderit sursum, fit fragor sine fulmine. Sin autem impetus ille deorsum tendat, tamen tantus non sit, quod usque ad obstaculum pervenerit, nondum est fulmen. Cum vero ad obstaculum pervenerit, obstantia findit; sed, quia proprius est motus aeris tendere sursum, nulla materia exire videtur ${ }^{177}$, sparsosque (aer) ignes recolligit. Si vero in hac inferiori parte aeris multus sit humor, aer existens in illo impetu igniri ${ }^{178}$ non potest, fitque fulmen findens, non urens. Sin autem ibi non sit humor, ex motu et siccitate ignescit fitque fulmen urens. Est ergo fulmen pars aeris collisione aliqua usque ad obstaculum perveniens cum impetu; tonitruum vero est partium aeris cum impetu concurrentium sonus ; coruscatio vero est pars aeris ex impetu ignita et splendens. Non est fulmen lapidea substantia, ut quidam dicunt : si enim lapidea esset substantia, non huc illucque discurreret, nec sursum reverteretur, et, cum aliquem feriret, carnem et ossa comminueret. <Ideo> fulmen sepius alta sternit, quia, cum ab alto aliquando descenderit, citius alta reperit. Et notandum quod quorundam sententia est fulmen esse lapidee substantie », et assignant rationes, quia «cum fumus humidus ad superiora ascenderit, cum eo elevatur aliquid terrene substantie, quod ex calore solis in lapideam substantiam transit contineturque in concavitate nubium, donec nubes impetu aliquo dividatur", et sic cadens subiectum concutiat. "Hinc digne queritur: "Cum in omni tempore anni fumus humidus, ut prediximus, ascendat : quare non in omni tempore tonitrua contingunt et fulmina ?" Cui questioni responderi potest et si ex humido fumo $<$ humido ascendente> habeant esse tonitrua ", tamen "dum inferiores partes aeris ipse obtinet fumus et non ad superiora conscendit, inspissatur iuxta terram et non potest huc illucque impellere aera'. Si autem « ad summum pervenerit, huc et illuc ex habilitate eum impellit fiuntque tonitrua et fulmina ; in hyeme vero, et si aer spissus sit, non est tamen tantus calor, qui spissum fumum ad summum possit aeris impellere <nec etiam in vere > : remanens ergo in inferiori parte aeris, ventos gignit et pluvias (et non tonitrua); in estate vero, cum est maximus calor, humor usque ad summum aeris elevatur fitque partium aeris diversa incursio, et inde contingunt <fulmina et> tonitrua ; in autumpno vero, quia frigidus est et siccus, neque est humor qui elevetur neque calor qui elevet $»{ }^{179}$ 

calore nichil vivere posset, in medio eiusdem torride zone fontem humoris supposuit, ex quo calor fervidus temperetur; hic est ergo in medio equinoctialis circuli terram (ex omni parte) circumdans $»{ }^{184} \mathrm{Ex}$ isto igitur fonte « in occidente due refluxiones, una ad austrum, alia ad septentrionem dividuntur, in quarum separatione aer utique commovetur. Cuius commotionis impulsus si tantus fuerit, ut ad nos usque perveniat, ventum Zephyrum generat. Due vero orientales refluxiones sua divisione commote generant Eurum : hic est orientalis. Cum vero orientalis et occidentalis ad septentrionem se vergentes in medio sibi occurrerint, movetur aer fitque Boreas ${ }^{185}$, et est frigidus quia in frigida oritur zona ». «Similiter, cum due refluxiones vergentes ad austrum in medio sibi occurrerint, generant Austrum ». ${ }^{186}$ "Viso unde quatuor cardinales venti oriantur, videamus unde collaterales venti oriuntur. Igitur, si in predictis refluxionibus ad septentrionem vergentibus, Boreamque predicto modo generantibus, hoc contingat, quod orientalis ex aliquo accidenti sit velocior, ultra medium septentrionis occidentali occurrit, nascunturque duo venti collaterales inter Boream <et Zephyrum. Si vero occidentalis ultra medium, orientali occurrit, fit ventus collateralis inter Boream $>^{187}$ et Eurum ${ }^{188}$. Similiter et de ceteris dicimus. ${ }^{* *}$

\section{Liber XIX : De quatuor elementis}

\section{5. De aere quod est tertium elementum}

113 «Aer est omne quod inani simile, a terra usque ad Lunam conspicitur, <de quo vitalis spiritus hauritur $>189$ ». «In hoc commorantur demones ${ }^{190}$, ${ }^{* *}$ quorum ordinem et naturam in Tymeo Plato diffinit : "Tertius ordo ", inquit, « in hac humecta parte aeris <quod ita deffinitur> animal rationale, immortale, patibile, cuius est officium $<$ humanitati> invidere et ex invidia insidiari ». 'Hos nominat cacodemones, id est malum 
scientes'. ${ }^{191}$ ** " cum tormento diem iudicii prestolantes, ex eo corpora sibi sumunt, dum hominibus apparent $»^{192}$.

extenditur. Is tantum est aere subtilior quantum aer aqua tenuior, <aqua> terra rarior. Is etiam ether dicitur, qui purus aer nominatur, et quia perpetuo splendore letatur. De hoc angeli corpora assumunt cum ad homines missi veniunt », sicut demones in aere inferiori caliginoso. ${ }^{193}$ ** 'Angelorum autem duos ordines in Tymeo Plato distinguit, primum autem sic: "In ethere", inquit, "“...> $>194$ a firmamento usque ad lunam $<. . .>195$ est animal rationale, immortale, impatibile, ethereum, cuius officium est soli divine contemplationi vacare et de eius contemplatione delectari". Secundus autem diffinitur sic: "In inferiori", inquit, "loco, circa superiorem partem aeris vicinum lune, <...>196 est animal aereum rationale, immortale, patibile, diligentiam hominibus impartiens". Et est notandum quod dicit patibile, quia, cum diligit bonos, congaudet eorum prosperitati, compatitur adversitati ; horum officium est offerre preces Deo et voluntatem Dei hominibus, vel per sompnia, vel per visa, vel per intimam aspirationem, vel per vocalem ammonitionem. Et hii calodemones appellantur, id est bonum scientes'. ${ }^{197}$ Notandum autem quod Plato male intellexit angelos in ethere commorari, cum in empyreo celo divine maiestati deservire probantur, nisi dicas intellexisse Platonem angelos quandoque esse in ethere ad hoc tantum, ut de celo empyreo descendentes corpora sumant in ethere, in quibus possint hominibus apparere. ${ }^{198 * *}$

\section{B. Sezioni derivate dal trattato Non omnes quidem}

\section{Liber I : De anathomia humani corporis}

\section{De arte obstetricandi}

Hinc sequitur de partu et arte obstetricandi in libro Cleopatre que se vocari voluit medicam reginarum; precepit autem ipsa eadem Cleopatra filie sue ad quam librum scripsit, ut nulli tam singularem rem facile credat. ${ }^{199}$ 'Primo ergo dicendum est que sunt impedimenta partus. Observandum est quidem in partu, ne sit pariens verecunda, vel multum timida, aut iracunda, aut corpus habeat parvulum, vel nimis gracile, aut multum pingue, aut imbecillis matrix, vel orificium angustum, aut contortum, aut utraque parte clausum, aut ubi in vicinitate emorroide sunt, aut collectiones humorum, aut infans grande caput habeat aut corpus excedens in quantitate, aut mortuus, aut gibbosus, aut contra naturam positus' ${ }^{200}$.

\section{Quot modis nascuntur pueri}

119 'Generaliter quatuor modis nascuntur pueri : in capite, in pedibus, in devexo iacens aut duplicatus. Specialia autem plurima sunt'.

120 « Si in capite ad partum descenderit, reliquas partes in latere habente, inmissa manu obstetrix puerum componat, manibus scilicet lateribus iunctis, ut in orificium rectus descendat. Quando iunctis pedibus descenderit, nunquam eum obstetrix adducat sicut descendere cepit ; inmissa manu eum teneat et sic adducat, ne puer brachya manusque divaricet et lateribus matris infigat.

121 Si grande caput habuerit ut exire non possit, inmissa manu obstetrix adducat tenens caput eius adiuvante ipsa pariente conatu suo $» .201$ 
" Si contra naturam positus sit, pariens in lecto iaceat, caput altius teneat et obstetrix, inmissa manu, secundum naturam eum componat et sic adducat. Lectus autem parientis sit durius stratus.

Si manum profert, iubemus, ut nunquam eum obstetrix adducat; plus enim inclinatio inter orificium obduratur. Nam ipse potest manum amittere et vitio obstetricis vitiosus esse. Iubemus, ergo, ut humero eius digitis infixis retrorsum revocetur et componat manum eius iunctis lateribus et apprehenso capite $<. . .>202$ paulatim adducat. Quod si brevissimum caput habuerit, caput eius ad orificium componat et sic per manus adducat.

Si pedes profert reliquo corpore in aliqua parte inclinato, sicut diximus, obstetrix, inmissa manu, eum componat et sic adducat.

25 Si unum pedem eiecerit, nunquam adducat nec conetur, sed primum digitis ad inguina infantis inflixis sursum eum revocet et post, inmissa manu, pedem alterum corrigat et, si fieri potest, manum eius lateribus iungat, et apprehensis pedibus foras adducat $»^{203}$.

«Si pedes in diversis partibus fixerit, manu inmissa obstetrix iungat et ad orificium componat et adducat.

Si caput conversum et contortum habuerit, inmissa manu obstetrix corrigat et humeris apprehensum leniter adducat, ne matrix ipsa sequatur vel ledatur ${ }^{204}$.

Si genua ostendat, retrorsum repellatur et correctis pedibus adducatur $»^{205}$.

«Si nates ad orificium veniant, obstetrix, inmissis digitis, leniter eum in latus convertat et integro scemate componat, id est ut caput infantis ad orificium veniat et sic adducat.

Si plures pariens in utero habuerit, et simul se contulerint ad orificium, ab obstetrice unus retrorsum repellatur aut in latere, vel commode fieri potest, et sic unus post alium sigillatim adducatur. Hec omnia fiant sine quassatione matricis et cum moderatione lenitatis, et ipse locus orificii cum oleo calido vel succo fenugreci ${ }^{206}$ et lini seminis et malve cocte perfundatur $»^{207}$.

Igitur mulieres de facili quiescunt post partum, ut dicit Aristotiles, que masculos pepererunt difficulter vero que feminas ${ }^{208}$.

\section{Sezioni derivate dalle Questiones naturales di Adelardo di Bath}

\section{Liber I : De anathomia humani corporis}

\section{De capite}

Testa capitis continet tres cellulas, unam anterius, secundam in medio, tertiam posterius. In prima anterius formatur virtus fantastica vel ymaginaria ; in secunda, que est in medio capitis, virtus intellectualis; in tertia, que est posterius, virtus memorialis: prima concipit, secunda discernit, tertia discussa et diiudicata custodit ${ }^{209}$; unde visum est aliquando ut homo, vulneratus in anteriori parte capitis, ymaginari non potuit; in posteriori vero parte capitis ${ }^{210}$ vulneratus memorie virtutem perdidit ${ }^{211}$. $* *$ «Ingenium quidem per humiditatem viget, memoria per siccitatem ». «Itaque qui humidum habent cerebrum, pollent ingenio, sed memoria fatiscunt ; qui vero siccum habent, hii memoria vigent, sed ingenio privati sunt ». Cera, enim, que « humida est facile sigilli impressione signatur, sed humiditatis inconstantia facile deletur, quod vero siccius est difficile formam recipit, sed acceptam semel non leviter amittet $» .{ }^{212}$ 'Hec sunt signa virtutis aut vitii', que ponit Aristotiles in libro De Animalibus, 'quibus cognosci homo possit in facie. 
Falluntur tamen signa quandoque ex eo quod anima se transfert ad actum contrarium et exercitio virtutis aut vitii in se consuetudinem, quasi alteram naturam constituit ; igitur, quando frons fuerit magna, significat ponderosum declinantem ad stultitiam; quando fuerit parva, significat bonitatem motus; quando fuerit lata, parvitatem discretionis; quando fuerit rotunda, iracundiam significat ${ }^{213}$.** animalibus secundum corporis quantitatem. Pisces autem magis possunt, quia maius fel habent secundum corporis quantitatem. ${ }^{226}$ « Ex quatuor enim humoribus constat corpus, quatuor elementorum qualitates proferentes. Ille quidem, qui igneam naturam sortitus est <naturam> proprietatemque calidam et siccam, in felle concipitur, clauditur et retinetur. Quod autem calidum et siccum est, id leve esse necesse est, quod autem naturaliter leve est, id nisi clausum teneatur, superius tendere consequens est $»^{227}$; unde accidit ut, cum homo in aqua submergitur, 'mox fundum petit; post paucos vero dies fluitat super aquas ${ }^{228}$. «Dum enim predicta cista fellea clausa tenet corporis levitatem, membra levare non potest. Cum vero rupto carcere per membra diffunditur, qualitativa necessitate ad superiora ferri suaque membra male levare effectivum est $»^{229}$. Huic rationi etsi obviari non potest, probari tamen non potest. Natandi vero possibilitatem in piscibus ex vesica potius credimus repleta vento quam ex felle ${ }^{230}$. 
$[\ldots]$

Questio quoque satis iocunda est quod 'aper dentes, leo ungues, taurus cornua habet, quibus vitent pericula; alia ut esse suum fuge levitate conservent ut capreoli, damme vel lepores : homo autem omnibus dignior ista non habet' ${ }^{231}$. Et solvitur: «homo quidem rationale animal atque ideo sociale aptum est ad duas operationes, actionem dico et consilium ». "In bellicis ergo negotiis armorum usum desiderari conversatio cotidiana docet; <in> pacis vero tempore eadem deponere.$_{.}^{232}$ « Si itaque arma innata sibi homo haberet, cum pacis federa tractaret, ea deponere non posset. Si item levitate fuge munitus esset, et constantiam vagus amitteret et gracile membrorum ineptitudine, cum imbecillis ${ }^{233}$ adesset, debilis reperiretur. Nunc vero et quando necesse est [arma] recipit, et eadem pace postulante deponit, et, cum eget velox esse, [ut per] vehicula industria potest, et necessitate sublata ad constantiam redire docetur ${ }^{234}$; sic ergo solvitur questio quare taurus et non homo cornua habet ${ }^{235}$.

Aristotiles ${ }^{236}$ :** Ambulantia omnia, que anhelant et sibi simile generant, cannam habent, per quam trahant aquam, et pulmonem qua trahunt aerem ${ }^{237}$.

«Diutius gestantur [in utero] quibus sunt longiora vite spatia » ${ }^{238}$, ut dicit Plinius. "Que solidas habent ungulas, singulos, que bissulcas <et> geminos pariunt. Quorum in digitis pedum fissura divisa est, <et> numerosiora in fetu, sed superiora omnia perfectos edunt fetus ${ }^{239}$, hec [autem] inchoatos, in quo genere sunt leena, vulpes et ursa $»^{240}$.

Queri potest 'quare quedam animalia ruminant" ${ }^{\text {"41. }}$. Solutio. "Ignis quiddam proprium habet, ut coniuncta dissolvat; animalia igitur que calidum habent stomachum, cibos facile coquunt ${ }^{242}$. Nulla, enim, ut dicit Gregorius in docendo, mora est ${ }^{243}$; ubi Sanctus Spiritus, doctor adest: "Spiritus enim scrutatur, etiam profunda" ${ }^{44}$ cordis, et ipse est spiritus intelligentie ${ }^{245}$. "Animalia vero que frigide nature sunt, dum cibos accipiunt, ex defectu complexionis cibos coquere nequeunt; unde fit, ut ad dentes revocent, ut ibi secundo triti, cibi facilius commoliri queant (et commolita decoquantur) ». Palam ergo est quod boves, cervi et similia horum animalia frigidioris nature sunt; habent autem hec animalia pinguedinem siccam et duriorem atque solidiorem quam alia. ${ }^{246}$ Huiusmodi animalia signant tepidos quosque ac frigidos scolares qui, quia spiritu ferventes non sunt, difficulter secreta Sacre Scripture capere possunt, quia « in malivolam animam non introibit sapientia $»^{247}$, illa maxime que sapida dicitur sapientia, « nec habitabit in corpore subdito peccatis $\aleph^{248}$. Hii duriorem et siccam pinguedinem habent, id est dulcedinem sine devotionem. Tales a posteriori parte prius ad terram cadunt, quia futurorum bonorum obliviscentes promissa terrenis inhiant. Unde invitante Moyse Iethro socerum suum, ut iret cum eis eo quod Dominus promisisset bona Israëli, noluit, sed rediit in Madian ${ }^{249}$, hoc est in causa vel in iudicio. Honores enim et cathedras tales querunt, et ideo disceptabit Dominus cum eis in valle Iosaphat, hoc est iudicium Domini. Tales quidem revertentes ad cor $\mathrm{ab}$ anteriori parte surgere debent et in anteriora extenti oblivisci debent posteriora. Calidiora vero (ut est porcus et ovis) pinguedinem habent molliorem et magis decoctam ${ }^{250}$ . 'Ruminat tamen ovis que calide nature est, sed hoc quia caret efficacia dentium, unde dicuntur bidentes' ${ }^{\prime 25}$.

Queri iterum potest "quare animalia que ruminant et sepum habent a posteriori parte prius accumbunt "252. Solutio. "utique talium animalium membris non inest equaliter frigiditas ; maior enim in posterioribus est et hoc ea de causa quia remotiores partes a corde sunt; igitur ubi maior frigiditas, ibi maiorem gravedinem necesse est esse. Iure ergo a graviori parte accumbunt ${ }^{253}$. 'Ab anteriori vero parte prius surgere debent' ${ }^{254}$, quia calidior locus est, et igni cordis proximior ${ }^{255}$; ignis autem semper sursum tendit ${ }^{256}$. 
Queri iterum potest 'quare vident quedam animalia melius nocte quam die ${ }^{257}$. Solutio. «In oculo, qui est instrumentum visus, plures sunt humores. Unus albus, (splendidus et clarus), per quem spiritus visibilis diffunditur; alius niger, per quem $<. . .>258$ cavetur (ne nimium disgregetur humor albus et splendidus) $»^{259}$. « Illa ergo animalia que minus de die vident, habundant in albissimo humore $<. . .{ }^{260}$; unde fit, ut magis diffundatur spiritus, et ratione diffusionis in die videndorum discretionem amittunt; nocte vero propter tenebras colligitur spiritus, et ita maior fit discretio $»^{261}$. Cum enim « discrete ${ }^{262}$ aliquid videre volumus, supercilia stringimus, ut collectus oculi spiritus non vagetur $»^{263}$.

Ut dicit magnus Basilius: 'Ovibus et capris aliisque perplurimis animantibus suppetit naturalis cavendi contraria sensus in herbis; solis intellectu discernenti bus lesionem artis medicine sollertia suppetit, et tamen rerum frequens experientia malarum eisdem valde difficilis ${ }^{264}$.

\section{Liber V : De natura avium}

\section{Primo generaliter}

«Avis que claudit oculos, non claudit eos nisi per palpebram inferiorem, $<\ldots>^{265}$ propter duritiam corii continentis caput $»^{266}$.

** « Illa quidem animalia, que lapillis harenisque vivunt (ut aves), plerumque stomachum non habent; sed quiddam durius habere necesse est, iecur dico, quod ipso stomacho ad digerendum fortius est harenarumque asperitatem et lapillorum fracturas ferre potest. Nam et exterius et interius fortissimo nervo munitum est, in medio vero carne solidissima aptum (ad digerendum) $»^{267}$.**

'Nulla avis habet vesicam, propter paucitatem potus, maxime tamen propter hoc, quia superfluitas aque transit omnibus avibus in plumas'268.

\section{Liber X : De arboribus communibus}

\section{Primo generaliter}

Modus autem transplantationis unus est, secundum Plinium, 'ut in vasis fictilibus, dato per cavernas radicibus spiramento ramorum seriem faciant ${ }^{269}$. Alius vero modus est, ut si rami parvi arboris prope terram sint, in terra stante, ab arbore deponantur; et sic cooperti grassiori terra pullulent in radices; et sic radicati rami decidantur ab arbore, et transplantentur. Est autem et modus alterandi a sua natura arbores ut succisa arbore trunco eius inseratur ramus alterius generis vendicetque sibi insertus ramus naturam totius arboris.

'Queritur ergo non immerito quomodo hoc possit fieri, ut cum ramus trunco insitus sit, totus fructus naturam sequitur insiti rami, cum sint tamen diversarum naturarum. [Solutio] Constat quod crescentia omnia nutrimentum habeant a terra. Cum ergo sint dissimilia, diversum habent nutrimentum, sed illud aut per medium truncum trahit aut aliunde, sed aliunde nequaquam ; per medium ergo truncum trahit; idem autem truncus aut idem trahit aut non; si non idem, interruptus est tractus, nec potest ad insitum ramum pervenire; si vero truncus idem trahit, ergo trahit suum contrarium, et sic suam appetit dissolutionem ${ }^{270}$. Solvitur sic: 'insertus ramus trahit suum nutrimentum per truncum, truncus autem sibi trahit et alii, unum quod retinet sibi, aliud quod alii transmittat, sicut stomachus. Sic ergo remanet truncus solus in propria natura, et ramus insitus cetera vendicat profutura' ${ }^{271}$. 

possent. 273. **

** Est et alius inserendi modus inter corticem et lignum $[. . .]^{272} * *$

Ex semine pomorum et multorum fructuum in partibus Europe nascuntur arbores. In Oriente quem Asia continet pauce sunt arbores, que hoc faciunt. Neque enim gariophilorum, muscatarum, aut mirti, vel balsami arbores ex suis fructibus arbores faciunt, sed a ramis et radicibus propagantur; et hec ratio, quia huiusmodi fructus in calore excedunt, et maxime in Europa, que partes frigidissimas habet, generare non

** Questio est « quare arbores quedam frondes citius emittunt, quedam [vero] tardius ?»

\section{Liber XII : De herbis aromaticis}

\section{Primo generaliter}

Generaliter primo dicendum est de herbis. Habet enim maximam questionem, qualiter nascantur herbe sine preiacenti materia vel semine ${ }^{274}$. Solvi autem potest sic : terra suis singulis operibus 'que sensui subiacet humano, quatuor elementa cum suis qualitatibus continet' ${ }^{275}$. Unde certum est, quod terra ista " composita est, quamvis eam simplicem falsa assignatione vocamus. Nullus enim veram et simplicem terram vel aquam tetigit, verum $^{276}$ ignem aut aerem vidit. Composita enim sunt hec que sensu percipimus nec ipsa elementa, sed ex ipsis sunt $»^{277}$.

Quare ergo potius terreum aliquid dicimus, aqueum vel igneum aut aereum quam terram ?278 Solutio. «Ex eo, in quo singula magis habundant, sortita sunt appellationem. Ergo cum in ea re, que terrea ea dicitur, licet subtiliter pulverizata, quatuor cause sint, necessarium est ex ipsis quatuor esse compositam, terreum tamen maxime (dici potest quod terreum videtur), aqueum quod parum videtur ${ }^{* *}$ (habere de terram) ${ }^{* *}$ aereum minus, igneum minime ${ }^{* *}$ (id est valde parum) ${ }^{* *}$, per terram coherens, per aquam diffundens, per ignem et aera surgens. Nisi enim in eo ignis conclusus esset, motum ad superiora habere non posset; nisi aquam et aera, non diffunderetur in latum $»^{279}$. 'Patet autem, quod omnia terre nascentia magis de terra percipiant quam de alio aliquo elemento, et ideo locum suum et nativitatem suam iuxta terram occupant' ${ }^{280}$.

'Cum ergo maior pars sit terrea: quare quidem quedam herbe reperiuntur calide et quedam frigide ?'281 Solutio. Secundum quod magis et minus rerum qualitatibus adheserunt ${ }^{282}$. «Duobus enim modis res se habent : uno modo secundum quantitatem, alio modo secundum efficaciam magis et minus $»^{283}$. "Secundum quantitatem materiam sequuntur, secundum efficaciam minime $»^{284}$.

1 'Proinde cum radices sunt inter se contrarie, una calida et alia frigida $<\ldots>^{285}$ : quare vivunt in eodem territorio"286; "cum unumquodque in suo simili nutritur et destruitur a contrario ?'287 Solutio. 'Nutrimentum herba suscipit non a terra simplici, sed composita, in qua illa quatuor elementa sunt ${ }^{\prime 288}$.

Unde habent singule herbe nutrimentum ?289 Ex eo, quod sibi competit et per quod adherebant ${ }^{290}$. Unde «cum eradicantur herbe, in aere nutrimentum reperiunt, sed aliter quam oportet "291. "Unde aer, licet in se illa quatuor elementa contineat, non tamen herbis eradicatis nutrimentum prebere potest, quia de eo quo minus egebant, hoc est aere, magis inveniunt ${ }^{292}$. Unde necesse est ea dissolvi, deficiente eis naturali nutrimento, scilicet terreno ${ }^{293}$. 
** 'Si serenda semina herbarum, quas comedere crudas volueris madefeceris per triduum in oleo laurino vel nardo vel in vino condito pulveribus gariophili vel muscate et postea siccata iterum madefeceris: eiusdem saporis sata nascentur, cuius succos semina conbiberunt'294; et hoc teste Palladio. ${ }^{* *}$

\section{Sezioni derivate dalle Questiones salernitane}

\section{Liber IV : De quadrupedibus}

\section{De glire}

Interea sopito vitali spiritu nulla commotio, sed hoc mirum : si sopitum animal ad aeris serena detuleris, paulatim inter manus tenentium spiritu convalescente resolvitur. ${ }^{295}$

** Queritur ergo quomodo hoc fit. «Sine anhelitu enim vivere animal impossibile est, si tamen dicatur anhelitus attractio aeris occulta, vel manifesta, ad repressionem innati caloris. Sed tamen tam modicus est ille igniculus, ut potius indigeat fomento quam temperamento, unde talibus animalibus sufficit aer tantum per poros subintrans ; pro hac etiam necessitate nullus ab eis cibus assumitur, quia calor lentus potius ab eo suffocatur quam a calore digeratur. Estque alia ratio: ubi nichil deperditur, ex necessitate nichil reparatur. Sed in istis nec ex calore exteriori aereo, vel interiori, nulla fit membrorum consumptio, unde nulla <vel modica> necessaria existit reparatio. Hec eadem ratio est in ciconia, que dum frigidissima sit, in hyeme loca que ex sui commixtione sortitur - scilicet aquas - quandoque petit et se eis immergit et frigiditate constricta iacet premortua. Que postmodum adveniente temporis tepore, naturaliter suscitatur aquasque egreditur, seseque a limo abluens, ad usum vite revertitur ${ }^{296}$. In hiis verbis ratione digesta gliris naturam ulterius prosequamur. ${ }^{* *}$

Itaque veris intrante tempore cum Sol calidos radios emiserit, bestia naturali more ad robur revertitur. ${ }^{297}$

\section{De leone}

«Et causa huius $<$ non $>^{298}$ est quia est paucorum filiorum mater, sed quia est modici lactis. Quoniam cibus transit in corpus et quoniam non comedit nisi raro, et non comedit nisi carnem $»^{299}$, que non facile transit in materiam lactis.

Augustinus : cum parit, catulus tribus diebus dormire dicitur, donec advenientis patris rugitu tremefactus excitetur ${ }^{300}$, ${ }^{* *}$ et hec ratio «quare mortuus generetur: leo siccissimum animal est, cuius siccitatis violentia humiditas cerebri ingrossatur et viscosa efficitur. Cassante ergo viscositate orificia et principia nervorum, per que animalis spiritus ad instrumenta sensuum transmitti debeat, licet vivificatum sit animal, iacet tamen quasi mortuum, quia pro impedimento spiritus nec sensum habet nec motum. Et quamvis calor fortis sit in eo, quia animal est multum calidum, tamen propter nimiam diaforesim pororum effectus caloris, <dum> in utero materno, debilitatur ut non possit viscosum humorem dissolvere et eufraxim nervorum facere. Egrediens ergo de utero, frigiditate aeris pori constringuntur calorque in interioribus confortatur. $<$ Et fortius $>$ in primo die et <in> secundo, calor incipit agere in humorem ut eum dissolvat; tertio vero die, quia animal calidissimum ${ }^{301}$ est, ex motu colere, que tertium ${ }^{302}$ habet insultum, calor plenissime $\mathrm{e}^{303}$ confortatur. At ubi leo pater, natura supra modum calidus ${ }^{304}$, supervenerit, fortem rugitum faciens, caliditate flatus et spiritus aerem calefacit; qui gratia similitudinis et violentia impulsionis, aures et nares subintrans leunculi, calori 
cooperatur naturali, qui duplicatus, immo triplicatus, humorem opilantem »; 'sensuum aditus patefacit, statimque motus et sensus perficitur et animal vivificatur'. 'Si vero queritur utrum leena mater hoc idem facere possit leunculo, dicitur quod non', quia leena « ex natura sexus humidior <est, unde> flatu suo humores potius ingrossaret quam dissolveret $» .{ }^{305 * *}$

Solinus : Leo nisi lesus facile non irascitur, sed cum ultra provocatur, confringit totaliter adversantem ; prostratis parcit, captivos obvios repedare permittit, hominem non nisi in magna fame perimit ${ }^{306}$. putrescunt afflata ${ }^{313}$

\section{Liber V : De natura avium}

\section{De strutione}

Igitur ovis calefactis harena a Sole irradiata, pulli educuntur ab eis ${ }^{314}$.** Queritur ergo « quare strutio ova sua harena suffodiat et ea non sicut cetere aves, sed solo visu foveat? Solutio. Omnis rerum generatio duplici eget exordio, causa materiali et efficienti ». « Est autem causa materialis materia, ex qua res esse suum trahit, calor causa efficiens. Calor enim corrumpit, digerit et transducit in speciem». "Materia autem multiplex est: grossissima, mediocris atque subtilis». "Qualis ergo materia, talem convenit esse calorem ». «Si ergo materia fuerit subtilis, ex debili calore poterit immutari, ut videmus in ovo galline, quod, quia subtilis est substantie, ex leni calore fovetur, ut ex eo animal generetur. Unde mulieres ea in gremio fovent ». "Ovum autem strutionis grossissimam substantiam habet et ideo fortissimo eget calore ». "Animal autem, cui ex potestate innititur, duram immo durissimam habet carnem, et est animal calidissimum, quod rei effectus ostendit, quia etiam ferrum digerit. Ex hoc ergo fit, quod structio ova harene involvit, ut calore harene magis calefiant. Ipse autem visu in ea intendit, ut calore visibilis spiritus, qui in eo potentialiter calidus est, quia ab animali calidissimo procedit aer qui circumfunditur, calefiat $<\ldots{ }^{315}$ fortique calore, grossissima substantia, dissoluta et corrupta motu generationis ex eo animal, cui ex potestate innititur, procreatur $» .316 * *$ 
Hec avis pennas habet herodii et accipitris, sed est tarda ad volandum ${ }^{317}$.

\section{Liber X : De arboribus communibus}

\section{Primo generaliter}

** Est et alius inserendi modus inter corticem et lignum $[. . .]^{318} * *$

Ex semine pomorum et multorum fructuum in partibus Europe nascuntur arbores; in Oriente, quem Asia continet, pauce sunt arbores que hoc faciunt. Neque enim gariophilorum, muscatarum aut mirti, vel balsami arbores, ex suis fructibus arbores faciunt, sed a ramis et radicibus propagantur ; et hec ratio, "quia huiusmodi fructus in calore excedunt " ${ }^{319}$ et maxime in Europa, que partes frigidissimas habet, generare non possent.

** Questio est. "Quare arbores quedam frondes citius emittunt, quedam [vero] tardius ?». Solvitur : "ubi subtilis humiditas est cum aliquanto calore, cito frondes producunt et cito deponunt, nisi superhabundet humiditas. Ubi vero grossior est cum mediocri calore, et tardius veniunt et tardius decidunt. Humiditas autem grossissima cum soliditate roboris, frondes perpetuare solet ". ${ }^{320}$

83 Questio. «Quare nuclei quorundam fructuum dulces sunt, quidam vero amari ? Solutio. Ex tali humiditate generatur medulla; in qua si calor prevaleat, efficit amarum: habet enim amarus sapor fieri ex multa caliditate et humiditate non multa. Dulce autem ex multo humore et non multo calore est ${ }^{321}$

44 Questio. "Quare in aliis fructibus cortices sunt amari, ut in nucibus vigilantis, in aliis acetosi, ut in nucibus avellanis, in aliis dulces, ut in persicis ?". Solutio. “Aquosior pars fructus circa superficiem se colligit, que, si tante subtilitatis fuerit, ut calor desiccando multum in ea prevaluerit, amarus sapor efficitur. Si vero humiditas multum calori prevaluerit, dulcis sapor est”. ${ }^{322}$

Questio. "Cur quedam pomorum habent nucleos disiunctos, quedam vero tantum unum ?”. Solutio. «Generatio nucleorum habet fieri ex grossiori humiditate fructuum, que autem grossior est, licet siccitate participet, quia tamen grossa est siccitas non potest in ea aliquid consumere, ut faciat incisionem, et tamen plures nucleos generat. Sed tantum in superficie quod liquidius est et subtilius consumit, unde fiunt nuclei rugosi et fissi, ut apparet in persicis. Inde est, quod non pluralitas, sed nucleorum unitas generatur. Humiditas <quia> autem minus grossa et magis liquida siccitate in eam agente, facile in alia parte potest consumi que subtilior est, et sic fit disiunctio unius partis ab alia, que partes desicca<n>te siccitate in nucleos convertuntur. Inde est, quod non unitas, sed $<$ nucleorum> pluralitas generatur, quod apparet in malogranatis (et in quibusdam aliis fructibus) $» .^{323}$

Questio. «Cur quedam pomorum habent pilosum corticem, quedam asperum et rugosum? $»^{324}$. Solutio. "Cortex habet procreari de subtiliori (fructus) humiditate. Pilositas autem in fructibus habet procreari de subtili humiditate et pauca siccitate. Quia subtilis est humiditas, sufficit fumus per calorem resolutus ab ea ad exteriora progredi ${ }^{325}$. Quia vero modica siccitate participat, indurari in solidum non potest, sed in pilos convertitur, ut apparet in cytoniis. Rugositas vero procreatur ex grossa humiditate (et caliditate) et <multa> siccitate. Siccitas autem consumit quod subtilius est in superficie, quod reliquum est indurat, ut in glandibus apparet. Spinositas autem habet procreari de subtili humiditate et multa siccitate. Quia vero subtilis est humiditas, subtilis [est] fumus 
$a b$ ea resolutus ${ }^{326}$, et ideo facile ad exteriora progreditur et in acumen ${ }^{327}$ tendit. Quia autem multa est siccitas, sufficit fumositatem indurare et in spinam convertere, ut in castaneis apparet $<\ldots>^{328} \|^{329} . * *$

\section{E. Sezioni dialogiche non attribuite}

\section{Liber IV : De quadrupedibus}

\section{De caco}

"Cacus monstrum est animal in Archadia. Hoc animal totum setosum est, quasi porcus, et - sicut scribit Andelmus philosophus - flammas de pectore suo eructuat, id est anhelitum et spiritum flammeum "; facit autem hoc maxime, cum ira permotum fuerit. ${ }^{330}$

Sed queri potest quomodo flammas aut spiritum flammeum de ore suo possit evomere, et ipsas flammas esse efficaces ad comburendum proxime contrectata et non ipsum corpus animalis flammis absumi. Respondere possumus, quia, cum anhelitus adhuc in visceribus animalis per membra multa, ac diversa late diffusus est, tepidus usquequaque non extuberatur in flammas, sed eructuatus continuatur ac multiplicatur in obiectum aliquod corpus virtutemque recipit comburendi. Verbi gratia : sicut videmus per medium berilli lapidis solare lumen multiplicare radios et in supremo unitionis acumine radiorum ignis virtutem suscipere in subiectam materiam et ignem effici violentum. Horum animalium similia fuerunt illa de quibus in libro Sapientie Scriptura testatur divina, quod ignes de ore suo spirabunt ${ }^{331}$.

\section{De linche}

"Lyns", ut dicunt Plinius et Iacobus et Lapidarius, "bestia est" ${ }^{332}$, "que ita perspicaces habet oculos quod solida corpora subtilitate visus penetrare dicatur $»^{333}$.

** Questio autem non modica est quomodo hoc possit. Constat, secundum philosophum, quod oculus situs est in humido ${ }^{334}$. Tria autem in aqua sunt : aquea humiditas, dyafanitas et perspicacitas lucis, et hanc ultimam communicat cum natura celesti, et hec est ultima depuratio a materia in natura lucis; et, quia lux est ultima perspicacitas in corpore terminato, ideo si ponatur aquea substantia in ultima sua depuratione quantum ad perspicacitatem, in oculo lincis poterit penetrare corpus solidum et obscurum. ${ }^{335} \mathrm{Hoc}$ quoque in natura eius mirabile reperitur, quod « quicquid <autem> viderit, statim cum oculos averterit, obliviscitur $»^{336}$.**

Ut Plinius dicit : Nisi tantum unum facit fetum ${ }^{337}$.

\section{Liber IX : De lapidibus pretiosis}

\section{Primo generaliter}

Generaliter primo dicendum est de lapidibus pretiosis.

* Est autem questio quomodo fiunt in visceribus terre. Et respondemus ex dictis philosophorum quod ex vaporibus fiunt, qui de inferioribus partibus terre consurgunt et intercluduntur, sortiunturque formam secundum locum quem vacuum in terra reperiunt; colorem vero secundum diversitates vaporum, sicut glanduli in carne animalis. Subito quidem intercluduntur atque formantur, sed successione temporis solidantur : si vapor magis ex terre elemento consurgit, grossus lapis fit et obscurus, si vero ex elemento aque, lucidus, si ex aere, ceruleus, si ex calore ignei elementi, rubeus, et 
sic secundum proprietates elementorum, nunc commixtim, nunc impermixtim, nunc magis $a b$ isto, nunc magis ab illo vapor exsurgens, colorum diversitates lapides sortiuntur. Hii vero lapides, qui virides vel crocei sunt, ex aliis coloribus colorem communicant, et hoc ex commixtione vaporum. Proinde lapides, qui de terrestri Paradiso ad nos per quatuor flumina deferuntur, magis pretiosi sunt atque rarissimi; sed et alii, qui in diversis regionibus inveniuntur, pretiosi sunt ac virtute potentes, et maxime hii qui in Orientis partibus sunt. Sunt autem claritate fulgoris ceteris cariores, et hoc quia ibi sunt vapores elementorum a sordibus puriores; sed, et questio magna est, unde et quomodo virtus inest lapidibus. $338 * *$

Quippe magna virtus eorum videtur et efficacia sanitatum, unde autem hoc habeant nisi a Deo, homini incompertum est, et quidem, hoc certum est, quod omnis virtus a Deo est ${ }^{339}$, [ut] sicut dicit Aristotiles in libro Metheororum.

\begin{tabular}{|c|c|}
\hline $\begin{array}{l}\text { In Rubro Mari } \\
\text { nascitur }{ }^{340} .{ }^{341}\end{array}$ & $\begin{array}{l}\text { ** nobilissimum ac clarissimum eius genus invenitur }{ }^{342} \text { et, circa Alpes, in Italia; } \\
\text { inveniuntur et huiusmodi lapides in partibus Germanie in locis saxosis } \\
\text { montium. }{ }^{343} \\
\text { Queritur autem quomodo fiat ut omnes fere sexangulares inveniantur; et } \\
\text { solvimus quod multi vapores de terra pariter ascendentes in terra, aliquando in } \\
\text { petris vero et in rupibus frequentissime intercluduntur, solidatique per } \\
\text { temporum intervalla ex compressione circumiacentium exceptis extremitatibus } \\
\text { medii sexangulares redduntur. Verbi gratia : ut, si candelas multas inter manus } \\
\text { compresseris, omnes in medio positas, sexangulares invenies; sexangulari enim } \\
\text { forma in circulo posita omnibus magis potest continuari, unde apes fetuum } \\
\text { cubilia sexangularia faciunt, ut nichil inutile, nichil vacuum in opere sit. Sic } \\
\text { ergo providus nature Deus omnia sua in numero, pondere et mensura disposuit } \\
\text { 344. } \\
\text { Constat autem quod vapor unde yris fit ex elemento aque consurgit et ideo } \\
\text { lucidus, et clarus in modum aque quasi glacies solidatur. }{ }^{345 * * 346}\end{array}$ \\
\hline
\end{tabular}

\section{Liber XVII : De septem planetis}

3. Generaliter de septem planetis et motu eorum, quomodo fiant aut et cuius ignis eorum mittatur.

« Hii igitur immensa celeritate <firmamenti> ab oriente in occidentem raptantur. Tamen naturali cursu contra mundum ire comprobantur, sicut musca, si in rota molendini circumferretur, ipsa tamen proprio motu contra revolutionem eius ire videretur. Hee nunc inferius, nunc superius propter obliquitatem signiferi vagantes, radiis solis prepedite, anomale, vel retrograde, vel stationarie fiunt $\aleph^{347}$.

Querendum est autem quo motu feruntur. Triplex est enim motus rerum: naturalis, violentus et voluntarius. Notandum est primo quod voluntarius motus non est in planetis quia sensus et motus determinat animal; sensus autem non est, et si motus est in planetis. Planete autem motu violento moventur cum firmamento, motu naturali_contra firmamentum. Ratione autem forme, que sperica est, firmamentum in instanti moveretur, nisi esset prohibens, et propterea positi sunt planete magni, qui motu naturali moventur contra firmamentum ad motus sui velocitatem impediendam, sed quia motus firmamenti 
prevalet in eis, rapiuntur cum firmamento motu violento; si autem moveretur firmamentum in instanti, esset rerum confusio nec esset generatio atque corruptio.

Proinde queritur unde planetarum ignis alatur. Solutio. Est ignis lux et ignis flamma et ignis carbo : ignis carbo est in materia terrea ; ignis flamma in materia aeris ; ignis lux in materia lucis et propterea non indiget nutrimento, quia non est ex contrariis agentibus. Ex isto ergo igne planete et stelle constant, et ideo non indigent nutrimenta; et ideo secundum cursum nature in evum lucere possent, non eos creatoris sui voluntas aliter ordinaret. Ipse enim ignis lux, unde planete constant, in propria regione ignis est sicut terra vel aer in propriis regionibus. Et ideo non habent respectum ad aliud unde trahat materiam aut formam lucis ignis lux. ${ }^{348}$

\section{BIBLIOGRAFIA}

\section{Manoscritti consultati}

London, British Libr., Royal 12.B.XII, f. 102v-104v

London, British Libr., Harley, 3717

Oxford, Bodleian Libr., Bodley 679, f. 101r-103v

Oxford, Bodleian Libr., Auct. F.3.10

Oxford, Bodleian Libr., e Museo 219, f. 141-145b

Oxford, Merton College Libr., Merton 324, f. 144r-150v

Paris, Bibl. nationale de France, Lat. 7798

Paris, Bibl. nationale de France, Lat. 15453, f. 214-216

Paris, Bibl. nationale de France, Lat. 7056, f. 89v-93r

Paris, Bibl. nationale de France, Lat. 523A

Paris, Bibl. nationale de France, Lat. 11219, f. 39r-v

Paris, Bibl. nationale de France, Lat. 15453, f. 214-216

Paris, Bibl. nationale de France, Lat. 18081

Praha, Národní knihovna Ceské republiky, XIV.A.15

\section{Fonti}

ADELARDUS BATHONIENSIS, Questiones naturales, in Adelard of Bath, Conversations with his Nephew : On the Same and the Different, Questions on Natural Science, and on Birds, BURNETT Charles, RONCA Italo, mantas espana Pedro, van den abeele Baudouin, (ed.), Cambridge, 1998. 
ALEXANDER NECKAM, De naturis rerum, II, 153, WRIGHT Thomas (ed.), London, 1863 (Rerum Britannicarum Medii Aevi Scriptores, 34).

AL-GHAZALI, Metaphysica, MUCKLE Joseph T. (ed.), Toronto, 1933.

ALEXANDER NECKAM, De laudibus divine sapientie, WRIGHT Thomas (ed.), London, 1863 (Rerum Britannicarum Medii Aevi Scriptores, 34).

RICHARDUS ANGLICUS : Anatomia Ricardi Anglici, TÖPLY EQUES Robertus (ed.), Wien, 1902.

ARISTOTELES : Aristotelis opera, I. Bekker, C. A. Brandis (ed.), Berlin, 1831-1870.

ARISTOTILES, Metereologica, schoonheIM Pieter L. (ed.), in Aristotle's 'Meteorology' in the Arabico-Latin tradition. A Critical Edition of the Texts, with Introduction and Indices, scHOONHEIM Pieter L. (ed.), Leiden-Boston-Köln, 2000 (Aristoteles Semitico-Latinus, 12).

ARISTOTILES, De animalibus libri XIX. Buch I-XIV. Aristoteles Latinus in der Übersetzung des Michael Scotus nach der Handschrift Rom, Biblioteca Apostolica Vaticana, Chigi E VIII 251 (s. XIII), fol. 1ra-108rb, mit Textkorr. aus den Handschriften Nürnberg, Stadtbibliothek, Cent. VI 10 und Pisa, Biblioteca di Santa Caterina, Cod. 11, HÜNEMÖRDER Christian (ed.), München, 1994, Tesi di dottorato.

ARISTOTILES, De animalibus. Michael Scot's Arabic-Latin Translation, Part II, Books XI-XIV: Parts of Animals, VAN opPENRAay Aafke M. I. (ed.), Leiden-Boston-Köln, 1998, (Aristoteles Semitico-Latinus, 5.2).

ARISTOTILES, De animalibus, Michael Scot's Arabic-Latin translation, Part III, Books XV-XIX: Generation of Animals, VAN oppenRaAy Aafke M. I. (ed.), Leiden-Boston-Köln, 1992 (Aristoteles Semitico-Latinus, $5.3)$.

AUGUSTINUS, Confessiones, o’Donnell James J. (ed.), Oxford, 1992.

AUGUSTINUS, Contra Faustum Manicheum, in J-P. MIGNE (ed.), (Patrologia Latina, 42), col. 207-518.

AVICENNA, Metaphysica, IX, 2, Bonus locatellus (ed.), Venezia, 1530.

BARTHOLOMAEUS ANGLICUS, De rerum proprietatibus, Frankfurt, 1964, facsmile edizione 1601.

BARTholomeus DE MESSANA, Problemata Aristotelis, SEligsohn Rudolf (ed.), in Die Übersetzung der Ps.aristotelischen Problemata durch Bartholomaeus von Messina : Text und textkritische Untersuchungen zum ersten Buch, Berlin, 1934.

EUSTATHIUS : Ancienne version latine des neuf homélies sur l'Hexaéméron de Basile de Césarée, DE MENDIETA Amand E., RUDBERG Stig Y. (ed.), Berlin, 1958 (Texte und Untersuchungen zur Geschichte der altchristlichen Literatur, 66 = V.11).

BAUDRI De BouRGUeIL, Poèmes, TILLIETTE Jean-Yves (ed.), Paris, 1998-2002.

BAUDRI DE BOURGUEIL, « Poème adressé à Adèle, fille de Guillaume le Conquérant, par Baudri, abbé de Bourgueil », DELISLE Leopold (ed.), in Mémoires de la Société des antiquaires de Normandie, 8, 1871, p. 187-224.

BEDA VENERABILIS, De natura rerum, MIGNE Jean-Paul (ed.), (Patrologia latina,110), col. 187-278.

CALCIDIUS, Timaeus a Calcidio translatus commentarioque instructus, WASZINK Jan H. (ed.), London, 1962.

MARCUS TULLIUS CICERO, De natura deorum libri tres, MAYOR Joseph B., sWAINSON John H., CambridgeLondon, 1883-1891. 
Das 'Lorscher Arzneibuch'. Ein Medizinisches Kompendium des 8. Jahrhunderts (Codex Bambergensis Medicinalis, 1). Text, Übersetzung und Fachglossar, KEIL Gundolf, sTOLL Ulrich, OHLMEYER Albert (ed.), Stuttgart, 1989.

DAVID DE DINANT, Quaternulorum fragmenta, CASADEI Elena (ed.), in I testi di David di Dinant. Filosofia della natura e metafisica a confronto col pensiero antico, CASADEI Elena (ed.), Spoleto, 2008, p. 189-233. GAIUS PLINIUS SECUNDUS, Naturalis Historia, IAN Ludwig, MAYHOFF Karl. F. T. (ed.), Leipzig, 5 vol., 1892-1909 (Teubner).

Gesta Romanorum, OESTERLEY Hermann (ed.), Hildesheim, 1963.

GREGORIUS I MAGNUS, Homiliarum in Evangelia libri duo, MIGNE Jean-Paul (ed.), (Patrologia latina, 76), col. 1075-1312.

GUlielmus De CONCHIS, Philosophia, ALBERTAZzi Marco (ed.), Lavis, 2010.

HONORIUS AUGUSTODUNENSIS, Elucidarium, MIGNE Jean-Paul (ed.), (Patrologia latina, 172), col. 1109-1176D.

HONORIUS AUGUSTODUNENSIS, De imagine mundi, MIGNE Jean-Paul (ed.), (Patrologia latina, 172), col. 115-188C.

HUGO SANCTALLENSIS, Liber Apollonii de secretis naturae - Kitâb sirr al-Khalîqa, HUDRY Francoise (ed.), in "Cinq traités alchimiques médiévaux », Chrysopoeia. Revue publiée par la Société d'Étude de l'Histoire de l'Alchimie, 6, 1997-1999, p. 1-154.

IACOBUS DE VITRIACO, Historia orientalis, DONNADIEU Jean (ed.), Turnhout, 2008

IOHANNES BLUND, Tractatus de anima, CALLUS Daniel A., HUNT Richard W. (ed.), London, 2013.

IOHANNES SARESBERIENSIS, Polycraticus, MIGNE Jean-Paul (ed.), (Patrologia Latina, 199), col. 385-822.

Liber monstrorum, ORCHARD Andy (ed.), in Pride and Prodigies. Studies in the Monsters of the BeowulfManuscript, ORCHARD Andy (ed.), Toronto-Buffalo-London, 1995, p. 254-317.

Lucius Annaei Senecae Naturalivm qvaestionvm libros, HINE Harry M. (ed.), Stuttgart, 1996.

MACROBIUS, Commentarii in Somnium Scipionis, willis Jacob (ed.), Leipzig, 1970.

MACROBIUS, Saturnalia, WILLIS Jacob (ed.), Leipzig, 1963.

MARBODUS REDONENSIS, Lapidario. Liber lapidum. édición, traducción y commentario, HERRERA Maria E. (ed.), Paris, Les Belles-Lettres, 2005 (Auteurs latins du Moyen Âge).

MATTHAEUS PARIS, Chronica majora, anno 1241, LUARD Richard (ed.), London, 1872.

MAURUS, Regole urinarum, DE RENZI Salvatore (ed.), in Collectio salernitana, DE RENZI Salvatore (ed.), vol. III, p. 1-51.

MICHAEl SCotus, Quaestiones Nicolai Peripatetici, wIElgus Stanislaw (ed.), in Mediaevalia Philosophica Polonorum, 17, 1973, p. 57-155.

NEMESIUS, Premnon Physicon a N. Alfano in Latinum translatus, BURKHARDT Karl (ed.), Leipzig, 1917 (Teubner).

PALlADIUS, Opus agricolturae, De veterinaria medicina. De insitione, RODGERS Robert H. (ed.), Leipzig, 1975 (Teubner).

PETRUS HISPANUS, Questiones super libro ‘De Animalibus' Aristotelis, NAVARRO SÁNCHEZ Francisca (ed.), Farnham, 2013. 
Die Philosophischen Werke des Robert Grosseteste, Bischofs von Lincoln, BAUR Ludwig (ed.), Münster, 1912.

Physiologus Latinus, versio B-Is., MANN Max F. (ed.), in Der 'Bestiaire Divin' des Guillaume le Clerc, Max F. MANN (ed.), Heilbronn, 1888, p. 37-73.

The Prose Salernitan Questions. Edited from a Bodleian Manuscript (Auct. F.3.10), an Anonymous Collection Dealing with Science and Medicine Written by an Englishman c. 1200, with an Appendix of Ten Related Collections, LAWN Brian (ed.), London, 1979.

PSEUDO-BOETIUS, De disciplina scolarium, WEIJERS Olga (ed.), Leiden-Köln, 1976.

PSEUDO-CLEOPATRA, Gyneciorum, hoc est, de mulierum tum aliis, tum gravidarum, parientium et puerperarum affectibus et morbis, libri veterum ac recentiorum aliquot, partim nunc primum editi, partim multo quam antea castigatiores, wolf Casparus (ed.), Basileae, 1566.

PSEUDO-SORANUS, Quaestiones medicinales, ROSE Valentin (ed.), in Anecdota graeca et graecolatina, ROSE Valentin (ed.), Berlin, 1870, vol. II, p. 243-280.

Questiones Cratonis, WEIJERS Olga (ed.), in Les Questions de Craton et leurs commentaires, WEIJERS Olga (ed.), Leiden-Köln, 1981.

Quaestiones super de animalibus, FILTHAUT Ephrem (ed.), in Alberti Magni ordinis fratrum praedicatorum: 'Liber de natura et origine animae', 'Liber de principiis motus processivi', 'Quaestiones super de animalibus', GEYER B. (ed.), Münster, 1954, p. 148-154.

Questions philosophiques adressés aux savants musulmans, par l'empereur Frédéric II, AMARI Michele (ed. ), in AMARI Michele, «Questions philosophiques adressés aux savants musulmans, par l'empereur Frédéric II », in Journal asiatique, V.1, 1853, p. 240-274.

Questions philosophiques, MEHREN August Ferdinand Michael (ed.), in MEHREN August Ferdinand Michael, « Correspondance du philosophe soufi Ibn Sab'în Abd Oul-Haqq avec l'Empereur Frédéric II. de Hohenstaufen, publiée d'après le manuscrit de la Bibliothèque Bodléienne, contenant l'analyse générale de cette correspondance et la traduction du quatrième traité sur l'immortalité de l'âme ", in Journal asiatique, VII.14, 1879, p. 341-454.

ROBERTO GROSSATESTA, Liber qui uocatur Suda, DORANDI Tiziano, TRIZIo Michele (ed.), in DORANDI Tiziano, TRIzIo Michele, « Editio princeps del 'Liber qui uocatur Suda' di Roberto Grossatesta », in Studia graeco-arabica, 4, 2014, p. 145-190.

CAIUS IULIUS SOLINUS, Polyhistor, MOMMSEN Theodor (ed.), Berlin, $1894^{2}$.

SORANUS : Sorani Gyneciorum vetus translatio Latina, ROSE Valentin (ed.), Leipzig, 1882.

Summarium Heinrici (versio I), HILDEBRANDT Reiner (ed.), Berlin-New York, 1974.

THOMAS CANTIMPRATENSIS, Bonum universale de apibus, COLVENERIUS Georgius (ed.), Douai, 1627.

THOMAS CANTIMPRATENSIS, The Collected Saints' Lives: Abbot John of Camtimpre, Christina the Astonishing, Margaret of Ypres, and Lutgard of Aywieres, NEWMAN Barbara, Margot H. KING (ed.), Turnhout, 1998.

THOMAS CANTIMPRATENSIS, Liber de natura rerum, CIPRIANI Mattia (ed.), in CIPRIANI Mattia, La place de Thomas de Cantimpré dans l'encyclopédisme médiéval : les sources du Liber de natura rerum, Tesi, Paris-Firenze, 2014, vol. I.

THOMAS CANTIMPRATENSIS, Liber de naturis rerum, BOESE Helmut (ed.), Berlin-New York, 1973. 
THOMAS CANTIMPRATENSIS, Vita preclare virginis Margarete Yprensis, MEERSSEMAN G. (ed.), in « Les frères prêcheurs et le mouvement dévot en Flandre au XIII ${ }^{\mathrm{e}}$ siècle », MEERSSEMAN G. (ed.), in Archivum Fratrum Praedicatorum, 18, 1948, p. 106-130.

URSO, Aphorismi : CREUTZ Rudolf (ed.), in Die medizinisch-naturphilosophischen Aphorismen und Kommentare des Magister Urso Salernitanus, CREUTZ Rudolf (ed.), Berlin, 1936, p. 1-192.

Vetus Latina. Die Reste der altlateinischen Bibel, SABATIER Petrus ET AL. (ed.), 26 vol., Freiburg, 1949-2000.

\section{Letteratura secondaria}

BALDWIN John H., The Language of Sex: Five Voices from Northern France around 1200, Chicago, 1994.

BAZÀN Bernardo C., WIPPEL John W., FRANSEN Gérard, JACQUART Danielle, Questions disputées et les questions quodlibétiques dans les facultés de théologie, de droit et de médecine (Typologie des sources du Moyen Age occidental, 44-45), Turnhout, 1985.

BECCARIA Augusto, I codici di medicina del periodo presalernitano (secoli IX, X e XI), Roma, 1956.

BOESE Helmut, « Zur Textüberlieferung von Thomas Cantimpratensis' Liber de natura rerum », in Archivum fratrum praedicatorum, 39, 1969, p. 53-68.

CARDELLE DE HARTMANN Carmen, Lateinische Dialoge 1200-1400 : literaturhistorische Studien und Repertorium, Leiden-Boston, 2007.

CIPRIANI Mattia, La place de Thomas de Cantimpré dans l'encyclopédisme médiéval. Les sources du Liber de natura rerum - Tommaso di Cantimpré nell'enciclopedismo medievale: le fonti del Liber de natura rerum. Partie I : Texte; Partie II : Commentaire. Thèse de doctorat en cotutelle Ecole pratique des hautes études, Paris - Scuola normale superiore, Pisa, 2 vol., 2014.

CIPRIANI Mattia, « Un esempio dell'enciclopedismo di Tommaso di Cantimpré : la sezione ‘De lapidibus pretiosis' del 'Liber de natura rerum' ", in Médiévales, 72, printemps 2017, p. 155-174.

CLESSE Gregory, « Thomas de Cantimpré et l'Orient : les sources arabes dans les chapitres zoologiques du Liber de natura rerum », in Reinardus, 25, 1, 2013, p. 53-77.

CORDEZ Philippe, « Materielle Metonymie. Thomas von Cantimpré und das erste Horn des Einhorns », in Bildwelten des Wissens, Kunsthistorisches Jahrbuch für Bildkritik, 9, 2012, p. 85-92.

CORNER George W., Anatomical Texts of the earlier Middle Ages : A Study in the Transmission of Culture, Washington, 1927.

DEBOUTTE Alfred, «Thomas van Cantimpré als auditor van Albertus Magnus », in Ons geestelijk erf, 58,1984, p. $192-209$

DEBOUTTE Alfred, « Thomas van Cantimpré. Zijn opleiding te Kamerijk I », in Ons geestelijk erf, 56, 1982, p. 283-299.

DEBOUTTE Alfred, « Thomas van Cantimpré. Zijn opleiding te Kamerijk II », in Ons geestelijk erf, 57, 1983, p. 14-28.

DEBOUtTE Alfred, « Thomas van Cantimpré. Zijn opleiding te Kamerijk III », in Ons geestelijk erf, 60, 1986, p. 283-299.

DEBOUTTE Alfred, «Thomas de Cantimpré », in Dictionnaire de spiritualité ascétique et mystique :

doctrine et histoire, M. Viller-F. Cavallera-J. de Guibert (ed.), Paris, 1991, t. XV, col. 784-792. 
DRAELANTS Isabelle, « La question ou le débat scolastique comme forme du discours scientifique dans les encyclopédies naturelles du XIII ${ }^{\mathrm{e}}$ siècle : Thomas de Cantimpré et Vincent de Beauvais », in Scientiarum historia, 31, 2, 2005, p. 125-153.

DRAELANTS Isabelle, FRUNZEANU Eduard, « Le savoir astronomique et ses sources dans le De mundo et corporibus celestibus de Barthélemy l'Anglais », in Rursus-Spicae, 11, nov. 2017.

DUTTON Paul E., The Mistery of the Missing Heresy Trial of William of Conches, Toronto, 2006.

DUTTON Paul E., « The Little Matter of a Title : Philosophia Magistri Willelmi de Conchis », in Guillaume de Conches : philosophie et science au XII siècle, B. OBRIST - I. CAIAZZo (ed.), Firenze, 2011.

ELFORD Dorothy, « William of Conches ", in A History of Twelfth-Century Western Philosophy, DRONKE Peter (ed.), p. 308-327.

L'enciclopedismo medievale, PICONE Michelangelo (ed.), Ravenna, 1994.

L'encyclopédisme (Actes du Colloque de Caen, 12-16 janvier 1987), BECQ Annie (ed.), Paris, 1991.

Enzyklopädien der frühen Neuzeit : Beiträge zu ihrer Erforschung, EYBL Franz M. (ed.), Tübingen, 1995.

ENGELS Joseph, « Thomas Cantimpratensis redivivus », in Vivarium, 12, 1974, p. 124-132.

Die Enzyklopädie im Wandel vom Hochmittelalter bis zur frühen Neuzeit (Akten des Kolloquiums des Projekts D im Sonderforschungsbereich 231 : 29.11.-1.12.1996), MEIER Christel, sCHULER Stefan, HECKENKAMP Marcus (dir.), München, 2002 (Münstersche Mittelalter-Schriften, 78).

Der 'Experimentator'. Eine anonyme lateinische Naturenzyklopädie des frühen 13. Jahrunderts, DEUS Janine (ed.), Dissertation zur Erlangung der Würde des Doktors der Philosophie des Fachbereichs Geschichtswissenshaft der Universität Hamburg, 1998.

FERCKEL Cristoph, Die Gynäkologie des Thomas von Brabant. Ein Beitrag zur Kenntnis der mittelaterlichen Gynäkologie und ihrer Quellen, Alte Meister der Medizin und Naturkunde, Facsimile-Ausgaben und Neudrucken, München, 1912.

FRENCH, Roger, CUNNINGHAM, Andrew, Before Science. The Invention of the Friars' Natural Philosophy, Cambridge, 1996.

FRIEDMAN John B., « Albert the Great's topoi of Direct Observation and his Debt to Thomas of Cantimpré », in Pre-Modern Encyclopaedic Texts, Peter Binkley (ed.), Leiden, 1997, p. 379-392.

FRUNZEANU Eduard, Les configurations de la natura dans le 'Speculum maius' de Vincent de Beauvais, Thèse d'histoire, Montréal, 2007.

FRUNZEANU Eduard, KUHRY Emmanuelle, «L'apport des gloses, des paraphrases et des syntagmes synonymiques à la compréhension des textes : le cas de quelques encyclopédies du XIII siècle », in Spicce, Cahiers de l'Atelier Vincent de Beauvais, Nouvelle série, 1, 2011, p. 39-49.

DE GANDILLAC Maurice, La pensée encyclopédique au Moyen Âge, Neuchâtel, [1966].

GRABMANN Martin, «Der Einfluss Alberts des Grossen auf das mittelalterliches Geistesleben », in Zeitschrift für katholische Theologie, 25, 3, 1928, p. 153-182 e 313-356.

GRABMANN Martin, Handschriftliche Forschungen und Mitteilungen zum Schrifttum des Wilhelm von Conches und zu Bearbeitungen seiner naturwissenschaftlichen Werke, München, 1935.

GREEN Monica H., “'Traittié tout de mençonges' : The Secrés des dames, 'Trotula', and Attitudes towards Women's Medicine in Fourteenth- and Early Fifteenth-Century France », in Christine de Pizan and the Categories of Difference, DESMOND Marilynn (ed.), Minneapolis, 1998, p. 146-178. 
GREEN Monica H., Genecia Cleopatre, URL: https://www.academia.edu/11313234/

HANSON Ann E., GREEN Monica H., Soranus of Ephesus : methodicorum princeps, in Aufstieg und Niedergang der Römischen Welt, Berlin-New York, 1994, vol. II (37, 2), p. 968-1075.

HASKINS Charles H., Studies in the History of Mediaeval Science, Cambridge, 1927.

HERRERA Maria E., « La historia del texto del Liber lapidum de Marbodo de Rennes a través de los manuscritos provenientes de las bibliotecas francesas del siglo XII ", in Du copiste au collectionneur, NEBBIAI-DALlA GUARDA Donatella- GENEST Jean-François (ed)., Turnhout, 1998, p. 153-168.

HÜNEMÖRDER Christian, « Die Bedeutung und Arbeitsweise des Thomas von Cantimpré und sein Beitrag zur Naturkunde des Mittelalters », in Medizinhistorisches Journal, 3, 1968, p. 345-357.

HÜNEMÖRDER Christian, « Die Vermittlung medizinisch-naturkundlichen Wissens in Enzyklopädien », in Wissensorganisierende und wissensvermittelnde Literatur im Mittelalter. Perspektiven ihrer Erforschun, wolf Norbert R. (ed.), Wiesbaden, 1987, p. 255-277.

HÜNEMÖRDER Christian, « Probleme der Intention und Quellenerschliessung der sogenannten 3. Fassung des 'Liber de natura rerum' des Thomas von Cantimpré », in Arbor amoena comis. 25 Jahre Mittellateinisches Seminar in Bonn, 1965-1990, KÖNSGEN Ewald (ed.), Stuttgart, 1990, p. 241-249.

JACQUART Danielle, MICHEAU Françoise, La médecine arabe et l'Occident médiéval, Paris, 1996. JoLIVET Jean, Les quaestiones naturales d'Adélard de Bath ou la nature sans le Livre, Poitiers, 1974. KAUfMANN Alexander, Thomas von Chantimpré, Köln, 1899.

LAWN Brian, The Salernitan Questions : an Introduction to the History of Medieval and Renaissance Problem Literature, Oxford, 1963.

LAWN Brian, I quesiti salernitani : introduzione alla storia della letteratura problematica medica e scientifica nel Medio Evo e nel Rinascimento, Cava dei Tirreni, 1969.

LAWN Brian, Introduction, in The Prose Salernitan Questions : Edited from a Bodleian Manuscript (Auct. F.3.10), an Anonymous Collection Dealing with Science and Medicine Written by an Englishman c. 1200, with an Appendix of Ten Related Collections, London, 1979.

LAWN Brian, The Rise and Decline of the Scholastic 'Questio disputata', with Special Emphasis on its Use in the Teaching of Medicine and Science, Leiden-New York, 1993.

MAIERÙ Alfonso, University Training in Medieval Europe, New York, 1993.

MEIER Christel, « Ecce auctor. Beiträge zur Ikonographie literarischer Urheberschaft im Mittelalter », in Frühmittelalterliche Studien, 34, 2000, p. 338-392.

MEYER Heinz, «Intentio auctoris, utilitas libri. Wirkungsabsicht und Nutzen literarischer Werke nach Accessus-Prologen des 11. bis 13. Jahrhunderts », in Frühmittelalterliche Studien, 31, 1997, p. 390-413.

MEYER Heinz, Die Enzyklopädie des Bartholomäus Anglicus. Untersuchungen zur Überlieferungs- und Rezeptionsgeschichte von 'De proprietatibus rerum', München, 2000 (Münstersche MittelalterSchriften, 77).

Pre-Modern Encyclopaedic Texts (Proceedings of the second COMERS Congress, Groningen, 1-4 July 1996), BINKLEY Peter (ed.), Leiden-New York, 1997 (Brill's Studies in intellectual history, 79).

RIBÉMONT Bernard, «L'animal comme exemple dans les encyclopédies médiévales : morale et 'naturalisme' dans le 'Livre des propriétés des choses' ", in L'animal exemplaire au Moyen Âge, $V^{e}-X V$ ${ }^{e}$ siècles, BERLIOZ Jacques, POLO DE BEAULIEU Marie-Anne (ed.), Rennes, 1999, p. 191-205. 
RONCA Italo, Introduction, in GUILLELMUS DE CONCHIS, Dragmaticon philosophiae, ed. RONCA Italo, Turnhout, 1997.

ROSE Valentin, Praefatio, in Sorani Gyneciorum Vetus translatio Latina, RoSE Valentin (éd.), Leipzig, 1882 (Teubner).

SARTON George, Introduction to the History of Science, Baltimore, 3 vol., 1927-1948.

SCHMITZ Max, Le Viridarium du juriste avignonnais Jean Raynaud : une encyclopédie latine du Moyen Age tardif, Thèse, Université catholique de Louvain, Louvain-la-Neuve, 2012, p. 94-180.

SILVERSTEIN Theodore, " Adelard, Aristotle, and the 'De natura deorum' », in Classical Philology, 47, 1952, p. 82-86.

SPEER Andreas, Die entdeckte Natur : Untersuchungen zu Begründungsversuchen einer 'scientia naturalis' im 12. Jahrhundert, Leiden-New York, 1995 (Studien und Texte zur Geistesgeschichte des Mittelalters, 45).

SUDHOFF Karl, « Der Micrologus : Text der Anatomia Richards des Engländers », in Archiv fur Geschichte der Medizin, 19, 3, 1927.

THORNDIKE Lynn, « More Manuscripts of the Dragmaticon and Philosophia of William of Conches », in Speculum, 20, 1945, p. 84-87.

VAN DEN ABEELE Baudouin, «L'allégorie animale dans les encyclopédies latines du Moyen Âge », in L'animal exemplaire..., p. 123-143.

VAN DEN ABEELE Baudouin, «A la recherche de l'Experimentator de Thomas de Cantimpré » in 'Expertus sum'. L'expérience par les sens dans la philosophie naturelle médiévale, T. BÉNATOUÏL, I. DRAELANTS (éd.), Firenze, 2011, p. 41-65.

VAN DEN ABEELE Baudouin, «Diffusion et avatars d'une encyclopédie : le Liber de natura rerum de Thomas de Cantimpré », in DE CALLATAŸ Godefroid - B. VAN DEN ABEELE Baudouin (éd.), Une lumière venue d'ailleurs, Turnhout, 2008, p. 141-176.

VAN DER LUUGT Maaike, Le ver, le démon et la Vierge : les théories médiévales de la génération extraordinaire. Une étude sur les rapports entre théologie, philosophie naturelle et médecine, Paris, 2004 (L'âne d'or).

VENTURA Iolanda, «Per modum quaestionis compilatum... The Collections of Natural Questions and their Development from the Thirteenth to the Sixteenth Century ", in All you need to know: Encyclopaedias and the Idea of General Knowledge (Conference de Prangins, Switzerland, 18-20 Septembre 2003), P. MICHEL-M. HERREN-M. RÜESCH (ed.), e-book disponibile al sito www.enzyklopaedie.ch. VENTURA Iolanda, «Quaestiones and Encyclopedias : Some Aspects of the Late Medieval Reception of Pseudo-Aristotelian Problemata in Encyclopedic and Scientific Culture ", in Schooling and Society : the Ordering and Reordering of Knowledge in the Western Middle Ages, A. A. MACDONALD-M. W. TWOMEY (ed.), Leuven, 2004, p. 23-42.

VENTURA Iolanda, Introduzione, in BARTHOLOMAEUS ANGLICUS, De proprietatibus rerum. Volume VI : Liber XVII, I. VENTURA (ed.), Turnhout, 2007.

VENTURA Iolanda, « On the representation of the animal world in the collections of natural questions between Late Middle Ages and Early Modern Times ", in Reinardus, 21, 2009, p. 182-201. VENTURA Iolanda, « Bartolomeo Anglico e la cultura filosofica e scientifica dei frati nel XIII secolo : Aristotelismo e medicina nel De proprietatibus rerum ", in I francescani e le scienze (Atti del XXXIX 
Convegno internazionale : Assisi, 6-8 ottobre 2011), Spoleto, 2012 (Atti dei convegni della Società internazionale di studi francescani e del Centro interuniversitario di studi francescani), p. 49-140.

VOLLMANN Benedikt K., « La vitalità delle enciclopedie di scienza naturale », in L'enciclopedismo, PICONE (ed.), p. 135-146.

WALSTRA G. J. J., " Thomas de Cantimpré, De naturis rerum. État de la question », in Vivarium, 5, 1967, p. 146-171.

WALSTRA G. J. J., « Thomas de Cantimpré, De naturis rerum. État de la question (suite et fin) », in Vivarium, 6, 1968, p. 46-61.

WEIJERS Olga, «L'enseignement du 'trivium' à la Faculté des arts de Paris: la 'questio' », in Manuels, programmes de cours et techniques d'enseignement dans les universités médiévales (Actes du Colloque international de Louvain-la-Neuve, 9-11 septembre 1993), J. HAMESSE (ed.), Louvain-la-Neuve, 1994, p. 57-74.

WEIJERS Olga, La Disputatio à la Faculté des arts de Paris (1200-1350 environ) : esquisse d'une typologie, Turnhout, 1995.

WEINDLER Fritz, Geschichte der gynäkologisch-anatomischen Abbildung, Dresden, 1908.

\section{NOTE}

1. * Il presente articolo è stato terminato durante il nostro soggiorno post-doc all' Institut de recherche et d'histoire des textes (IRHT) di Parigi sovvenzionato da una borsa LabEx Hastec / EPHE. Per una panoramica sulla questione, cf., fra gli altri, DE GANDILLAC M., La pensée encyclopédique au Moyen Age, Neuchâtel, 1966; L'enciclopedismo medievale, PICONE M. (dir.), Ravenna, 1994; L'encyclopédisme (Actes du Colloque de Caen, 12-16 janvier 1987), BECQ. A. (ed.), Paris, 1991 ; Enzyklopädien der frühen Neuzeit : Beiträge zu ihrer Erforschung, EYBL F. M. (ed.), Tübingen, 1995 ; PreModern Encyclopaedic Texts (Proceedings of the second COMERS Congress, Groningen, 1-4 July 1996), BINKLEY P. (ed.), Leiden-New York, 1997 (Brill's Studies in Intellectual History, 79) ; Die Enzyklopädie im Wandel vom Hochmittelalter bis zur frühen Neuzeit (Akten des Kolloquiums des Projekts D im Sonderforschungsbereich 231 : 29.11.-1.12.1996), MEIER et alii, München, 2002 (Münstersche Mittelalter-Schriften, 78) ; MEYER H., «Intentio auctoris, utilitas libri. Wirkungsabsicht und Nutzen literarischer Werke nach Accessus-Prologen des 11. bis 13. Jahrhunderts », in Frühmittelalterliche Studien, 31, 1997, p. 390-413; MEIER C., «Ecce auctor. Beiträge zur Ikonographie literarischer Urheberschaft im Mittelalter », in Frühmittelalterliche Studien, 34, 2000, p. 338-392.

2. Indicazioni e citazioni di questo articolo rimandano all'edizione del Liber di Tommaso di Cantimpré (d'ora in poi, in nota, $L d N R$ e TdC) realizzata per la nostra tesi di dottorato (CIPRIANI M., La place de Thomas de Cantimpré dans l'encyclopédisme médiéval : les sources du Liber de natura rerum, Tesi, Paris-Firenze, 2014, 2 voll.). Per una spiegazione approfondita su questa edizione e i brani dei LdNR nominati nei vari paragrafi, cf. infra, § Appendice. Sulla base delle indicazioni fornite è comunque possibile individuare $\mathrm{i}$ dati discussi anche nella ben più diffusa edizione THOMAS CANTIMPRATENSIS, Liber de naturis rerum, BOESE H. (ed.), Berlin-New York, 1973.

3. Sulle altre versioni del Liber e le loro varianti, strutture, fonti e contenuti, cf. volLMANN B. K., «La vitalità delle enciclopedie di scienza naturale », in L'enciclopedismo, PICONE, M. (ed.), Ravenna, 1994, p. 135-146 ; FRUNZEANU E., Les configurations de la natura dans le 'Speculum maius'de Vincent de Beauvais, Tesi, Montréal, 2007 : 39-40 ; i rimandi in VAN DEN ABEELE B., « Diffusion et avatars d'une encyclopédie : le Liber de natura rerum de Thomas de Cantimpré », in DE CALLATAŸ G.- VAN DEN ABEELE B. (ed.), Une lumière venue d'ailleurs, Turnhout, 2008, p. 141-176 ; scHMITZ M., Le Viridarium 
du juriste avignonnais Jean Raynaud : une encyclopédie latine du Moyen Age tardif, Tesi, Louvain-laNeuve, 2012 : 94-180 ; e CIPRIANI, La place..., I : xiii-xx, e II : 19-34.

4. Queste datazioni - che modificano leggermente il canone classico - sono basate su un incrocio fra $L d N R$, dati in esso contenuti e fonti di Tommaso. Nello specifico, la datazione di Thomas I deriva da : 1) un riferimento parallelo con la Chronica di Matteo Paris, ovvero la scoperta di nuove miniere di stagno in Germania : la vicenda è datata 1241 nell'opera del benedettino ed è collocata dallo stesso Tommaso in modernis temporibus (sulla questione, cf. LdNR, XV, 6, e MATTHAEUS PARIS, Chronica majora, anno 1241, LUARD R. (ed.): 151) ; 2) l'impiego diffuso, da parte di Tommaso, dell' Anatomia di Riccardo Anglico (datata 1242-1252 : su quest'opera cf. Anatomia Ricardi Anglici, TöPlY EQUES R. (ed.), Wien, 1902 : v-vi ; CORNER G. W., Anatomical Texts of the earlier Middle Ages : a Study in the Transmission of Culture, Washington, $1927: 17$ e 35-36 ; SARTON G. , Introduction to the History of Science, Baltimore, 1927-1948, II : 657 ; SUdHOFF K., « Der Micrologus : Text der Anatomia Richards des Engländers ", in Archiv fur Geschichte der Medizin, 19, 3, 1927, p. 209-212). La datazione di Thomas II è invece data da un incrocio con il Bonum universale de apibus (1256) dello stesso Tommaso (colvenerius G. (ed.), Douai, 1627 : cf. ad es. 100, 149, 245, 312, 333, 349, 540, 549), che riporta passi di Thomas II (per le datazioni di quest'opera, cf. cORDEZ P. , « Materielle Metonymie. Thomas von Cantimpré und das erste Horn des Einhorns », Bildwelten des Wissens, Kunsthistorisches Jahrbuch für Bildkritik, 9, 2012, p. 85-92). Per approfondimenti, cf. CIPRIANI, La place, II, in part. 25-28, ma anche ID., « Un esempio dell'enciclopedismo di Tommaso di Cantimpré : la sezione 'De lapidibus pretiosis' del 'Liber de natura rerum' ( (Médiévales, 72, printemps 2017, p. 155-174).

5. Sulla propensione 'pratica' di Thomas II, cf. infra. Per un'analisi approfondita dello 'stile enciclopedico' del frate di Cantimpré, cf. anche CIPRIANI, La place, II : 35-54 ; e ID., « Un esempio ».

6. Per Thomas II è infatti stato notato un primo passaggio, seguito poi, in un secondo momento, da altri ampliamenti. Le tappe delle diverse evoluzioni sono ad esempio evidenti in due mss. contemporaneti a Tommaso (l'Harley 3717 della British Libr. di Londra e il ms. 410 della Stadsbibliotheek di Brugge) ; questi testimoni hanno marginalia che espandono il contenuto di Th I con singoli particolari o intere voci, ma sono privi del libro XX e di altri passaggi nuovi. Il secondo ampliamento a Thomas II aggiunge così le parti mancanti. Per tutta la questione, cf. BOESE H., « Zur Textüberlieferung von Thomas Cantimpratensis' 'Liber de natura rerum' », in Archivum fratrum praedicatorum, 39, 1969, p.53-68; VAN DEN ABEELE, «Diffusion et avatars ». Per una descrizione precisa delle sottili differenze fra le diverse sotto-versioni di Thomas I e Thomas II, cf. CIPRIANI, La place, I : xiii, anche n. 18 , e p. xiv.

7. Ovvero : LdNR, I, 29, De sanguine ; 30, De febre effimera ; 31, De cotidiana febre, 32, De tertiana febre, 33, De quartana febre, 34, De continua febre ; IV, 108, De uranoscopo ; V, 67, De isopigi ; 69, De kiliodromo ; 107, De passere harundineo ; VI, 1, Primo generaliter ; 7, De cervo marino ; 37, De ono ; 51, De tunno ; VII, 26, De capitonibus maris ; 28, De capa ; 37, De ezochio marino ; 39, De fundula ; 89, De uranoscopo ; VIII, 8, De cameleone ; 22, De ydro serpente fluviali ; IX, 11, De cervo volante ; XII, 22, De primula veris... ; XIII, 3, Gyon ; 31, De fonte gelidissimo Norvegie ; XIV, 57, De pyrophilo ; XVIII, 5, Expositio... ; 6, Alia opinio... ; 7, Ratio unde venti... .

8. Sulla questione, cf. CIPRIANI, La place, I : xlvii-civ, e II : 22-25.

9. Oltre che da quanto detto, l'autorialità di questa versione è autenticata anche dallo stesso $\mathrm{TdC}$ nell'introduzione al nuovo libro XX; in questa occasione egli afferma infatti : " Post finem laboris nostri, vicesimam quoque editionem apponimus, sed hanc non tanquam ex nostra compilatione, sed tanquam necessariam ipsi operi precedenti ». Per la genesi del LdNR e delle sue versioni autoriali, si rimanda ancora a BOESE, « Zur Textüberlieferung ».

10. LdNR, Prologus. Sulla questione, cf. RIBÉmont B., "L'animal comme exemple dans les encyclopédies médiévales : morale et 'naturalisme' dans le 'Livre des propriétés des choses' », in L'animal exemplaire au Moyen Âge, $V^{e}-X V^{e}$ siècles, BERLIOZ J., POLO DE BEAULIEU M.-A. (DIR.), Rennes, 1999, p. 191-205 ; FRENCH R., CUNNINGHAM A., Before Science. The Invention of the Friars' Natural 
Philosophy, Cambridge, 1996 : 217 sq. ; l'allegoria tommasiana è ben approfondita in VAN DEN ABEELE , «L'allégorie animale dans les encyclopédies latines du Moyen Âge », in L'animal exemplaire: 123-143.

11. Per una panoramica sulle scelte tommasiane e sull'uso di tali auctoritates nel LdNR, cf. CIPRIANI, La place, II : 36, 68-74, 179-183, 94, 99, 127-128 e 210-212. Un'approfondita spiegazione sulla selezione delle fonti enciclopediche è presente anche in VENTURA I., «Bartolomeo Anglico e la cultura filosofica e scientifica dei frati nel XIII secolo : aristotelismo e medicina nel De proprietatibus rerum ", in I francescani e le scienze (Atti del XXXIX Convegno internazionale : Assisi, 6-8 ottobre 2011), Spoleto, 2012, p. 49-140.

12. Su questa auctoritas, cf. CIPRIANI, La place, II : 168-169. Tutto ciò non significa tuttavia che il domenicano di Cantimpré non abbia ripreso autori arabi : come già accennato, non è infatti da escludere che qualcuno dei philosophi / phisici anonimi di Tommaso sia arabo (sulla questione, cf. anche ibid.: 170-177); non si deve inoltre scartare completamente l'idea che il frate abbia lavorato in biblioteche che contentevano solo pochissime opere arabe, e che quindi la sua scelta non sia stata tanto ideologica e soggettiva, ma piuttosto legata alla non-disponibilità oggettiva di tali testi. Per una carellata sulle fonti non-usate dal domenicano di Cantimpré, cf. ibid. : 35-37.

13. Lo stesso TdC, nel Prologus del LdNR, enumera le sue fonti principali, ovvero : Agostino, Aristotele, Plinio, Solino, Ambrogio, Basilio, Isidoro di Siviglia, Giacomo di Vitry, il piccolo e misterioso Liber rerum, il contemporaneo Experimentator, Galeno (in realtà Riccardo Anglico), Plateario, il Fisiologo, Adelmo di Malmesbury; il domenicano aggiunge anche che userà «ceteri vero [...] non tam auctores in rerum naturis sunt quam pro scriptorum suorum oportunitatibus assertores » e, per concludere, le rispettate vulgi opiniones. Fra le altre cose, chi scrive sta preparando un dettagliato articolo sul Liber rerum e l'Experimentor tommasiani.

14. Su queste fonti, cf. CIPRIANI, La place, II : 107-114 e 210-212.

15. La discussione su Experimentator è, ad oggi, ancora aperta : anche se questo non è il contesto per approfondirla, un breve sunto delle sue diverse problematiche principali è comunque necessario, anche per quanto mostrato nell' § Appendice. Nel 1998, J. Deus - approfondendo le idee di C. W. Hünemörder, suo direttore di ricerca -, editò per la sua tesi di dottorato una raccolta de proprietatibus rerum che riteneva molto simile all'Experimentator di $\mathrm{TdC}$; oltre alle numerose somiglianze di tale trattato con la fonte tommasiana, la ricercatrice riconobbe $: 1$ ) tre versioni (due lunghe e una abbreviata) di tale opera, 2) diverse similitudini (prembolo, struttura,...) fra la sua raccolta naturalistica e il De proprietatibus rerum di Bartolomeo Anglico. Sulla base di queste osservazioni, la tedesca ipotizzò quindi l'uso di questa fonte anche da parte dell'inglese e una possibile datazione della versione originale fra il 1220 e il 1225 / 1226. Qualche anno dopo le idee della studiosa di Amburgo vennero tuttavia negate da H. Meyer - che riteneva il trattato di J. Deus un rimaneggiamento in tredici libri del De proprietatibus rerum -, e, separatamente, da B. Van den Abeele - che condivideva le ipotesi di Meyer e ipotizzava, come già J. B Friedman, una possibile orgine orientale della fonte tommasiana -. Tutta la questione è stata ripresa più recentemente da I. Draelants ed E. Frunzeanu : analizzando le fonti di Bartolomeo, i due studiosi hanno approfondito quanto detto da J. Deus, dimostrando come una versione del Experimentator venga usato dal francescano inglese per la sua opera. Tutto il problema - ed in particolare il rapporto fra l'opera di J. Deus e $L d N R$ - è infine stato affrontato anche nella nostra tesi di dottorato, dove abbiamo dimostrato lo strettissimo rapporto intercorrente fra una versione espansa (ma non ancora riconosciuta) del testo di J. Deus e l'opera tommasiana (ci riserviamo comunque di approfondire queste nostre ricerche anche con l'analisi dei nuovi mss. non considerati dalla studiosa tedesca). Per un'analisi di tutta la questione, cf. in part. HÜNEMÖRDER C., «Die Bedeutung und Arbeitsweise des Thomas von Cantimpré und sein Beitrag zur Naturkunde des Mittelalters", in Medizinhistorisches Journal, 3, 1968, p. 345-357; ID., «Die Vermittlung medizinisch-naturkundlichen Wissens in Enzyklopädien», in Wissensorganisierende und 
wissensvermittelnde Literatur im Mittelalter. Perspektiven ihrer Erforschung, wolf N. R. (dir.), Wiesbaden, 1987, p. 255-277 ; FRIEDMAN J. B., « Albert the Great's topoi of Direct Observation and his Debt to Thomas of Cantimpré ", in Pre-Modern Encyclopaedic Texts, BINKLEY P. (dir.), Leiden, 1997, p.379-392; Der 'Experimentator'. Eine anonyme lateinische Naturenzyklopädie des frühen 13. Jahrunderts, Deus J. (ed.), Dissertation zur Erlangung der Würde des Doktors der Philosophie des Fachbereichs Geschichtswissenshaft der Universität Hamburg, 1998 ; MEYER H., Die Enzyklopädie des Bartholomäus Anglicus. Untersuchungen zur Überlieferungs- und Rezeptionsgeschichte von 'De proprietatibus rerum', München, 2000 (Münstersche Mittelalter-Schriften, 77), p.149-163, e vAN DEN ABEELE B., "A la recherche de l'Experimentator de Thomas de Cantimpré » in 'Expertus sum'. L'expérience par les sens dans la philosophie naturelle médiévale, BÉNATOUÏL T., I. DRAELANTS (dir.), Firenze, 2011, p. 41-65 ; CLESSE G., « Thomas de Cantimpré et l'Orient : les sources arabes dans les chapitres zoologiques du Liber de natura rerum ", in Reinardus, 25, 1, 2013, p. 53-77 (in part. 67-70 ; si ringrazia il Dottor Clesse per aver fornito copia dell'articolo) ; CIPRIANI, La place, II : 107-114 ; e da DRAELANTS I., FRUNZEANU E., "Le savoir astronomique et ses sources dans le De mundo et corporibus celestibus de Barthélemy l'Anglais ", in Rursus-Spicae, 2017 (cf. ivi, n. 28, per un rimando ai nuovi mss. menzionati supra; si ringrazia la Prof. I. Draelants per aver fornito preventivamente copia dell'articolo).

16. Sulla questione, cf CIPRIANI, La place, II : 164-166, e ID., « Un esempio ».

17. Cf. CIPRIANI, La place : 40-45.

18. Su tali auctoritates, cf. CIPRIANI, La place : 55-56, 99-100 e 114-115.

19. In tal senso è inoltre utile far notare che non vengono espansi i libri botanici $X$, De arboribus communibus, XI, De arboribus aromatici, e XII, De herbis aromaticis : già in Thomas I hanno infatti una forte componenete pratico-concreta.

20. Ad oggi abbiamo riconosciuto 18 opere aggiunte solo in Thomas II, ma questo numero è destinato ad aumentare : non è stato infatti ancora possibile riconoscere, ad esempio, tutte le nuove fonti mediche di Tdc. Sulle queste nuove auctoritates, cf. CIPRIANI, La place, II : 22-25, 116-118, 166-168 e 189-191, ma anche VAN DEN ABEELE, « Diffusion et avatars », in part. 143-144.

21. Oltre alle nuove auctoritates, il compilatore di Cantimpré usa comunque anche testi già impiegati, ovvero il De animalibus di Aristotele, la Naturalis historia di Plinio, il Circa instans dello Pseudo-Matteo Plateario, l'Historia orientalis di Giacomo di Vitry, il Commentariorum in Ioelem Prophetam di Girolamo, il Summarium Heinrici, le Questiones naturales di Adelardo di Bath e la Philosophia di Guglielmo di Conches ; ad eccezione di quest'ultima opera - come vedremo infra - i nuovi excerpta sono abbastanza brevi.

22. Per Isidoro, ciò avviene in 59 casi ; sulla questione, cf. CIPRIANI, La place, II : 147, in part. n. 1. Sull'Epistola Alexandri, cf. ibid. : 100-101; altri esempi sono mostrati in ID., « Un esempio ».

23. Per un'analisi approfondita di questi caratteri, cf. CIPRIANI, La place, II : 50-51, 88-89 e 151-158 ; sul simbolismo tommasiano, cf. anche RIBÉMONT, « L'animal», in part. 194.

24. Sull'uso di Giacomo nel Liber, cf. CIPRIANI, La place, II : 132-135. Su quello di Marbodo, cf. ibid. : 160-163, e, soprattutto, ID., « Un esempio »; per chiarimenti sulle diverse versioni di quest'opera, cf. HERRERA M. E., « La historia del texto del Liber lapidum de Marbodo de Rennes a través de los manuscritos provenientes de las bibliotecas francesas del siglo XII ", in Du copiste au collectionneur, NEBBIA-DALlA GUARDA D., GENEST J.-F. (dir.)., Turnhout, 1998: 153-168 (per quanto interessa Tommaso, in part. 158, n. 30, e 160, n. 41) ; e MARBODUS REDONENSIS, Liber lapidum, HERRERA M. E. ( ed.), Paris, 2005 : xxiii-xxiv.

25. Ad oggi sono state riconosciute 121 fonti utilizzate da Tommaso nelle sue redazioni del $L d N R$ : come accennato supra n. 20, tale numero è destinato ad aumentare; per una panoramica generale sulle auctoritates usate dal domenicano di Cantimpré, cf. CIPRIANI, La place, I : cv-cxxiv, e II : 220-228 ; per una spiegazione dei generi impiegati dal frate, cf. ibid., II : 35-40. 
26. Cf. DRAELANTS I., «La question ou le débat scolastique comme forme du discours scientifique dans les encyclopédies naturelles du XIII ${ }^{\mathrm{e}}$ siècle : Thomas de Cantimpré et Vincent de Beauvais ", in Scientiarum historia, 31, 2, 2005, p. 125-153.

27. Sulle questiones naturales, cf. LAWN B., The Salernitan Questions : an Introduction to the History of Medieval and Renaissance Problem Literature, Oxford, 1963 ; ID., I quesiti salernitani : introduzione alla storia della letteratura problematica medica e scientifica nel Medio Evo e nel Rinascimento, Cava dei Tirreni, 1969 ; BALDWIN J. H., The Language of Sex : Five Voices from Northern France around 1200, Chicago, 1994. Per un'analisi della questio disputata, cf. BAZÀn B. C., WIPPEL J. W., FRANSEN G., JACQUART D., Questions disputées et les questions quodlibétiques dans les facultés de théologie, de droit et de médecine, Turnhout, 1985 (Typologie des sources du Moyen Age occidental, 44-45) ; LAWN B., The Rise and Decline of the Scholastic 'Questio disputata', with Special Emphasis on its Use in the Teaching of Medicine and Science, Leiden-New York, 1993 ; WEIJERS O., " L'enseignement du 'trivium' à la Faculté des arts de Paris: la 'questio' ", in Manuels, programmes de cours et techniques d' enseignement dans les universités médiévales (Actes du Colloque international de Louvain-la-Neuve, 9-11 septembre 1993), HAMESSE J. (dir.), Louvain-la-Neuve, 1994, p.57-74 ; ID., La Disputatio à la Faculté des arts de Paris (1200-1350 environ) : esquisse d'une typologie, Turnhout, 1995. Per ulteriori, attente considerazioni su questi generi, cf. SPEER A., Die entdeckte Natur : Untersuchungen zu Begründungsversuchen einer 'scientia naturalis' im 12. Jahrhundert, Leiden-New York, 1995 ; VENTURA I., «Per modum quaestionis compilatum... The Collections of Natural Questions and their Development from the Thirteenth to the Sixteenth Century ", in All you need to know: Encyclopaedias and the Idea of General Knowledge (Conference de Prangins, Switzerland, 18-20 Sept. 2003), MICHEL P., HERREN M., RÜESCH M. (ed.), e-book, www.enzyklopaedie.ch; VAN DER LUUGT M., Le ver, le démon et la Vierge : les théories médiévales de la génération extraordinaire. Une étude sur les rapports entre théologie, philosophie naturelle et médecine, Paris, 2004 ; VENTURA I., "Quaestiones and Encyclopedias : Some Aspects of the Late Medieval Reception of Pseudo-Aristotelian Problemata in Encyclopedic and Scientific Culture", in Schooling and Society : the Ordering and Reordering of Knowledge in the Western Middle Ages, MACDONALD A. A., twomey M. W. (ed.), Leuven, 2004, p. 23-42 ; CARDELLE DE HARTMANn C., Lateinische Dialoge 1200-1400 : literaturhistorische Studien und Repertorium, Leiden-Boston, 2007 ; VENTURA I., " On the representation of the animal world in the collections of natural questions between Late Middle Ages and Early Modern Times ", in Reinardus, 21, 2009, p. 182-201 (si ringrazia la Prof. I. Ventura per aver segnalato e fornito alcuni dei suoi articoli). Sull'uso di queste fonti nelle enciclopedie medievali, cf. LAWN B., The Salernitan Questions : 44 ; e ID., I quesiti salernitani : 63-64.

28. Sugli inteventi tommasiani nel Liber, cf. CIPRIANI, La place, II : 50-51.

29. Tali formule sono quelle ben segnalate da DRAELANTS, «La question » : $128:$ ad esse sono state aggiunte anche le simili probavi, improbavimus. Nonostante la generale fedeltà all'elenco proposto dalla Prof. Draelants, non abbiamo incluso le espressioni ita capitur e capitur hoc modo segnalate ibid. : 128 e 147, n. 19 : si può infatti notare che tali locuzioni non introducono incitazioni tommasiane alla comprensione, ma, piuttosto, indicazioni venatorie; tali suggerimenti - sempre anonimi e di cui non è stato ancora possibile trovare la fonte - erano evidentemente ben diffusi nel milieu culturale trecentesco : cf. ad esempio i dati in De elephante, che ricordano il capitolo De elephante et virginibus delle Gesta Romanorum (Gesta Romanorum, OESTERLEY H. (ed.), Hildesheim, 1963), e quelli in De urso, che sono invece simili all'omonima voce del DPR di Bartolomeo Anglico ( BARTHOLOMAeus ANGlicus, De rerum proprietatibus, Frankfurt, 1964, facsmile ed. 1601); per indicazioni più precise su tutta la questione, cf. le note in CIPRIANI, La place, I : 94, 103, 111, 145, $152,153-154,248,260,275,390$.

30. In LdNR, XX, 1 ; XX, 5, De motu aeris ; XX, 6, De axe linea ; XX, 7, De Saturno ; XX, 12 ; XX, 13; XX, 14 ; XX, 15 ; XX, 16, De eclipsi solis; XX, 17, Qualiter luna a sole accenditur. Sull'uso della Philosophia nel LdNR, cf. soprattutto VAN DEN ABEELE, «Diffusion et avatars »: 143; e CIPRIANI, La place, II : 124-127. Di parere diverso è invece DRAELANTS, «La question»: 129-134, che sostiene invece che 
Tommaso abbia fuso altre opere del maestro normanno, ovvero una riscrittura dialettica del Dragmaticon e le Glosae super Boethium. Per precisazioni sulla questione, cf. anche VENTURA I., Introduzione, in BARTHOLOMAEUS ANGLICUS, De proprietatibus rerum. Volume VI : Liber XVII, VENTURA I. (ed.), Turnhout, 2007 : xxx e seguenti ; e infra.

31. In $L d N R, I V, 105$, De urso. Per un'attenta analisi di queste particolari opere naturalistiche, cf. LAWN, The Salernitan Questions, in part.16-80; ID., I quesiti salernitani, in part. 34-105; ID., Introduction, in The Prose Salernitan Questions. Edited from a Bodleian Manuscript (Auct. F.3.10), an Anonymous Collection Dealing with Science and Medicine Written by an Englishman c. 1200, with an Appendix of Ten Related Collections, London, 1979.

32. Per queste espressioni, cf. ancora una volta DRAELANTS, « La question » : 135-138.

33. Per una panoramica su tutte le sezioni che $\mathrm{TdC}$ copia dalle Questiones naturales, cf. infra $\mathrm{n} .50$, ma anche § Appendice. Oltre a LAwN, The Salernitan Questions : 16-39; e ID., I quesiti salernitani : 34-59; sulle Questiones naturales del maestro inglese, cf. soprattutto JOLIVET J., Les quaestiones naturales d'Adélard de Bath ou la nature sans le Livre, Poitiers, 1974 ; e BURNETT C. , Introduction, in Adelard of Bath, Conversations with his Nephew, BURnETT C. (ed.), Cambridge, 2006 : xi-lii.

34. In LdNR, I, 72, De impregnatione mulieris; I, 74, De virtute nascitiva; I, XVIII, 2, De tonitruo choruscatione fulmine. Cf. infra n. 42, ma anche § Appendice. L'uso tommasiano di Gugliellmo era già stato segnalato da HÜNEMÖRDER C. , «Probleme der Intention und Quellenerschliessung der sogenannten 3. Fassung des 'Liber de natura rerum' des Thomas von Cantimpré », in Arbor amoena comis. 25 Jahre Mittellateinisches Seminar in Bonn, 1965-1990, KÖNSGEN E. (dir.), Stuttgart, 1990, p. 241-249, in part. 242 ; la questione è inoltre accennata anche in DRAELANTS, FRUNZEANU, «Le savoir astronomique ».

35. Per un approfondimento su queste discussioni, cf. infra, § Le questiones non riconosciute, ma anche § Appendice.

36. Ciò avviene infatti solo in LdNR III, 1 , Incipit prologus de hominibus monstruosis orientis ; $\mathrm{X}, 43$, De sethim unde et ligna sethim; XVII, 4, De ventis generaliter primo dicendum est.

37. $L d N R$, I, 75, e I, 76. Sull'uso di questa fonte nel LdNR, cf. HANSON A. E., GREEN M. H., Soranus of Ephesus : methodicorum princeps, in Aufstieg und Niedergang der Römischen Welt, Berlin-New York, 1994, II $(37,2)$, p. 968-1075 : 1058, e n. 340 ; ma soprattutto CIPRIANI, La place, II : 200-201. Sulla questione, cf. infra anche § Appendice.

38. Su quest'opera, la sua abbreviazione e il loro rapporto con i trattati attribuiti alla PseudoCleopatra, cf. V. RoSE., Praefatio, in Sorani Gyneciorum vetus translatio Latina, ROSE V. (ed.), Leipzig, 1882 ; WEINDLER F., Geschichte der gynäkologisch-anatomischen abbildung, Dresden, 1908 ; BECCARIA A., I codici di medicina del periodo presalernitano (secoli IX, X e XI), Roma, 1956: 62, 115, 120 e 240 ; GREEN M. H., "'Traittié tout de mençonges' : The Secrés des dames, 'Trotula', and Attitudes towards Women's Medicine in Fourteenth- and Early Fifteenth-Century France », in Christine de Pizan and the Categories of Difference, M. DESMOND (dir.), Minneapolis, 1998, p. 146-178 : 170, n.15 ; HANSON, GREEN, Soranus; e il riassuntivo M.H. GREEN, Genecia Cleopatre (visto URL: https:// www.academia.edu/11313234/Monica_H._Green). Sul ruolo della Gynecia originaria fra i testi dialogici, cf. invece LAWN, The Salernitan Questions: 3-12; e ID., I quesiti salernitani : 21-30. Sulle sezioni monografiche del LdNR, cf. supra.

39. LdNR, IV, 46, De gli ; IV, 54, De leone ; IV, 85, De ove ; V, 110, De strutione ; X, 1, Primo generaliter. 40. Le sezioni usate nella prima redazione del Liber sono : I, 13.42 ; III, 6.13, 6.14, 6.15, 6.16, 6.17, 7.18; IV, 10.17, 11.18, 11.20, 12.20, 13.21, 14.22, 14.23, 15.24, 21.37 (tali riferimenti rimandano all'edizione GULIELMUS DE CONCHIS, Philosophia, ALBERTAZzi M. (ed.), Lavis, 2010). Sulla questione, cf. infra, anche §Appendice A.

41. Oltre ai luoghi evidenziati supra, n. 34, excerpta della Philosophia sono ripresi anche in LdNR, I, 2, De capite; I, 73, De infusione anime rationalis et unde anima; I, 78, Sequitur de septem etatibus 
hominis, et primo de prima etate, que est infantia ; IV, 80, De onagro; XVIII, 3, De quod stelle aliquando cadere videntur. Sulla questione, cf. infra, anche § Appendice A.

42. Una volta in LdNR, I, 72, De impregnatione mulieris, e due I, 73, De infusione anime rationalis et unde anima. Per un'idea sulla questione, cf. infra, Appendice.

43. Ciò avviene in LdNR, I, 72, De impregnatione mulieris (con le locuzioni : Proinde dicunt..., disseramus) ; I, 73, De infusione anime rationalis et unde anima (Merito autem queritur... quomodo...) ; I, 74, De vuirtute nascitiva (Habet enim questionem quare... quare... respondent phisici...) ; I, XVIII, 2, De tonitruo choruscatione fulmine (Hinc digne queritur... quare... Cui questioni responderi potest) ; I, 3, De quod stelle aliquando cadere videntur (Quid est quod stellam illam postea non videmus?).

44. In LdNR, XVIII, 7, Ratio unde venti ortum habent; XIX, 5, De aere quod est tertium elementum ; XIX, 6, De igne quod est quartum elementum. Tali sezioni sono derivarte dalla Philosophia, I, 5.14, 5.15 ; III, $9.20,10.24,10.25,10.26$.

45. $L d N R \mathrm{XX}, 1$. Ciò sembra comunque indicare anche la considerazione in cui $\mathrm{TdC}$ doveva tenere Guglielmo di Conches e la sua opera.

46. TdC riprende le aggiunte al libro XX da Philosophia, II, 1.3, 2.4, 4.11, 4.12, 5.13, 5.15, 6.4, 7.16, 7.17, 7.18, 7.19, 8.20, 8.21, 9.22, 9.23, 9.24, 9.25, 10.27, 11.28, 12.29, 12.30, 12.31, 13.32, 14.33, 14.34, $14.35,14.36,14.37,14.38,14.39,40,14.41,14.42,14.43,14.44,14.45,14.46,14.47,14.48,14.49,14.50$, $14.51,14.52,14.53,14.54,14.55,14.56,14.57,14.58,14.59,14.60,14.61,14.62,14.63,14.64,14.65$, 14.66, 14.67, 15.68, 15.59, 15.70, 15.71, 15.72 ; ibid., III, 8.19.

47. L'idea è già in FERCKEL C., Die Gynäkologie des Thomas von Brabant. Ein Beitrag zur Kenntnis der mittelaterlichen Gynäkologie und ihrer Quellen, Alte Meister der Medizin und Naturkunde, FacsimileAusgaben und Neudrucken, München, 1912: 57 (oltre che a Guglielmo, il tedesco rimanda anche all'antologia del macedone Johannes Stobaeus, vissuto nel V sec.), e HÜNEMÖRDER, « Probleme der Intention $»: 242$.

48. La questione è ben spiegata in DUTTON P. E., «The Little Matter of a Title : Philosophia Magistri Willelmi de Conchis ", in Guillaume de Conches : philosophie et science au XII e siècle, OBRIST B.- CAIAzzO I. (dir.), Firenze, 2011, p. 467-486; e accennata anche in THORNDIKE L., « More Manuscripts of the Dragmaticon and Philosophia of William of Conches ", in Speculum, 20, 1945, p. 84-87 ; e RONCA I., Introduction, in GUILLELMUS DE CONCHIS, Dragmaticon philosophiae, ed. RONCA I., Turnholt, 1997 : xi.

49. I 'comportamenti particolari' tommasiani sono discussi per esteso in CIPRIANI, La place, II : 45-47, 59-63 e 103-107.

50. La questione è trattata anche CIPRIANI, La place, II : 126 e 140. Sull'anonimato delle opere di Guglielmo, cf. ancora DUTTON, « The Little Matter».

51. Cf. GRABMANN M., Handschriftliche Forschungen und Mitteilungen zum Schriftum des Wilhelm von Conches und zu Bearbeitungen seiner naturwissenschaftlichen Werke, München, 1935: 6, attesta l'esistenza di una Defloratio philosophie magistri Guilelmi nel ms. Brugge, Stadsbibl., 154, f. 156r-157v : in questo caso sembra tuttavia trattarsi di una defloratio del Dragmaticon e non della Philosophia. Isabelle Draelants ha gentilmente segnalato a chi scrive il ms. Wellcome Library, 12, f. 196-257 (origine: Certosa di Colonia), con un'opera catalogata come 'Commentum super libro Florum Philosophiae' e attribuita ad Aimerico di Campo (un'altra copia di quest'opera è segnalata a Cracovia da GRABMANN M., "Der Einfluss Alberts des Grossen auf das mittelalterliches Geistesleben ", in Zeitschrift für katholische Theologie, 25, 3, 1928 : 153-182 e 313-356) : in questo caso il filosofo brabantino potrebbe quindi aver commentato il Liber florum philosophie usato anche da Tommaso. Si ringrazia la Prof. Draelants per le informazioni, i suggerimenti e gli input su tutto il discorso guglielmino qui affrontato.

52. $L d N R, \mathrm{~V}, 58$.

53. Su tutta questa discussione, cf. M. CIPRIANI, La place, II : 126 e 140-141.

54. Sebbene non sia oggi possibile dire con precisione quale versione delle Philosophia - prior, altera e Summa Philosophiae - sia stata utilizzata da Tommaso. Stiamo preparando un articolo 
specifico a riguardo : in tale contesto si prevede anche una ricerca più approfondita riguardante il misterioso Flores philosophie. Sulle varie versioni dell'opera di Guglielmo, cf. DUTTON P. E., The My stery of the Missing Heresy Trial of William of Conches, Toronto, 2006 : 25-40.

55. Tale trattato è stato consultato nel ms. Paris, B.n.F., lat. 7056, f. 89va-93ra: le sezioni di ostetricia usate da TdC sono concentrate ai f. 91vb-92rb. Per un confronto fra LdNR e Non omnes quidem, cf. infra, § Appendice B.

56. Oltre a DUTTON, "The Little Matter», sulla percezione della Philosophia nella cultura medievale, cf. ELFORD D., "William of Conches ", in A History of Twelfth-Century Western Philosophy, DRONKE P. (ed.), p. 308-327 ; e JACQUART D., MICHEAU F., La médecine arabe et l'Occident médiéval, Paris, 1996 : 128. Su quello del trattato Non omnes quidem, cf. HANSON, GREEN, Soranus, in part. 1058-59.

57. Per un'analisi introduttiva alla questione, si rimanda nuovamente a CIPRIANI, La place, II : 124-127, e 200-201. Anche in questo caso, stiamo preparando un articolo specifico sul rapporto fra Liber e Non omnes quidem.

58. Questiones naturales, De eodem et diverso e De avibus tractatus consitutiscono la produzione dialogica di Adelardo e sono le opere tramite cui egli approfondisce la sua visione della filosofia naturale : nel De eodem, il philosophus cerca infatti di conciliare filosofia platonica e aristotelismo, nelle Questiones spiega il Creato al nipote, e, nel De avibus, infine, istruisce sul comportamento e l'addestramento degli uccelli da preda. Per indicazioni bibliografiche specifiche sull'inglese, le sue idee e le sue opere, cf. supra, n. 33.

59. I quesiti usati da TdC sono : $1.1,1.2 ; 2.1,2.2 ; 3.1,3.4 ; 4.2 ; 6.1,6.2,7.1,7.2,7.6 ; 8.1,8.2 ; 9.1$; $11.2 ; 12.1,12.2 ; 15.1,15.3,15.6 ; 16.2 ; 17.4 ; 18.2 ; 36.2 ; 47.1,47.2$ (tali numerazioni rimandano all'edizione ADELARDUS BATHONIENSIS, Questiones naturales, in Adelard of Bath, conversations with his nephew, BURNETT C. (ed.), Cambridge, 1998, p. 81-236). Sono usate già in Thomas I, le questiones : 1.1, $1.2 ; 2.1,2.2 ; 3.1,3.4 ; 4.2 ; 6.1,6.2 ; 7.1,7.2,7.6 ; 8.1,8.2 ; 9.1 ; 12.1,12.2 ; 18.2$; sono invece riprese per aggiunte di Thomas II, le questiones : $11.2,15.1,15.3,15.6 ; 16.2 ; 17.4 ; 36.2 ; 47.1,2$.

60. Rispettivamente : LdNR, I, 2 ; I, 23 ; I, 36 ; IV , 1 ; V, 1 ; X, 1 ; XII, 1.

61. Per l'esemplificazione de i rimandi qui indicati, si rimanda a infra, § Appendice $C$.

62. Questo atteggiamento si ha, in $L d N R$, IV, 1 , Primo generaliter, con le questioni 47.1-47.2 e 15.1-15.3-15.6, e in LdNR, X, Primo generaliter, con le questioni 1.2-2.1-2.2, 3.1-3.4 e 4.2.

63. Su questo atteggiamento, tipico del modus scribendi tommasiano, cf. supra, § Introduzione.

64. Come evidenzia BURNETT, Introduction: xxii, Adelardo divide le Questiones in tre sezioni di lunghezza quasi identica : quella sugli animali e le piante (questioni 1-14), quella sull'uomo (15-47), ed, infine, quella sul cielo (48-76). Sugli argomenti discussi nelle Questiones, cf. anche LAWN, The Salernitan Questions : 20-21; ID., I quesiti salernitani : 38-39; e JOLIVET, Les quaestiones.

65. Per l'osservazione di come i passi degli autori dialogici sono combinati con gli altri autori, cf. infra, § Appendice.

66. Cf. infra, § Le Questiones salernitane.

67. Rispettivamente in LdNR, I, 36, De nervibus ; IV, 1, Primo generaliter ; e V, 1, Primo generaliter.

68. Cf. BURNETT, Introduction : xxvii.

69. Sulla questione, cf. supra, n. 59.

70. Riguardo a tale atteggiamento, cf. DRAELANTS, « La question » : 130-131.

71. Sulla questione, cf. supra, n. 59.

72. Per un elenco dei 28 mss. delle Questiones naturales, cf. BURNETT, Introduction : xliii-xliv; sulla circolazione del testo adelardino : xxxi-xxxii.

73. Cf. ADELARdus bathoniensis, Questiones naturales, $74.4: 220-221$. Per la discussione su questo argomento e una breve bibliografia ad esso relativa, cf. infra, § Le questiones non riconosciute, in part. n. 107. 
74. Le Questiones salernitane in prosa sono dei testi naturalistici che, sottoforma di disputa maestro-allievo, spiegano molti aspetti del Creato, dalle bestie ai cieli. Tali Questiones iniziarono ad essere redatte durante il XII sec. come base per i dibattiti nelle scuole mediche e vennero usate fino al XIII sec. nelle facoltà universitarie europee. Benché siano tramandate da molti mss., non esiste tuttavia un vero e proprio canone nella loro trasmissione : i codici le riportano infatti sempre in modo disugale, sia nel numero che nei contenuti, in quanto non era inusuale che i vari maestri rispondessero in modo differente ai vari quesiti. Per indicazioni bibliografiche su queste opere, cf. supra, n. 27.

75. Sono ricavate dalle questiones: B 61, B 62, B 64, B 65, B 66 ; Ba 10 ; N 62, N 64, N 66 (tutte le numerazioni dei quesiti rimandano all'edizione The Prose Salernitan Questions, in questo caso p. 28-31, 162 e 318-323).

76. Rispettivamente : $L d N R$, IV, 46 ; IV, 54 ; IV, 105 ; V, 110 ; X, 1. Il fatto che le sezioni dialogiche siano espanse in Thomas II è sottolineato anche da DRAELANTS, « La question » : 128-129.

77. Cf. The Prose Salernitan Questions, N 64 : 319-320.

78. LdNR, I, 1 ; I, 85 ; I, VIII, 9 ; I, XV, 8.

79. Come ben evidenziato da Lawn in The Prose Salernitan Questions : 2, n. 9-11; 46, n. 98 ; 48, n. $10-17$; e 322 , n. 2-6. Inoltre, sebbene sia indubbio che $\mathrm{TdC}$ abbia ricopiato questi in versi, è interessante notare come la maggior parte delle sezioni dialogiche del Liber (quelle su leone, orso, lince, struzzo ceraste e ferro) siano presenti anche nelle Questiones phisicales in versi ; sulla questione, cf. LAWN, The Salernitan Questions: 40-49; e ID., I quesiti salernitani : 59-68. Per un confronto con il testo, cf. l'edizione delle Questiones presente in ID., The Salernitan Questions: 158-176, in part. v. 52-83 : 160-162 ; e ID., I quesiti salernitani : 188-197, in part. v. 52-83 : 190-192.

80. In un modo simile a quanto fatto anche da Alexander Neckam nel De natura rerum e nel De laudibus divine sapientie; sulla questione, cf. LAWN, The Salernitan Questions : 44-46; e ID., I quesiti salernitani : 63-64.

81. Altri esempi di questo atteggiamento - molto comune a Tommaso - possono essere trovati nelle sezioni riprese da Elio Donato, Cofone di Salerno e Guglielmo di Conches; per un approfondimento, cf. CIPRIANI, La place, II : 94-95, 99-100 e 124-127. Non è comunque nemmeno da escludere che il frate abbia inglobato glosse ai mss. che stava ricopiando; su questo comportamento tommasiano, ibid. : 50-51, ma anche FRUNZEANU E., KUHRY E., «L'apport des gloses, des paraphrases et des syntagmes synonymiques à la compréhension des textes : le cas de quelques encyclopédies du XIII ${ }^{\mathrm{e}}$ siècle ", in Spica, Cahiers de l'Atelier Vincent de Beauvais, Nouvelle série, 1, 2011, p. 39-49.

82. Cf. infra, § Appendice D.

83. Oltre a quelli editi da Lawn (cf. Introduction, in The Prose Salernitan Questions : ix-xxxi), sono stati visionati anche quelli presenti nei mss. : London, British Libr., Royal 12.B.XII, f. 102v-104v ; Oxford, Bodleian Libr., Bodley 679, f. 101r-103v ; Oxford, Bodleian Libr., e Museo 219, f. 141-145b ; Oxford, Merton College Libr., Merton 324, f. 144r-150v; e Paris, B.n.F., Lat. 11219, f. 39r-v; e nelle edizioni : Quaestiones super de animalibus, FILTHAUT E. (ed.), in Alberti Magni ordinis fratrum praedicatorum : 'Liber de natura et origine animae', 'Liber de principiis motus processivi', 'Quaestiones super de animalibus', GEYER B. (ed.) : 148-154.

84. Lawn denomina questi mss., rispettivamente, B / Ba e N : il ms. di Oxford - di origine sconosciuta - è composto da più parti assemblate nel tempo, con le sezioni $\mathrm{B} / \mathrm{Ba}$ che sono datate dall'inglese agli inizi del XIII sec.; il codice di Parigi, che faceva parte della biblioteca di NotreDame e contiene anche le Questiones naturales di Adelardo, è invece datato al 1230-1240 (e quindi in un periodo e in un contesto molto vicini a TdC). Per informazioni su questi mss., cf. LAwN, Introduction, in The Prose Salernitan Questions : ix-xii e p. xxx. Oltre a xvi-xx, per indicazioni su questi codici, cf. anche cf. ID., The Salernitan Questions : 35-39 e n. $1: 37$; e ID., I quesiti salernitani, in part. 53-56, anche n. 112, e p. 92. 
85. Cf. ad esempio The Prose Salernitan questions, B $261: 127-127$; e N 54 : 308-309. La questione è discussa anche ID., The Salernitan Questions : 37-39; e ID., I quesiti salernitani : 57-58.

86. Sull'uso di questi autori nel Liber, cf. CIPRIANI, La place, II : 81-82, 91-92 e 94-95. Stiamo inoltre preparando un'analisi attenta delle fonti medico-pratiche introdotte in Thomas II.

87. Rispettivamente : LdNR, IV, 20 ; IV, 58 ; XIV, 1 ; XIV, 41 ; XVII, 3.

88. Oltre alle Questiones naturales, alle Questiones salernitane edite da Lawn e a quelle viste sui mss. (su queste ultime opere, cf. supra, n. 76), per trovare le fonti delle sezioni dialogiche nonriconosciute sono state consultate anche altre opere del tempo, ovvero gli Aforismi di Urso di Calabria, il De disciplina scolarium dello Pseudo-Boezio, l'Elucidarium di Onorio di Autun, il Liber de secretis nature di Apollonio di Tiana tradotto da Ugo di Santalla, il Lorscher Arzneibuch, le poesie di Baudri de Bourgueil, il Premnon Physicon nella traduzione di Alfano, i Problemata Aristotelis nella traduzione di Bartolomeo da Messina, i Quaternulorum fragmenta di Davide di Dinant, le Questiones medicinales dello Pseudo-Sorano, le Questiones naturales di Seneca, le Questiones Cratonis, le Questiones Nicolai peripatetici di Michele Scoto, i quesiti ‘siciliani’ di Federico II, le Questiones super libro 'De Animalibus' Aristotelis di Pietro di Spagna, le Regole urinarum di Mauro e il Tractatus de anima di John Blund. Tali opere sono state consultate nelle edizioni : URSO, Aphorismi, CREUTZ R. (ed.), in Die medizinisch-naturphilosophischen Aphorismen und Kommentare des Magister Urso Salernitanus, CREUTZ R. (ed.), Berlin, 1936, p. 1-192 ; PSEUDO-BOETIUS, De disciplina scolarium, WEIJERS O. (ed.), Leiden-Köln, 1976 ; HONORIUS AUGUSTODUNENSIS, Elucidarium, PL 172, col. 1109-1176D ; HUGO SANCTALLENSIS, Liber Apollonii de secretis naturae - Kitâb sirr al-Khalîqa, HUDRY F. (ed.), in «Cinq traités alchimiques médiévaux ", Chrysopoeia. Revue publiée par la Société d'Étude de l'Histoire de l'Alchimie, 6, 1997-1999, p. 1-154 ; Das Lorscher Arzneibuch, KEIL G., STOLL U., OHLMEYER A. (ed.), Stuttgart, 1989 ; BAUdRI DE BOURGUeIL, Poèmes, TILliETTE J.-Y. (ed.), Paris, 1998-2002, e anche "Poème adressé à Adèle, fille de Guillaume le Conquérant, par Baudri, abbé de Bourgueil ", DELISLE L. (ed.), in Mémoires de la Société des antiquaires de Normandie, 8, 1871, p. 187-224 ; NEMESIUS, Premnon Physicon a N. Alfano in Latinum translatus, BURKHARDT K. (ed.), Leipzig, 1917 ; BARTholomeus de messana, Problemata Aristotelis, seligsohn R. (ed.), in Die Übersetzung der Ps.aristotelischen Problemata durch Bartholomaeus von Messina : Text und textkritische Untersuchungen zum ersten Buch, Berlin, 1934 ; MICHAEL scotus, Quaestiones Nicolai Peripatetici, WIELGUS S. (ed.), in Mediaevalia Philosophica Polonorum, 17, 1973, p.57-155; AMARI M., "Questions philosophiques adressés aux savants musulmans, par l'empereur Frédéric II », in Journal asiatique, V.1, 1853, p. 240-274; e MEHREN M. A.-F., « Correspondance du philosophe soufi Ibn Sab'în Abd Oul-Haqq avec l'Empereur Frédéric II. de Hohenstaufen, publiée d'après le manuscrit de la Bibliothèque Bodléienne, contenant l'analyse générale de cette correspondance et la traduction du quatrième traité sur l'immortalité de l'âme ", in Journal asiatique, VII.14, 1879, p. 341-454 ; PETRUS HISPANUS, Questiones super libro 'De Animalibus' Aristotelis, NAVARRO SÁNCHEZ F. (ed.), Farnham, 2013 ; DAVID DE DINANT, Quaternulorum fragmenta, CASADEI E. (ed.), in I testi di David di Dinant. Filosofia della natura e metafisica a confronto col pensiero antico, CASADEI E. (ed.), Spoleto, 2008, p. 189-233, ma anche il ms. Paris, B.n.F., Lat. 15453, f. 214-216 ; PSEUDO-SORANUS, Quaestiones medicinales, RoSE V. (ed.), in Anecdota graeca et graecolatina, ROSE V. (ed.), Berlin, 1870, II, p. 243-280 ; Lucius Annaei Senecae Naturalivm qvaestionvm libros, HINE H. M. (ed.), Stuttgart, 1996 ; Questiones Cratonis, WEIJERS O. (ed.), in Les Questions de Craton : et leurs commentaires, O. WEIJERS (ed.), Leiden-Köln, Brill, 1981; MACROBIUS, Saturnalia, WILLIS J. (ed.), Leipzig, 1963 ; MAURUS, Regole urinarum, DE RENZI S. (ed.), in Collectio salernitana, DE RENZI S. (ed.), III, p. 1-51; IOHANNES BLUND, Tractatus de anima, CALLUS D. A., HUNT R. W. (ed.), London, 2013.

89. Sull'uso di Aldelmo nel Liber, cf. supra, n. 49.

90. Sulla questione, cf. soprattutto LAWN, I quesiti salernitani : 17-18; ma anche i contenuri di The Prose Salernitan Questions, B 105, e, soprattutto, N 61.

91. Cf. infra, \& Conclusione. 
92. Il Summarium Heinrici è una fonte decisamente secondaria nell'economia del LdNR : il frate di Cantimpré sembra infatti usarlo solo tre volte in tutta l'opera. Per un approfondimento sull'uso di questa auctoritas da parte di TdC, cf. CIPRIANI, La place, II : 213-214.

93. Cf. URSO, Aphorismi, Glosula 38 : 68 ; ALEXANDER NECKAM, De naturis rerum, II, 153, WRIGHT T. (ed.) 1863 : 237 ; e ID., De laudibus divine sapientie, VIII, v. 137-138, T. WRIGHT (ed.) 1863 : 468. La questione è discussa anche in LAWN, The Salernitan Questions : 182-182, n. $74: 184, \mathrm{n}$. 89 , e p. 197, n. 38 ; e ID., I quesiti salernitani : 214 , n. 83 . Parallelismi minori si possono trovare anche nei Quaternulorum fragmenta di Davide di Dinant.

94. Sulla questione, cf. FRENCH R, CUNNINGHAM A., Before Science. The Invention of the Friars' Natural Philosophy, Cambridge, 1996 : 230-237. Le opere scientifiche dell'inglese sono state campionate nelle edizioni : Die Philosophischen Werke des Robert Grosseteste, Bischofs von Lincoln, BAUR L. (ed.), Münster, 1912 ; e « Editio princeps del 'Liber qui uocatur Suda' di Roberto Grossatesta », DORANDI T., TRIZIO M. (ed.), in Studia graeco-arabica, 4, 2014 : 145-190.

95. Ed. THOMAS CANTIMPRATENSIS, Vita preclare virginis Margarete Yprensis, MEERSSEMAN G. (ed.), in "Les frères prêcheurs et le mouvement dévot en Flandre au XIIIe siècle ", MEERSSEMAN G. (ed.), in Archivum Fratrum Praedicatorum, 18, 1948 : 106-130, in part. 123.

96. Cf. THOMAS CANTIMPRATENSIS, Vita preclare, 34 : Tria autem in aqua sunt : aquea humiditas, diaphaneitas et perspicuitas lucis. Per la versione del Liber, cf. infra, § Appendice E. Tutto ciò è evidenziato anche in thomas CANTIMPRATENSIS, The Collected Saints' Lives: Abbot John of Camtimpre, Christina the Astonishing, Margaret of Ypres, and Lutgard of Aywieres, NEWMAN B., KING M. H. (ed.), Turnholt, 1998 : 194, n. 122. Nonostante tutto la versione della Vita sembra comunque la più corretta : visto il tema discusso nella sezione sembra infatti più corretta la perspicuitas (trasparenza, chiarezza, perspicuità) del testo agiografico che la perspicacitas (perspicacia, intelligenza acuta) dell'enciclopedia.

97. Cf. MEERSSEMAN, « Les frères prêcheurs» : 106-110.

98. Sulla questione, cf. supra, n. 4 .

99. Sull'uso di appunti intermedi fra testo e Liber, si rimanda CIPRIANI, « Un esempio ».

100. Cf. supra, § Le questiones salernitane.

101. Per notizie sulla vita di TdC, cf. soprattutto KaUfmann A., Thomas von Chantimpré, Köln, 1899 ; WAlstRa G. J. J., "Thomas de Cantimpré, De naturis rerum. État de la question», in Vivarium, 5, 1967, p. 146-171 ; ID., " Thomas de Cantimpré, De naturis rerum. État de la question (suite et fin) », in Vivarium, 6, 1968, p. 46-61 ; ENGELS J., "Thomas Cantimpratensis redivivus", in Vivarium, 12, 1974, p. 124-132 ; DEBOUtTE A., "Thomas van Cantimpré. Zijn opleiding te Kamerijk I », in Ons geestelijk erf, 56, 1982, p. 283-299 ; ID., " Thomas van Cantimpré. Zijn opleiding te Kamerijk II », in Ibidem, 57, 1983, p. 14-28; ID., "Thomas van Cantimpré als auditor van Albertus Magnus ", in Ibidem, 58, 1984, p.192-209; ID., "Thomas van Cantimpré. Zijn opleiding te Kamerijk III », in Ibidem, 60, 1986, p. 283-299 ; ID., " Thomas de Cantimpré », in Dictionnaire de spiritualité ascétique et mystique : doctrine et histoire, VILleR M., CAVAlLERA F., DE GUIBERT J. (dir.), Paris, 1991, t. XV, col. 784-792. Altre notizie sono presenti in COLVENERIUS G., Gesta venerabilis Thomae de Cantimprato e ID., Alia eisudem Thomae Cantimpratani Vita, in thOMAS CANTIMPRATENSIS, Bonum universale de apibus, COLVENERIUS G. (ed.), Douai, 1627 (le pagine non sono numerate).

102. Come è stato ad esempio fatto anche da Alberto Magno con le Quaestiones super de animalibus ; su quest'opera, cf. supra, n. 83.

103. Per un'analisi dell'uso di quest'opera nel Liber, cf. CIPRIANI, La place, II, in part. 72-73.

104. Come dimostra B. LAWN, The Salernitan Questions : 37 ; e ID., I quesiti salernitani : 56. 
105. Cf. ad esempio The Prose Salernitan Questions, B 178, Ba 32, N 67, P 56 e P 57 : 97-98, 169-170, 323 e 226-227; ma anche le Quaestiones super de animalibus, $3: 149$. Contenuti simili sono poi presenti anche in URSO, Aphorismi, Glosula $6: 27-29$.

106. In questo caso, infatti, non si tratta di una semplice aggiunta, ma di una variante che modifica leggermente la parte finale del capitolo e vi aggiunge parecchio materiale. Nella prima redazione del LdNR si trova infatti : in Rubro Mari nascitur ; nella seconda invece : nobilissimum ac clarissimum eius genus invenitur, et circa... Per un chiarimento sui mss. usati nella nostra edizione, si rimanda ancora infra, nell'introduzione all'§ Appendice.

107. Cf. ADELARDUS Bathoniensis, Questiones naturales, $74.4: 220-221$ (cf. anche supra, n. 67); aVicenna, Metaphysica, IX, 2, Bonus locatellus (ed.), Venezia, 1530, f. 102v, col. 1; AL-GHazAli, Metaphysica, I, 4, 3.1, J. T. MUCKLE (ed.), Toronto, 1933 : 104-106 ; ALEXANDER NECKAM, De naturis rerum, I, 17, T. WRIGHT (ed.), London, $1863: 55$; IOHANNES BLundus, Tractatus de anima, I, 2, 3-5, D. A. CALLUS-R. W. HUNT (ed.), London 1970 : 3-6. Oltre a T. SILVERSTEIN, « Adelard, Aristotle, and the 'De natura deorum' ", in Classical Philology, 47, 1952 : 82-86 ; sulla questione, cf. C. H. HASKINS, Studies in the History of Mediaeval Science, Cambridge, 1927 : 38, anche n. 89 ; e C. BURNETT, Introduction : xxviixxviii.

108. L'idea è già in SILVERSTEIN, "Adelard, Aristotle »: 83. Per un'analisi del rapporto fra Tommaso e gli autori arabi, cf. supra, § Introduzione, n. 12.

109. Sulle probabili motivazioni della scelta tommasiana, cf. supra, § Le Questiones naturales.

110. Oltre alla bibliografia indicata supra, n. 27, sulla questione, cf. anche MAIERÙ A., University Training in Medieval Europe, New York, $1993: 130$ sq.

111. Su tutto, cf. LAWN, The Salernitan Questions : 20-32 ; ID., I quesiti salernitani : 38-50 ; BURNETT, Introduction : xii e p. xxxi-xxxii ; ma anche VENTURA, «Per modum quaestionis » : 280 sq.

112. Sulle motivazioni storiche dell'educazione domenicana e tommasiana, cf. FRENCH, CUNNINGHAM, Before Science: 139-142, 178, 200 e 217 ; CIPRIANI, La place, II : 31-33 e 243-244.

113. Vista la tipologia di ripresa della Philosophia da parte di Tommaso, per Guglielmo riportiamo solo le sezioni introdotte nei libri I-XIX, e non l'intero libro XX. Sulla questione, cf. supra, § Auctoritates dialogiche come fonti specialistiche, anche n. 46.

114. Cf. supra, n. 2.

115. Per una descrizione accurata sulle differenze fra questi mss. e le loro caratterisctiche, cf. CIPRIANI, La place, I : xiii-Xxiii.

116. Ed. Liber monstrorum, ORCHARD A. (ed.), in Pride and Prodigies. Studies in the Monsters of the Beowulf-Manuscript, ORCHARD A. (ed.), Toronto-Buffalo-London, 1995, p. 254-317.

117. Consultate nelle edizioni : Aristotelis opera, I. Bekker, C. A. Brandis (ed.), Berlin, 1831-1870 ; Aristotle's "Meteorology» in the Arabico-Latin tradition. A Critical Edition of the Texts, with Introduction and Indices, schoonHEIM P. L. (ed.), Leiden-Boston-Köln, 2000 ; De animalibus libri XIX. Buch I-XIV. Aristoteles Latinus in der Übersetzung des Michael Scotus nach der Handschrift Rom, Biblioteca Apostolica Vaticana, Chigi E VIII 251 (s. XIII), fol. 1ra-108rb, mit Textkorr. aus den Handschriften Nürnberg, Stadtbibliothek, Cent. VI 10 und Pisa, Biblioteca di Santa Caterina, Cod. 11, HÜNEMÖRDER C. (ed.), München, 1994 ; De animalibus. Michael Scot's Arabic-Latin Translation, Part II, Books XI-XIV: Parts of Animals, VAN OPPENRAAY A. M. I. (ed.), Leiden-Boston-Köln, 1998; De animalibus, Michael Scot's Arabic-Latin translation, Part III, Books XV-XIX: Generation of Animals, VAN OPPENRAAY A. M. I. (ed.), Leiden-Boston-Köln, 1992.

118. Ed. : Confessiones, o'DonNELl J. J. (ed.), Oxford, 1992 ; Contra Faustum Manicheum, in PL 42, col. 207-518.

119. Ed. DE MENDiETA E. A., RUDBERg S. Y. (ed.), Berlin, 1958. 
120. Ed. De natura rerum, in PL 110, col. 187-278.

121. Ed. Timaeus a Calcidio translatus commentarioque instructus, WASZINK J. H. (ed.), London, 1962.

122. Ed. De natura deorum libri tres, MAYOR J. B., J.H. SWAINSON (ed.), Cambridge-London, 1883-1891.

123. Ed. Vetus Latina. Die Reste der altlateinischen Bibel, SABATIER P. ET AL. (ed.), 26 voll., Freiburg, 1949-2000.

124. Su quest'opera e la nostra scelta in merito, cf. supra, n. 15 : onde evitare cattive comprensioni, si preferisce modificare il titolo del testo fornito da J. Deus.

125. Ed. Homiliarum in Evangelia libri duo, in PL 76, col. 1075-1312.

126. Ed. De imagine mundi, in PL 172, col. 115-188C.

127. Ed. Historia orientalis, DONNADIEU J. (ed.), Turnhout, 2008.

128. Ed. Polycraticus, in PL 199, col. 385-822.

129. Ed. Commentarii in Somnium Scipionis, WILLIS J. (ed.), Leipzig, 1970.

130. Ed. Liber lapidum, HERRERA M. E. (ed.), Paris, 2005.

131. Ed. Opus agricolturae, De veterinaria medicina. De insitione, RODGERS R. H. (ed.), Leipzig, 1975.

132. Ed. Physiologus Latinus, versio B-Is., MANN M. F. (ed.), in Der 'Bestiaire Divin» des Guillaume le Clerc, M. F. MANN (ed.), Heilbronn, 1888, p. 37-73.

133. Ed. Naturalis Historia, IAN L., MAYHOFF C. (ed.), Leipzig, 1892-1909.

134. Ed. Gyneciorum, hoc est, de mulierum tum aliis, tum gravidarum, parientium et puerperarum affectibus et morbis, libri veterum ac recentiorum aliquot, partim nunc primum editi, partim multo quam antea castigatiores, wolf C. (ed.), Basileae, 1566, f. $4^{\mathrm{r}}$.

135. Ed. Anatomia Ricardi Anglici, TöPLY EQUES R. (ed.), Vindobonae, 1902.

136. Ed. Polyhistor, T. MOMMSEN (ed.), Berlin, 1894.

137. Ed. Summarium Heinrici (versio I), R. HILDEBRANDT (ed.), Berlin-New York, 1974.

138. Cf. Arist., De animal., XVI, 6.744a1-18.

139. Cf. Guill. Conch., Phil., IV, 21.37.

140. capitis] corporis Par Lon, capitis Pr; nella fonte : capitis.

141. Cf. Guill. Conch., Phil., IV, 21.37.

142. Cf. infra, Adelard.

143. Guill. Conch., Phil., IV, 10.18.

144. Ibid., 11.18 .

145. Arist., De animal.,VII, 4.585a2-4.

146. Ibid., 4.584a2-5.

147. merito queritur] manca Par, merito queritur Lon, merito queritur Pr.

148. Guill. Conch., Phil., IV, 11.20.

149. est, quod] manca Par, est, quod Lon, est, quod Pr.

150. Guill. Conch., Phil., IV, 11.20.

151. Ibid., 12.20 .

152. Macr., Comm. Somn., I, 6.65.

153. Guill. Conch., Phil., IV, 13.21.

154. Guill. Conch., Phil., IV, 13.21.

155. Arist., De animal., XVI, 3.736b28-30. 
156. Guill. Conch., Phil., IV, 14.22. Su questa domnda, anche Quest. sal., B 25.

157. Guill. Conch., Phil., IV, 14.22 .

158. pueri] manca Par, pueri Lon, pueri Pr.

159. Guill. Conch., Phil., IV, 14.22 .

160. Guill. Conch., Phil., IV, 14.22 .

161. in] manca Par, in Lon, in Pr.

162. Guill. Conch., Phil., IV, 14.23.

163. Plin., Nat. Hist., XI, 112.270.

164. Gen., 3.9.

165. Cf. ibid., 3.16 .

166. Arist., De animal., VII, 10.587b13-19.

167. Solo in Pr.

168. Guill. Conch., Phil., IV, 15.24.

169. Non inveni.

170. Plin., Nat. Hist., VIII, 46.108.

171. Cf. Guill. Conch., Phil., I, 13.42.

172. Cf. Exp.-D. A, XIII, 47.5.

173. igne] igne Par, om. Lon Pr. Nella fonte: igne.

174. Hon. Aug., Imag., I, 52.

175. Guill. Conch., Phil., III, 6.13.

176. Cf. Sen., Nat. Quest., II, 12.6.

177. Nella fonte : vetante revertitur.

178. igniri] igni et Par, igniri Lon, igniri Pr ; nella fonte : igniri.

179. Guill. Conch., Phil., III, 6.13-17.

180. Cf. Bed., De nat., 30.

181. Guill. Conch., Phil., III, 7.18.

182. Hon. Aug., Imag., I, 51.

183. Guill. Conch., Phil., III, 7.18.

184. Guill. Conch., Phil., III, 9.20.

185. Nella fonte: fitque ventus septemtrionalis qui 'Boreas' dicitur.

186. Guill. Conch., Phil., III, 10.24-10.25.

187. 'Pesce' dell'autore o del copista.

188. Guill. Conch., Phil., III, 10.26 .

189. de quo vitalis spiritus hauritur] om. Par, de quo vitalis spiritus hauritur Lon $\mathrm{Pr}$

190. Hon. Aug., Imag., I, 53.

191. Guill. Conch., Phil., I, 5.15. Cf. anche Calc., Comm. II, 134-135.

192. Hon. Aug., Imag., I, 53.

193. Hon. Aug., Imag. I, 67.

194. Nella fonte : quoddam genus invisibilis animalis, id est.

195. Nella fonte : primum in ordine demonum, quod ita diffinitur.

196. Nella fonte : dicit aliud esse genus, cuius est hec diffinitio.

197. Guill. Conch., Phil., I, 5.14-5.15. Cf. anche Calc., Comm., II, 134-135.

198. Non inveni.

199. Ps.-Cleop., Prol. Gyn.

200. Non omn., $91 \mathrm{vb.}$

201. Non omn., $91 \mathrm{vb.}$

202. Possibile pesce: $<$ foras eum adducat. Si ambas manus proferat. Duobus humeris eius manus suas utrasque parte infingens restrorsum eum revocetur sicut diximus, manus lateribus componat et apprehenso capite >.

203. Non omn., 91vb-92ra. 
204. Su questo punto, cf. anche Sorani Gyneciorum vetus translatio Latina, V. RoSE (ed.), Leipzig, $1882: 87$, n. 1.8 .

205. Non omn., 92ra.

206. E cioé feni greci.

207. Non omn., 92ra-92rb.

208. Cf. Arist., De animal., VII, 584b.

209. Cf. supra, Guill. Conch.

210. capitis] corporis Par, corporis Lon, capitis $\mathrm{Pr}$; nella fonte : capitis.

211. Adelard., Quest., 18.2.

212. Adelard., Quest., 17.4.

213. Arist., De animal., I, 9.491b9-15.

214. Plin., Nat. Hist., XI, 103.250.

215. Cf. Arist., De animal., XII, $9.654 b$.

216. Nella fonte : innata tibi vascula unde nature sufficienter aquam proponas.

217. Adelard., Quest., 36.2.

218. Io. Sar., Pol. V, 17.4.

219. Arist., De animal., III, 515b.

220. Adelard., Quest., 16.2.

221. Ps.-Gal., Anat., 3.

222. Cfr. ibid., I, 1.487a13-14.

223. Eccl., 33.31.

224. Psal., 144.15 .

225. Cf. Arist., De animal., II, 1.498b1-5. Cf. anche ibid.,VIII, 1.589b1-32.

226. Cf. ibid., VIII, 1.589b1-32.

227. Adelard., Quest., 47.2

228. Ibid., 47.1 .

229. Ibid., 47.2 .

230. Non inveni.

231. Adelard., Quest., 15.3.

232. Ibid., 15.6 .

233. $\mathrm{E}$ cioé in bellicis.

234. Adelard., Quest., 15.6.

235. Cf. ibid., 15.1.

236. Solo in Pr.

237. Arist., De animal., II, 14.505b32-35.

238. Plin., Nat. Hist., X, 83.175.

239. Nella fonte : partus.

240. Plin., Nat. Hist., X, 83.175-6.

241. Adelard., Quest., 7.1.

242. Ibid., 7.2.

243. Cf. Greg. Magn., Hom. Ev. XXX, 8.

244. I Cor., 2.10.

245. Cf. Greg. Magn., Hom. Ev. XXX, 3.

246. Adelard., Quest., 7.2.

247. Sap., 1.4 .

248. Ivi.

249. Ex.. 18.1.

250. Adelard., Quest., 7.2.

251. Ibid., 7.6. 
252. Ibid., 8.1.

253. Ibid., 8.2.

254. Ibid., 9.1.

255. Cf. Arist., De animal., XIII, 4.667a1-2.

256. Cf. Aug., Conf. XIII, 9.

257. Adelard., Quest., 12.1.

258. Nella fonte : ne nimium diffundatur.

259. Adelard., Quest., 12.2.

260. Nella fonte : minus vero nigrum.

261. Adelard., Quest., 12.2.

262. E cioé directe.

263. Adelard., Quest., 12.2 .

264. Bas., Hex. V, 4.5.

265. Nella fonte : et animal quadrupes ovans claudit ipsos per palpebram inferiorem .

266. Arist., De animal., XII, 13.657b5-7 ; ibid., 13.657a35-37 ; et ibid., II, 12.503b30-504b11.

267. Adelard., Quest., 11.2.

268. Arist., De animal., XIII, 9.671a26-28.

269. Plin., Nat. Hist., XII, 7.16.

270. Adelard., Quest., 6.1.

271. Ibid., 6.2.

272. Cf. Pall., Op. Agr., III, 17.1-2.

273. Cf. infra, Quest. sal..

274. Cf. Adelard., Quest., 1.1.

275. Ibid., 1.2 .

276. verum] verum Par, purum Lon Pr ; nella fonte : nullus.

277. Adelard., Quest., 1.2.

278. Cf. ivi.

279. Ivi.

280. Ibid., 2.1 .

281. Ivi.

282. Cf. ivi.

283. Ibid., 2.2 .

284. Ivi.

285. Nella fonte : hec sicca, illa humida.

286. Adelard., Quest., 3.1.

287. Ivi.

288. Ibid., 3.4.

289. Cf. ivi.

290. Cf. ivi.

291. Ibid., 4.2 (BURNETT : 98).

292. Ivi.

293. Ivi.

294. Pall., Op. Agr. IX, 4.3.

295. Non inveni.

296. Quest. sal., N 64.

297. Non inveni.

298. non] om. Par, non Lon $\mathrm{Pr}$

299. Arist., De animal., XIV, 10.688b1-4.

300. Cf. Aug., Contra Faust., XII, 42 ; et ID., Civ., XVI, 41.2.

301. calidus] colericus Lon Pr 
302. Nella fonte: magis.

303. Nella fonte: magis.

304. calidissimum] colericum Lon $\mathrm{Pr}$

305. Quest. sal., N 66.

306. Sol., Pol., 27.15.

307. Plin., Nat. Hist., VIII, 54.128-9.

308. Quest. sal., $\mathrm{N} 64$.

309. Nella fonte : grossities et subtilitas et mediocritas.

310. Nella fonte : calidus, quod patet quia.

311. Nella fonte: inferiora.

312. Quest. sal., N 64.

313. Plin., Nat. Hist., XI, 115.277.

314. Phys., 28.1 (ed. Mann : 62).

315. Nella fonte : sicque calor magis multiplicetur

316. Quest. sal., N 62.

317. Cf. Exp.-D. A IX, 34.4.

318. Cf. Pall., Op. Agr., III, 17.1-2.

319. Quest. sal., B 61.

320. Ibid., B 62.

321. Ibid., B 64.

322. Ibid., Ba 10

323. Ibid., B 65.

324. Ibid., B 66.

325. Nella fonte : purganda.

326. Nella fonte : resolvitur et acutus.

327. Nella fonte : acutum.

328. Nella fonte : Omnis enim spinosa res sicce est complexionis, ut tribali.

329. Quest. sal., B 66.

330. Aldel., Lib. monstr., I, 31.

331. Sap., 11.18 .

332. Plin., Nat. Hist.,VIII, 28.70 ; Iac. Vitr., Hist. or., 88.179 ; Marb., Lapid., 24, vv. 349-359.

333. Iac. Vitr., Hist. or., 88.179.

334. Cf. Arist., De anim., III, 425a ; ibid., XVI, 744a, et ibid. XIX, 779b.

335. Non inveni. Cf. TdC, Vita preclare, 34. La presenza del termine 'dyafanitas' permetta di collocare la fonte del passaggio a dopo il 1200 (si ringrazia Eduard Frunzeanu per il suggerimento).

336. Summ. Hein., III, 11.

337. Cf. Plin., Nat. Hist., VIII, 17.43.

338. Non inveni. Vista la sua natura, potrebbe anche essere una questione di mano tommasiana.

339. Cf. Arist., Meteor., I, 13.349a11-13.

340. Cf. Marb., Lapid., 47, v. 610.

341. Lezione di Par.

342. Cf. Plin., Nat. Hist., XXXVII, 52.136.

343. Non inveni.

344. Cf. Sap., 11.21.

345. Non inveni.

346. Lezione di Lon Pr.

347. Hon. Aug., Imag., I, 68.

348. Cf. Adelard., Quest., 74.3-4 ; Cic., De nat. deor., II, 15.40-41; II, 16.44 ; Arist., Phys., VIII, 254b7-33 ; e 255b-28-256a2 ; ID., De coel., II, 285b28-33 ; Macr., Comm., II.14 ; Al-Ghaz., Met., I, 4, 3.1 ; 
Avic., Met., IX, 2. Cf. anche Alex. Neck., De nat. rer., I, 17 (ed. WRIGHT : 57); fonte prima è comunque Aristotele, Topic., V, 134b26-135a10.

\section{RIASSUNTI}

Bien que tous les encyclopédistes du XIII ${ }^{\mathrm{e}}$ siècle utilisent un corpus commun de sources, chacun d'eux a une manière personnelle de choisir, "découper » et disposer les contenus tirés de ces auctoritates. Ces modi scribendi attentifs et distinctifs ne permettent pas seulement à un compilateur, qui recueille les prestigieux matériaux d'autrui, de devenir auteur, ce qui est prestigieux en soi, mais reflètent également les différentes formae mentis et les objectifs fondamentaux d'une encyclopédie médiévale. Grâce à l'analyse de la manière dont le Dominicain flamand Thomas de Cantimpré (1201-1270/1271) copie certains traités de questiones et responsiones - par exemple les Questiones naturales d'Adélard de Bath et les questiones salernitane anonymes dans ses rédactions successives du Liber de natura rerum (1242/1247-1255/1260), cet article vise donc à montrer comment Thomas utilise ces sources particulières pour arriver à ses fins marquées par un esprit à la fois pragmatique et dominicain.

Even though encyclopedists of the thirteenth century used a common corpus of sources, each had a precise and personal way to choose, 'tailorize' and arrange the contents taken from these auctoritates. The peculiar and custom modi scribendi permitted the compiler (who collects authoritative materials from others) to become an author (who in turn becomes authoritative), while also reflecting accurately the different forme mentis and purposes behind the encyclopedic texts. Through the analysis of the exclusive way in which the Flemish Dominican friar Thomas of Cantimpré (1201-1270/1271) copies dialogical treatises - such as Adelard of Bath' Questiones naturales and the anonymous questiones salernitane - in both authorial versions of his encyclopedia, Liber the natura rerum (approximately 1242/1247-1255/1260), this essay shows how Thomas uses these particular sources to reach his own pragmatic and dominican goals.

\section{INDICE}

Keywords : Liber de natura rerum, Thomas of Cantimpré, Questiones salernitane, Adelard of Bath, Sources of medieval encyclopedism

Mots-clés : Liber de natura rerum, Thomas de Cantimpré, Questiones salernitane, Adélard de Bath, Sources du encyclopédisme médiéval

\section{AUTORE}

\section{MATTIA CIPRIANI}

Mattia Cipriani est Docteur (2014) en Histoire, textes et documents de l'Ecole Pratique des Hautes Etudes di Parigi et en Antichità, Medioevo e Rinascimento de la Scuola Normale Superiore di Pisa, avec une thèse obtenue en co-tutelle, intitulée La place de Thomas de Cantimpré dans l'encyclopédisme médiéval : les sources du Liber de natura rerum". Ses recherches se 
concentrent principalement sur la transmission des textes naturalistes, en particulier zoologiques, et l'encyclopédisme médiéval. 